Florida International University FIU Digital Commons

7-25-2002

\title{
Characterization and interactions of mercury, dissolved organic matter and organic sulfur in surface waters of the Florida Everglades
}

Maria Asuncion Calero Sheils

Florida International University

DOI: $10.25148 /$ etd.FI14052538

Follow this and additional works at: https://digitalcommons.fiu.edu/etd

Part of the Chemistry Commons

\section{Recommended Citation}

Calero Sheils, Maria Asuncion, "Characterization and interactions of mercury, dissolved organic matter and organic sulfur in surface waters of the Florida Everglades" (2002). FIU Electronic Theses and Dissertations. 1974.

https://digitalcommons.fiu.edu/etd/1974 
Miami, Florida

CHARACTERIZATION AND INTERACTIONS OF MERCURY, DISSOLVED ORGANIC MATTER AND ORGANIC SULFUR IN SURFACE WATERS OF THE FLORIDA EVERGLADES

A thesis submitted in partial fulfillment of the requirements for the degree of

MASTER OF SCIENCE

in

CHEMISTRY

by

Maria Asuncion Calero Sheils 
To: Dean Arthur W. Herriott

College of Arts and Sciences

This thesis, written by Maria Asuncion Calero Sheils, and entitled Characterization and Interactions of Mercury, Dissolved Organic Matter and Organic Sulfur in Surface Waters of the Florida Everglades, having been approved in respect to style and intellectual content, is referred to you for judgment.

We have read this thesis and recommend that it be approved.

Ron Jones

Martin Quirke

Piero Gardinali

Rudolf Jaffe, Co-Major Professor

Yong Cai, Co-Major Professor

Date of Defense: July 25, 2002

The thesis of Maria Asuncion Calero Sheils is approved.

$\begin{gathered}\text { Dean Arthur W. Herriott } \\ \text { Cottege of Arts and Sciences }\end{gathered}$
University Graduate School

Florida International University, 2003 


\section{DEDICATION}

I dedicate this thesis to my family, especially to my husband John and to my mother-in-law Marta, because of their support.

A mi familia, especialmente a mi esposo John y a mi suegra Marta, gracias por su apoyo. 


\section{ACKNOWLEDGMENTS}

I thank my major Professor Dr. Yong Cai, Department of Chemistry Assistant Professor, for his guidance, for his suggestions through my graduate studies and for financial support through a research assistantship.

I would like to thank my co-major professor, Dr. Rudolf Jaffe, Department of Chemistry Professor and acting Director of the Southeast Environmental Research Center (SERC), for his helpful comments and support.

Special thanks to Dr. Ronald Jones, former Director of SERC, for giving me the opportunity to do research work in these laboratories and for financial support through a research assistantship.

Thanks to Dr. Martin Quirke and Dr. Gardinali for their time and interest.

I also would like to thank Dr. Kevin O'Shea, Department of Chemistry Graduate Program Coordinator, for granting financial support through a teaching assistantship, and Dr. Palmer Graves, General Chemistry Laboratory Coordinator, for his support.

Thanks to Dr. Miyoshi Toshikazu, Japan for the ${ }^{13} \mathrm{C}-\mathrm{NMR}$ CPMAS spectra measurements, and to Dr. Nagamitsu Maie for his helpful guidance, wonderful patience and great sense of humor.

I would like to thank the professors in the Department of Chemistry, Dr. Piero Gardinali, Dr. Jeffrey Joens, Dr. Stanislaw Wnuk, Dr. Kenneth Furton, Dr. Yong Cai Dr. Konstantinos Kavallieratos, Dr. Rudolf Jaffe and Dr. Stephen Winkle, because they taught me well with high standards of learning, and to the Department of 
Chemistry staff Annie Gilbar, Rosa Espindola and Judy Whitt, Lilia San Miguel, Lisa Chan and Armando Perez for their invaluable help.

I would like to recognize many students in the Department of Chemistry, because of their friendship and help towards the completion of this work: Duk Kyung Kim, Weihua Zhang, Myron Georgiadis, Ralph Mead, Alberto Sabucedo, Chen Yong Yan, Jinhui Su, Manolo Plasencia, Dr. Xiaqiao Lu, Dr. Carlos Yanes, Jim Ley, Xu Zhao and Loreta Alvarez-Fraga.

Also thanks to the SERC team: Pete Lorenzo, Rafael Gonzalez-Collado, Alana Sanders, Frank Tam, Todd Shipman, Elizabeth Elmore, George Meichel, Bill Gilhouly, Julio Lopez, Marta Bascoy and Gustavo Gonzalez. Thanks to Will Vangelder and John Sheils for collecting two of my samples and Serge Thomas for his help with the freeze concentration device design. Thanks to Dr. Will Anderson for letting me borrow his silver weighting boats for acid digestion.

Thanks to Pierre Sterling, Jose Cavalleiro and their team for their help with the electronic devices I needed to use. Also thanks to SERC secretaries Hellen Forlong, Doris Lopez, Nelsy Casanova and Oria Solis for their invaluable help, and Pura Rodriguez de la Vega and Ruth Justiniano for the quality control of my data.

Thanks to all the ones I didn't name, for their friendship.

And many thanks to my family for their support. 


\begin{abstract}
OF THE THESIS
CHARACTERIZATION AND INTERACTIONS OF MERCURY, DISSOLVED ORGANIC MATTER AND ORGANIC SULFUR IN SURFACE WATERS OF THE FLORIDA EVERGLADES

by
\end{abstract}

Maria Asuncion Calero Sheils

Florida International University, 2003

Miami, Florida

Professor Yong Cai, Co-Major Professor

Professor Rudolf Jaffe, Co-Major Professor

Two sampling stations in the Florida Everglades were selected based on the results from US Environmental Protection Agency and Florida International University Mercury Project. In both sites, most of the methylmercury is associated with the truly dissolved organic matter fraction $(<3 \mathrm{KDa})$, where total sulfur levels are also higher. Characterization of size fractionated dissolved organic matter by synchronous fluorescence, UV spectrometry and ${ }^{13} \mathrm{C}-\mathrm{NMR}$ was accomplished, revealing a decrease in the aromatic to aliphatic ratio in the DOM functionalities as the molecular weight of the fractions decrease. The determination of organic thiols at trace levels has been achieved in both particulate and dissolved phases by sensitive detection with fluorescence after a reverse-phase liquid chromatographic separation. The majority of the thiols are present in the dissolved fraction in surface waters of the Everglades. Three uncharacterized thiols were found for the first time in surface waters of the Florida Everglades. 


\section{CHAPTER I. INTRODUCTION}

1. Mercury contamination in the environment $\quad \ldots \ldots \ldots \ldots \ldots \ldots \ldots$

2. Sources of mercury in the environment $\ldots \ldots \ldots \ldots \ldots \ldots \ldots$

3. Biogeochemical cycling of mercury $\quad \ldots \ldots \ldots \ldots \ldots \ldots \ldots \ldots \ldots$

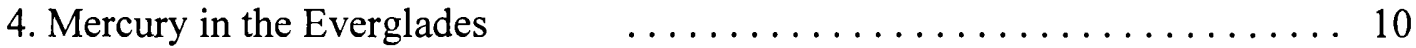

5. Interactions of mercury and dissolved organic matter $\ldots \ldots \ldots \ldots \ldots 13$

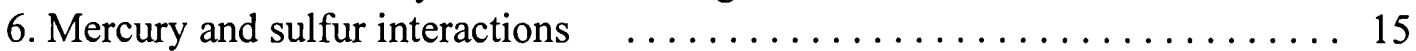

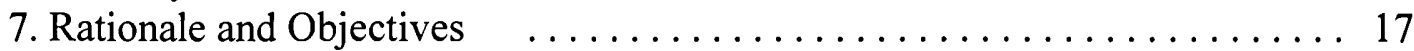

CHAPTER II. CHAACTERIZATION OF MERCURY SPECIES AND THEIR INTERACTIONS WITH DISSOLVED ORGANIC CARBON AND SULFUR IN SURFACE WATERS OF THE FLORIDA EVERGLADES.

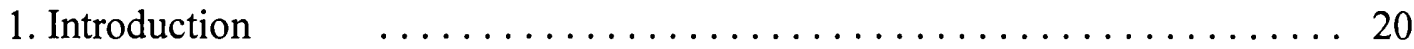

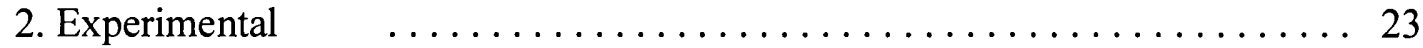

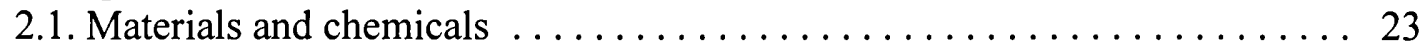

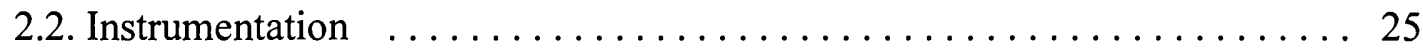

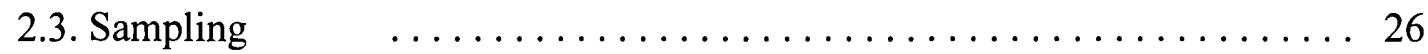

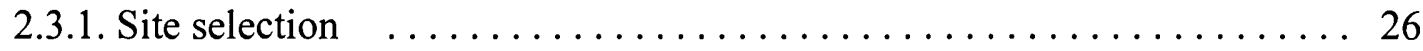

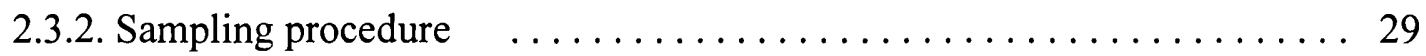

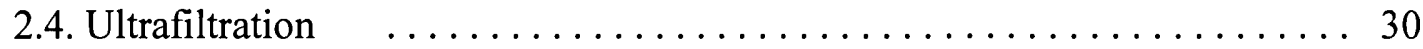

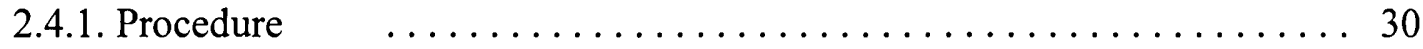

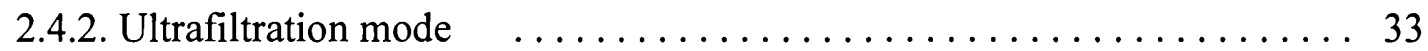

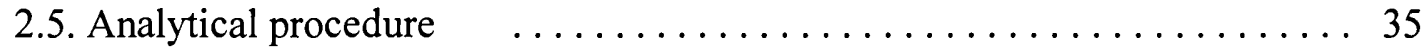

2.5.1. Determination of total mercury in water samples $\quad \ldots \ldots \ldots \ldots \ldots 35$

2.5.2. Determination of methylmercury in water samples $\ldots \ldots \ldots \ldots \ldots 36$

2.5.3. Determination of total sulfur in water samples $\quad \ldots \ldots \ldots \ldots \ldots 38$

2.5.4. Total organic carbon analysis in water samples $\quad \ldots \ldots \ldots \ldots . \ldots 39$

2.6. Method for determining the distribution coefficient, $K_{d} \ldots \ldots \ldots \ldots \ldots$

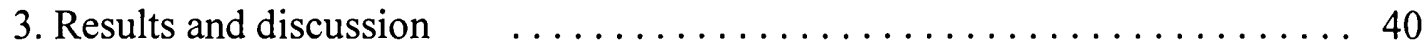

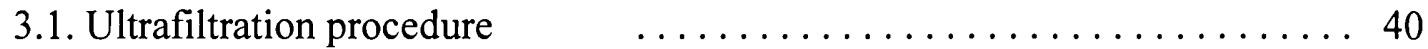

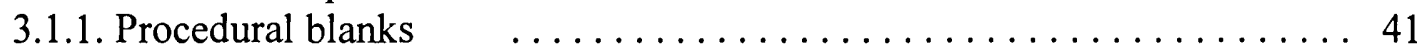

3.1.2. Ultrafiltration mass balance $\quad \ldots \ldots \ldots \ldots \ldots \ldots \ldots \ldots \ldots \ldots . \ldots \ldots 2$

3.2. Distribution of mercury species, TS ad DOC between different size fractions 43

3.2.1. Suspended particulate matter and DOC $\quad \ldots \ldots \ldots \ldots \ldots \ldots 44$

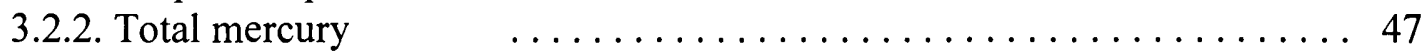

3.2.2.1. Total mercury in the particulate phase $(>0.2 \mu \mathrm{m}) \quad \ldots \ldots \ldots \ldots . \ldots 47$

3.2.2.2. Total mercury in the dissolved phases $\quad \ldots \ldots \ldots \ldots \ldots \ldots 47$

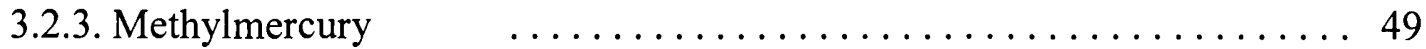

3.2.3.1. Methylmercury in the particulate phase $(>0.2 \mu \mathrm{m}) \ldots \ldots \ldots . \ldots 49$ 
3.2.3.2. Methylmercury in the dissolved phase

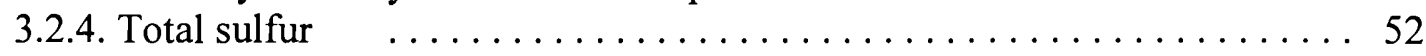

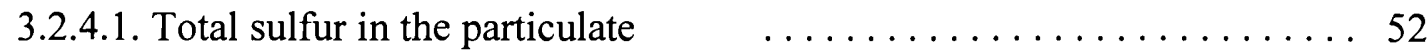

3.3. Correlations between different chemical parameters $\quad \ldots \ldots \ldots \ldots \ldots 55$

3.3.1. Interactions of $\mathrm{DOC}$ with $\mathrm{THg}$ and $\mathrm{CH}_{3} \mathrm{Hg} \quad \ldots \ldots \ldots \ldots \ldots \ldots \ldots \ldots$

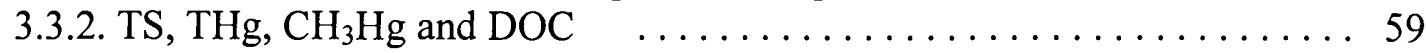

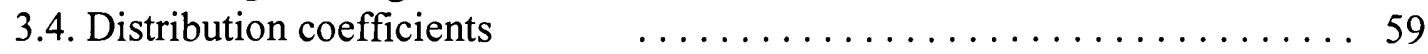

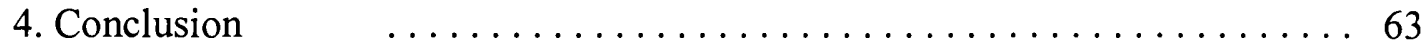

CHAPTER III. SPECTROSCOPIC STUDIES OF DOM SIZE

FRACTIONATEDISOLATES FROM SURFACE WATERS OF THE FLORIDA EVERGLADES

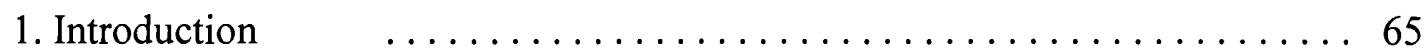

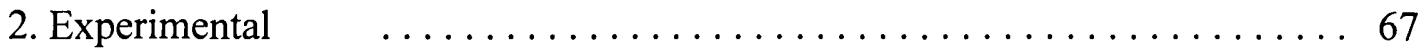

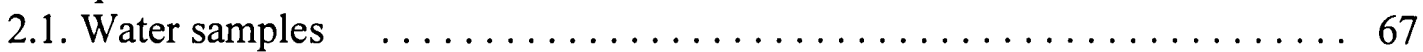

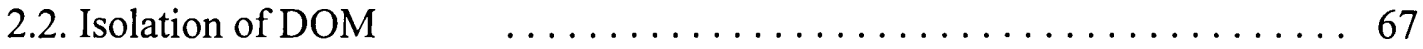

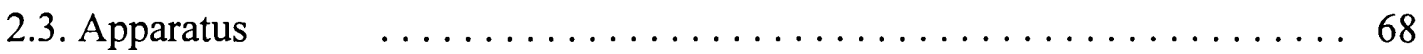

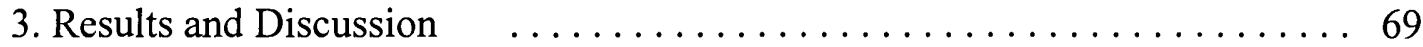

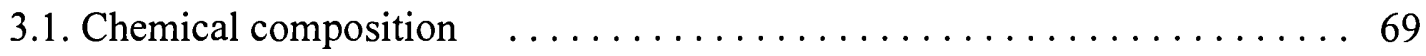

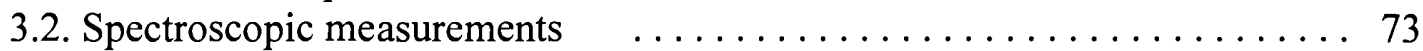

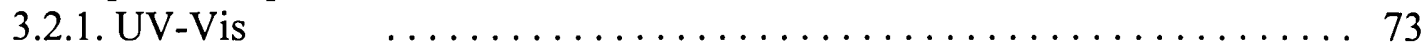

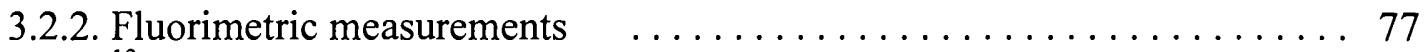

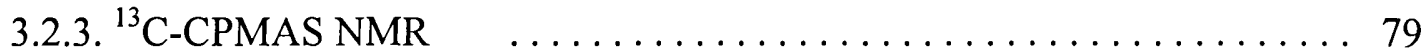

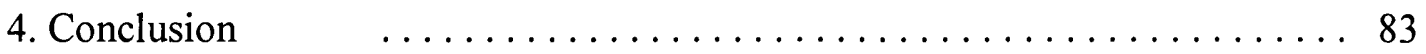

CHAPTER IV. LOW MOLECULAR WEIGHT THIOL-CONTAINING COMPOUNDS IN NATURAL WATER AND SUSPENDED PARTICULATE FROM THE FLORIDA EVERGLADES

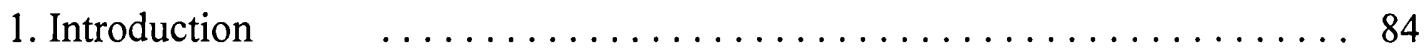

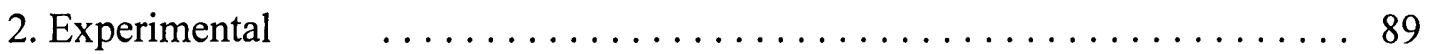

2.1. Fluorimetric assay of thiols with SBD-F $\quad \ldots \ldots \ldots \ldots \ldots \ldots \ldots$

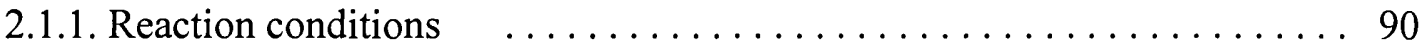

2.2. Analysis of thiols in natural waters $\quad \ldots \ldots \ldots \ldots \ldots \ldots \ldots \ldots \ldots \ldots$

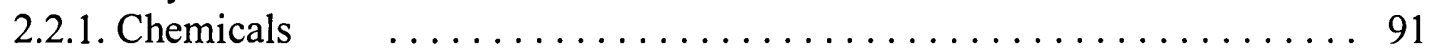

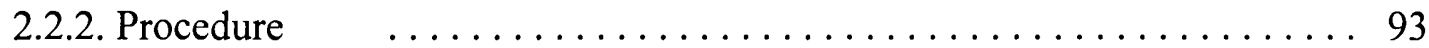

2.3. Determination of thiols in suspended particulate matter $\quad \ldots \ldots \ldots 99$

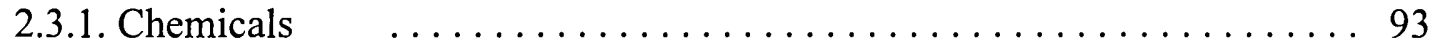

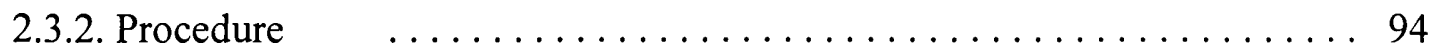

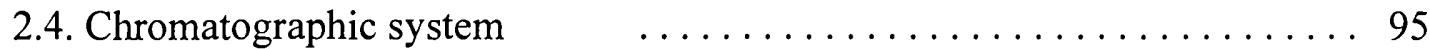

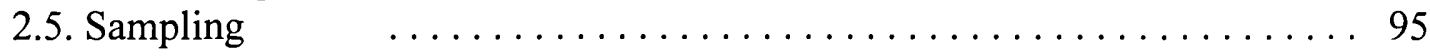

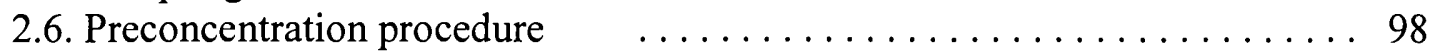

2.6.1. Lyophillization (freeze drying) $\quad \ldots \ldots \ldots \ldots \ldots \ldots \ldots \ldots \ldots \ldots$

2.6.2. Rotary evaporation and Lyophillization $\quad \ldots \ldots \ldots \ldots \ldots \ldots \ldots$ 


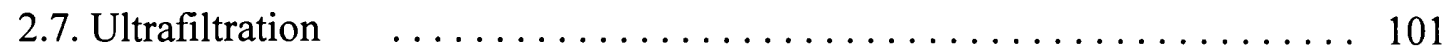

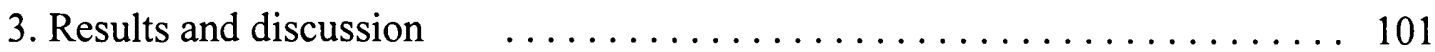

3.1. Conditions for the derivatization reaction $\quad \ldots \ldots \ldots \ldots \ldots \ldots \ldots 10 \ldots \ldots$

3.1.1. Termination of the reaction and stability $\quad \ldots \ldots \ldots \ldots \ldots \ldots \ldots 10 \ldots \ldots \ldots$

3.1.2. Reduction of oxidized thiols by TBP $\quad \ldots \ldots \ldots \ldots \ldots \ldots \ldots \ldots 102$

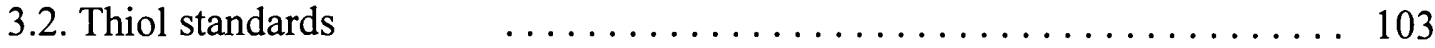

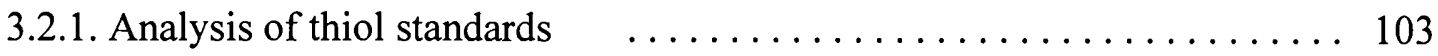

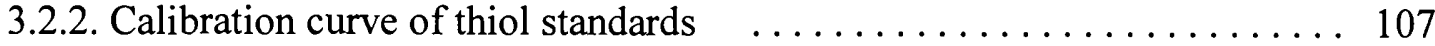

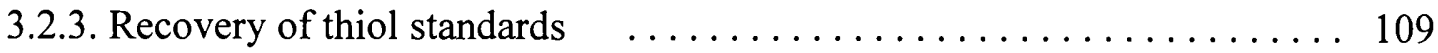

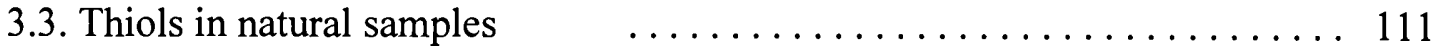

3.3.1. Thiols in surface waters $\quad \ldots \ldots \ldots \ldots \ldots \ldots \ldots \ldots \ldots \ldots \ldots \ldots 11$

3.3.2. Thiol characterization of size-fractionated samples $\ldots \ldots \ldots \ldots \ldots 119$

3.3.3. Alternative preconcentration technique for water samples $\ldots \ldots \ldots \ldots 121$

3.3.4. Thiols in suspended articulate matter $\quad \ldots \ldots \ldots \ldots \ldots \ldots \ldots 123$

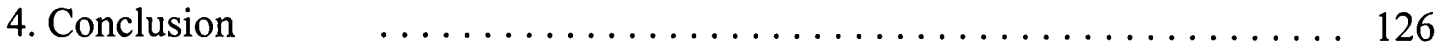

V. FUTURE RESEARCH $\quad \ldots \ldots \ldots \ldots \ldots \ldots \ldots \ldots \ldots \ldots \ldots \ldots \ldots$

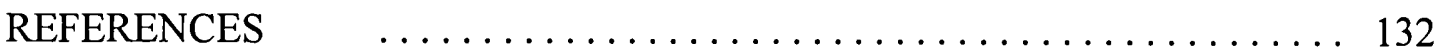


TABLE

PAGE

CHAPTER I. INTRODUCTION

Table I-1. Stability constants for Hg-DOM complexes reported in

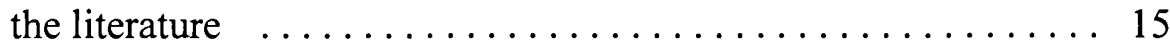

CHAPTER II. CHARACTERIZATION OF MERCURY SPECIES AND THEIR INTERACTIONS WITH DISSOLVED ORGANIC CARBON AND SULFUR IN SURFACE WATERS OF THE FLORIDA EVERGLADES.

Table II-1 Calibration standards (and second source standards) for total sulfur determination in water samples $\ldots \ldots \ldots \ldots \ldots 25$

Table II-2 Comparisons of analyte mean concentrations in water $\ldots 28$

Table II-3 Mathematical calculations for solute permeation from retentate

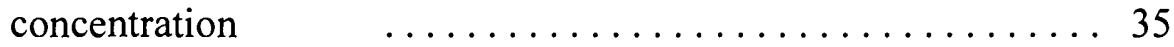

Table II-4 Concentrations of DOC and TS found in the blanks $\quad \ldots .41$

Table II-5 Operational definitions of the molecular weight fractions . . . 43

Table II-6 Physico-chemical characteristics ( $\mathrm{pH}$, Temperature, conductivity and dissolved oxygen) of the natural water samples collected in two locations in the Florida Everglades. SPM and concentrations of DOC in different size fractions of the dissolved phase were obtained by ultrafiltration $\ldots \ldots \ldots \ldots \ldots \ldots \ldots \ldots$

Table II-7 Concentrations of THg in SPM and in different size fractions of the dissolved phase obtained by ultrafiltration of water samples collected in two locations of the Florida Everglades $\ldots . .46$

Table II-8 Concentrations of $\mathrm{CH}_{3} \mathrm{Hg}$ in SPM and in different size fractions of the dissolved phase obtained by ultrafiltration of water samples collected in two locations of the Florida Everglades 50

Table II-9 Concentrations of TS in different colloidal fractions of the dissolved phase obtained by ultrafiltration of water samples collected in two locations of the Florida Everglades

Table II-10 Linear correlations $\left(\mathrm{R}^{2}\right)$ and regression expressed as $\% \mathrm{x}$ vs. \%y, for the different molecular weight fractions of the dissolved phase

Table II-11 Distribution coefficients for total mercury and Methylmercury with respect to DOC in surface waters of the Florida Everglades 
Table III-1 Characteristic properties for the studied natural water samples $\quad 70$

Table III-2 Elemental compositions of dissolved organic matter after using the prescribed vapor acidification procedure $\quad \ldots \ldots \ldots 71$

Table III-3 Assignment of $\mathrm{C} / \mathrm{N}$ ratios to possible sources of organic matter 72

Table III-4 Major chemical analysis of different dissolved organic matter

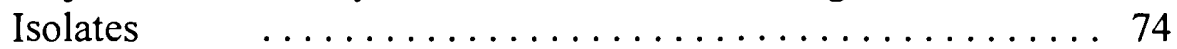

Table III-5 UV absorption measured at the indicated wavelength for different samples and the corresponding fractions obtained by parallel ultrafiltration $\quad \ldots \ldots \ldots \ldots \ldots \ldots \ldots \ldots$

Table III-6 $\quad{ }^{13} \mathrm{C}$-NMR spectra chief chemical shift ranges (ppm relative to tetramethylsilane) $\quad \ldots \ldots \ldots \ldots \ldots \ldots \ldots \ldots \ldots \ldots$

Table III-7 Distribution of carbon intensity in different regions of ${ }^{13} \mathrm{C}-\mathrm{NMR}$ spectra of different DOM isolates from surface waters from the Florida Everglades

CHAPTER IV. LOW MOLECULAR WEIGHT THIOL-CONTAINING COMPOUNDS IN NATURAL WATER AND SUSPENDED PARTICULATE FROM THE FLORIDA EVERGLADES

Table IV-1 Operating conditions for HPLC with fluorescence detection for thiol analysis in water samples $\ldots \ldots \ldots \ldots \ldots \ldots . \ldots 96$

Table IV-2 Operating conditions used to measure thiolic compounds in Particles

Table IV-3 Comparison of representative methods for the concentration of trace organic compounds in water

Table IV-4 Percent recovery of thiols spiked into Everglades freshwater Samples

Table IV-5 Percent recovery of relevant thiols spiked into preconcentrated natural water samples and suspended particulate

Table IV-6 Concentration of different thiols in the different molecular weight cut off fractions of the dissolved organic matter from the Florida Everglades. ${ }^{\text {a }}$ Concentrations of unidentified thiols were calculated based on the glutathione standard response.

${ }^{\mathrm{b}}$ Ratio obtained with respect the thiol concentration in the dissolved phase $(<0.2 \mu \mathrm{m})$

Table IV-7 Analysis of thiols extracted from the SPM from water samples from different locations in the Florida Everglades 


\section{LIST OF FIGURES}

FIGURE

PAGE

\section{CHAPTER I. INTRODUCTION}

Figure I-1. The mercury cycle. Sources and fate

Figure I-2. Diagram summarizing the biogeochemical cycling of mercury in aquatic environments

CHAPTER II. CHAACTERIZATION OF MERCURY SPECIES AND THEIR INTERACTIONS WITH DISSOLVED ORGANIC CARBON AND SULFUR IN SURFACE WATERS OF THE FLORIDA EVERGLADES.

Figure II-1 Schematic map of South Florida showing the sampling locations (marked), as well as the Everglades Agricultural Area (EAA), Water Conservation Areas (WCA) and Everglades National Park

Figure II-2 Data showing the minimum volume of solvent $(1 \% \mathrm{HCl})$ Necessary to achieve low blank levels in filtered samples

Figure II-3 Schematic diagram of the ultrafiltration system for determination of the initial concentration of an analyte from its retentate concentration $\ldots \ldots \ldots \ldots \ldots \ldots \ldots \ldots \ldots \ldots$

Figure II-4 Outline of the filtration procedure $\quad \ldots \ldots \ldots \ldots \ldots \ldots \ldots$

Figure II-5 Schematic diagram for the organomercurial column pre-concentration apparatus

Figure II-6 Results of the mass balance calculated by difference (expressed in wt\%) between the input and output of analyte quantities through the $3 \mathrm{KDa}$ filtration membrane

Figure II-7 Distribution in suspended particulate matter and in different colloidal fractions of dissolved total mercury for two locations in the Florida Everglades

Figure II-8 Distribution of dissolved methylmercury in suspended particulate matter and in different colloidal fractions for two locations in the Florida Everglades

Figure II-9 Distribution in suspended particulate matter and in different colloidal fractions of TS and DOC for two locations in the Florida Everglades

Figure II-10 Percent DOC, THg, $\mathrm{CH}_{3} \mathrm{Hg}$ and TS associated with different molecular weight fractions of the dissolved phase

Figure II-11 A) Percent methylmercury and B) percent total mercury in different molecular weight fractions of the dissolved phase versus the percent DOC in each fraction 
Figure II-12 A) Percent methylmercury and B) percent total mercury in different molecular weight fractions of the dissolved phase versus the percent TS in each fraction

CHAPTER III. SPECTROSCOPIC STUDIES OF DOM SIZE

FRACTIONATEDISOLATES FROM SURFACE WATERS OF THE FLORIDA EVERGLADES

Figure III-1 Absorbance ratio $\left(\mathrm{A}_{\text {fraction }} / \mathrm{A}_{\text {sample }}\right)$ of different size fractions of surface waters with respect to the absorbance of the unfractionated sample

Figure III-2 Synchronous fluorescence spectra of a natural sample from the Florida Everglades

Figure III-3 ${ }^{13}$ C-CPMAS NMR spectra of various DOM size fraction isolates obtained by sequential ultrafiltration. A) $<3 \mathrm{KDa}$; B) $30 \mathrm{kDa}-3 \mathrm{kDa}$; C) $<30 \mathrm{kDa}$; D) $0.2 \mu \mathrm{m}-30 \mathrm{KDa}$; E) $<0.2 \mu \mathrm{m}$

CHAPTER IV. LOW MOLECULAR WEIGHT THIOL-CONTAINING COMPOUNDS IN NATURAL WATER AND SUSPENDED PARTICULATE FROM THE FLORIDA EVERGLADES

Figure IV-1 Chromatograms of SBD-cysteine derivatives that illustrates the effects of the presence and absence of the reducing agent TBP: A) without TBP; B) with TBP. 1: cysteine; 2,3: impurities or side reaction products 105

Figure IV-2 Chromatograms of $\mathrm{L}_{\mathrm{L}}$-cysteinyl-glycine shows

1: SBD-L-cysteinyl-glycine and 2: other products resulted from decomposition and/or rearrangement reactions, likely SBD- $\gamma$-L-glutamil-L-cysteine 106

Figure IV-3 Chromatograms of multiple SBD-thiol standard derivatives.

1: ${ }_{\mathrm{L}}$-cysteine; 2 : cystamine; $3:{ }_{\mathrm{L}}$-homocysteine; 4 : glutathione;

5: $\gamma$-L-glutamil-L-cysteine

Figure IV-4

Calibration curves of three low molecular weight thiols 109

Figure IV-5 Determination of thiols and disulfides in a natural preconcentrated water sample collected in the Florida Everglades. A) Derivatized sample without reduction; B) Derivatized sample after reduction with TBP; C) Natural freshwater sample blank, treated in the same manner as the latter but without the fluorogenic tagging reagent (SBD-F)

Figure IV-6 HPLC chromatograms of the preconcentrated natural water sample collected in the Florida Everglades (WCA-1A):

A) sample blank without any reagents; B) sample blank after reduction with TBP. 
Figure IV-7 HPLC chromatograms of the SBD-thiol derivatives of a preconcentrated natural water sample collected in the Florida Everglades: A) derivatized sample without reduction with TBP; B) derivatized sample after reduction with TBP

Figure IV-8 Determination of thiols and disulfides in the truly dissolved fraction $(<3 \mathrm{KDa})$ of preconcentrated natural water sample collected in the Florida Everglades (WCA-1A). A) Natural sample blank, reduced with TBP but without the fluorogenic tagging reagent (SBD-F); B) Reduced thiols in the derivatized sample obtained without adding TBP; C) Oxidized thiols, derivatized sample after treatment with TBP; D) Mixture of three standards: cysteine, glutathione and $\mathrm{N}$-acetyl-cysteine

Figure IV-9. Determination of thiols and disulfides in a natural water sample collected in the Florida Everglades preconcentrated by cross-flow ultrafiltration and desalted. A) Natural sample blank, reduced with TBP but without the fluorogenic tagging reagent (SBD-F); B) Reduced thiols in the derivatized sample obtained without adding TBP; C) Oxidized thiols, derivatized sample after treatment with TBP

Figure IV-10. A) The presence of multiple peaks for a single standard in the absence of TBP is illustrated for L-cysteynil-glycine.

B) Key to compunds: decomposition and/or rearrangement reactions give yield to these products. 


\section{LIST OF ACRONYMS}

$\mathrm{C}_{3 \mathrm{~F}} \quad$ Analyte concentration in the filtrate through a $3 \mathrm{KDa}$ membrane

$\mathrm{C}_{0.2} \mathrm{~F} \quad$ Initial analyte concentration

$\mathrm{C}_{3 \mathrm{R}} \quad$ Analyte concentration in the retentate through a $3 \mathrm{KDa}$ membrane

$\mathrm{CH}_{3} \mathrm{Hg} \quad$ Methylmercury

${ }^{13} \mathrm{C}$-NMR $\quad{ }^{13} \mathrm{C}$ - Nuclear Magnetic Resonance

Cond Conductivity

CPMAS Cross-Polarization and Magic Angle Spinning

CSM Cystamine

CST Cystine

CTHIO Cystathionine

CYS L-Cysteine

CYS-GLY L-Cysteynyl-Glycine

DDIW Distilled deionized water

DIW Deionized Water

DMF N,N-Dimethylformamide

DO Dissolved Oxygen

DOC Dissolved Organic Carbon

DOM Dissolved Organic Matter

DTS Dissolved Total Sulfur

EDTA Ethylenediaminetetraacetic acid

FTIR Fourier Transform Infrared Spectroscopy

GSH Glutathione 
$\gamma$-GLU-CYS Gamma-L-Glutamyl-L-Cysteine

HCYS Homocysteine

HCST Homocystine

HPLC High Performance Liquid Chromatography

IC Inorganic Carbon

ICP-MS Inductively Coupled Plasma Mass Spectrometry

$\mathrm{K}_{\mathrm{c}} \quad$ Distribution of mercury species in the colloidal phase $(0.2 \mu \mathrm{m}-3 \mathrm{KDa})$

in relation to the truly dissolved phase

$\mathrm{K}_{\mathrm{d}} \quad$ Distribution coefficient

KDa Kilo Dalton

$\mathrm{K}_{\mathrm{p}} \quad$ Distribution of mercury species in the particulate in relation to the truly dissolved phase

$\mathrm{K}_{\mathrm{p}+\mathrm{c}} \quad$ Distribution of mercury species in the particulate and colloidal phase

$(0.2 \mu \mathrm{m}-3 \mathrm{KDa})$ in relation to the truly dissolved phase

$\mathrm{MBrB} \quad$ Monobromobimane

MBSR Monobromobimane thioester

MSA Methanesulfonic acid

NAC N-Acetyl-L-(+)-Cysteine

OC Organic Carbon

OPA o-phthalaldehyde

ROS Reducing Organic Sulfur

SBD-F Ammonium 7-fluorobenzo-2-oxa-1,3-diazole-4-sulphonate

SPM Suspended Particulate Matter 
Temperature

TBP Tributylphosphine

TFA Trifluoroacetic acid

TN Total Nitrogen

THg Total mercury

TOC Total Organic Carbon

TS Total sulfur

USEPA United States Environmental Protection Agency

$\mathrm{V}_{3 \mathrm{~F}} \quad$ Volume of filtrate through a $3 \mathrm{KDa}$ membrane

$\mathrm{V}_{0} \quad$ Initial volume of sample

$\mathrm{V}_{3 \mathrm{R}} \quad$ Volume of retentate through a $3 \mathrm{KDa}$ membrane

WCA Water Conservation Area 


\section{Chapter I. Introduction}

\section{Mercury contamination in the environment}

Mercury is a liquid metal at ambient temperatures and pressures. It forms salts in two ionic states: mercury(I) and mercury(II). Mercury(II) salts are much more common in the environment, and if soluble in water are bioavailable and considered toxic. Mercury also forms organometallic compounds, many of which have industrial and agricultural uses. Elementary mercury gives rise to a vapor that is only slightly soluble in water, but is problematic because of easy transport in the atmosphere. The most common form of mercury is insoluble mercury(II) sulfide (naturally occurring cinnabar) which is less bioavailable ( Pirrone, 2001; Renneberg and Dudas, 2001).

In contrast to many other metal/metalloid contaminants, mercury displays a complex environmental speciation behavior. Widespread, detectable environmental mercury species include divalent mercury $\left(\mathrm{Hg}^{2+}\right)$, elemental mercury $\left(\mathrm{Hg}^{0}\right)$ and monomethylmercury $\left(\mathrm{CH}_{3} \mathrm{Hg}^{+}\right)$(Schroeder et al., 1989; Akagi et al., 2000). Less frequently encountered compounds include dimethylmercury (Mason et al., 1995), monovalent mercury $\left(\mathrm{Hg}_{2}{ }^{2+}\right.$; a species that disproportionates via the following reaction: $\mathrm{Hg}_{2}{ }^{2+} \rightarrow \mathrm{Hg}^{2+}+\mathrm{Hg}$ (Pehkonen and Li, 1989) and, more recently, detectable quantities of ethylmercury compounds (e.g., $\mathrm{C}_{2} \mathrm{H}_{5} \mathrm{Hg}^{+}, \mathrm{C}_{2} \mathrm{H}_{5} \mathrm{HgC}_{2} \mathrm{H}_{5}$, etc.) have been reported in environmental media (Cai et al., 1997; Hintelmann and Wilken, 1995).

Elemental mercury is known to be globally transported before deposited on soil or water (Pilgrim et al., 2001). Mercury contamination has long been recognized as a problem for both humans and ecosystems. Mercury is considered by the United States Environmental Protection Agency (EPA) as a highly dangerous element because 
methylated mercury is accumulative and persistent in the environment and biota. Since mercury does not degrade once it is released to the environment it will always be present in one form or another (USEPA, 2000a). Mercury in natural waters is mostly in the form of inorganic species; however, its biological toxic effects are primarily due to methylmercury. Unfortunately, the inorganic mercury released into the environment can be converted, by naturally-occurring biological processes, into methylmercury species. This highly toxic organomercury species is present in much lower concentrations and is readily accumulated by aquatic organisms (Sanchez-Uria and Sanz-Medel, 1998).

Methylmercury is neurotoxic, causes blockage of binding sites of enzymes, interferes with protein synthesis, impedes thymidine incorporation into DNA, among other factors (Thayer, 1984; Halbach, 1995). The short chain alkylmercury compounds are toxic and tend to bioaccumulate more readily than other species of mercury. The mercury-carbon bond is very stable, and the presence of the alkyl groups confers lipid solubility. Nearly all mercury found in fish flesh (>95\%) occurs as methylmercury (Porcella, 1994), and most of the mercury present in humans originates from fish in the food supply (USEPA, 2000b) via the following processes: (1) emission of mercury to the air; (2) mercury air transport and deposition on land and water; (3) transformation of mercury to methylmercury in water bodies; (4) methylmercury uptake and bioaccumulation in fish; and (5) consumption of contaminated fish by mammals, including humans. Mercury and methylmercury exposures can result in permanent damage to the brain and kidneys, in both humans and wildlife. Many organisms and agencies have addressed the level of methylmercury exposure to humans. 
Several pollution events have been associated with the anthropogenic use of organomercurials. The most documented case of methylmercury poisoning occurred in Minimata Bay, Japan (from 1932 until diagnosed in 1968), from which the name Minimata Disease derived (Clarkson, 1972, 1992; Hosokawa, 1993; Smith and Smith, 1975). More than 2,000 people were poisoned by the consumption of fish and shellfish contaminated with methylmercury. This was the first known case of mercury pollution in the aquatic environment. It was caused by the discharge of methylmercury into the drainage channel that leads into the Minimata Bay. Methylmercury was formed during the production of PVC formed by reacting acetaldehyde and inorganic mercury used as catalyst. Also organomercurials were used as fungicides for cereal infections in the 1960's. This caused a particularly disastrous outbreak in 1972 in Iraq, where the seed grain coated with antifungal methylmercuric preparations were consumed as homemade bread. As a result 6,530 victims were much ill (Watanabe and Satoh, 1996). The impact on ecological systems was noted earlier (1964) by Swedish ornithologists who observed a significant decrease in wild bird populations (Helander et al., 1982). Nowadays the pathway of exposure to methylmercury involves the emission of low concentrations of mercury, mainly from combustion sources. These emissions lead to build up of methylmercury in water bodies and fish tissue over time. It is important to stress that the most likely individuals who are being exposed to a high level of methylmercury are consumers of large quantities of fish. Pregnant women and young children are particularly sensitive to exposure of high levels of mercury.

During the past decade, a new trend has emerged with regards to mercury pollution (Kambey et al., 2001). Investigations initiated in the late 1980s in the northern-tier states 
of the United States, Canada and the Nordic countries found that fish, mainly from oligotrophic lakes and often in very remote areas, commonly have high levels of mercury. More recently fish sampling surveys in other regions of the United States have shown widespread mercury contamination in streams, wetlands, reservoirs and lakes (USGS, 1998).

Most of the mercury released to the atmosphere by anthropogenic activities is in the form of the elemental mercury vapor. It may also be bound to airborne particles that can be widely transported from the source of emission (USEPA, 1997). This element may be deposited into surface waters and lands. Most of the mercury in waters, soils, sediments, or plants and animals is in the form of inorganic mercury salts and organic forms of mercury. However, methylmercury has been found to be the predominant form of mercury in the tissues of fish caught in water containing predominantly inorganic mercury (Monsalud, 1999). Therefore a chemical transformation of inorganic mercury $\left(\mathrm{Hg}^{2+}\right)$ to methylmercury $\left(\mathrm{CH}_{3} \mathrm{Hg}^{+}\right)$occurs in the natural environment. Methylation of mercury has been shown to involve both biotic and abiotic pathways (Jensen and Jernelov, 1969; Nagase et al., 1982; Weber, 1993; Wood et al., 1969). By highly efficient bioaccumulation and biomagnification, neurotoxic methylmercury would eventually reach our food chain especially from seafood (Topping and Davies, 1981). USEPA (1997) conducted a quantitative human health risk assessment of methylmercury. The assessment estimated that between 1-3\% of women of childbearing age in the US eat sufficient amounts of fish for their fetuses to be at risk from methylmercury exposure. The EPA's reference dose for methylmercury of $0.1 \mu \mathrm{g}$ per g of body weight per day is 
viewed as a scientifically justifiable level (NRC, 2000) for protecting human health from the adverse effects of methylmercury.

\section{Sources of mercury in the environment}

Natural mercury emissions include volcanoes, natural mercury deposits and volatilization from the ocean (USGS, 1998) which was estimated recently by Mason et al. (1994) as 2000 tons per year. Naturally mercury-enriched material found associated with plate tectonic boundaries, areas of high crustal heat flow, precious and base metal mineralization, recent volcanism, and organic rich sedimentary rocks (Rasmussen, 1994). Large areas of land in the western United States are enriched in mercury, and mercury deposits are abundant (Jonasson and Boyle, 1972). However, since the $19^{\text {th }}$ century the total amount of mercury in the environment has grown by a factor of 2 to 5 above preindustrial levels (Mason et al., 1994). Mercury was widely used in industry because of its diverse properties. As a consequence, it is clear that industry was an important source of mercury in the environment. Human activities are primarily responsible for mercury pollution, mainly from combustion and waste incineration (Porcella et al., 1997), from scrubber water or coal cleaning water produced by coal fired power plants and solid waste incinerators (Carroll and Truman, 1995). The intentional use of mercury in products (i.e., batteries, paints, pesticides) in the US has decreased significantly in the past 20 years (US Dept. of Int., 1994).

Elevated levels of mercury in waters remote from anthropogenic emission sources have also been documented (Swain et al., 1992; Rasmussen, 1994; Sorensen et al., 1994). This indicates that atmospheric deposition is an important source of contamination. This situation raises concerns about increasing amounts of mercury in the global pool and the 
implications of mercury emissions and their impacts on both people and ecosystems worldwide. In December 2000, the EPA announced its intention to regulate mercury emissions from fossil fuel electric power plants under the Clean Air Act (Environmental Reporter, 2000). In addition to air emissions, mercury is also released in other ways, including waterborne discharges and direct disposal to the land.

Over the years, some mercury compounds have been specifically developed as pesticides, fungicides, and germicides to be used on grains, in paints, and with vaccines (USEPA, 2000a). The examples of the usage of organomercury compounds include methylmercury and ethylmercury and phenylmercury as a fungicide and cereal seed treatment; thiomersal and mercurochrome as antiseptics; mersalyl, chlormerodrin, mercurophen and mercurophylline as diuretics. Although some of these compounds are not used any longer, their removal is not uniform throughout the world: ranging from outright bans, to recommendations and voluntary codes (Craig,1986).

\section{Biogeochemical cycling of mercury}

Once released into the environment, mercury is subject to a variety of processes and interactions. Environmental mercury is thought to move through various environmental compartments, possibly changing forms and species during this process. Like other elements, these processes are conceptualized as a cycle. Figure I-1 illustrates mercury release by both natural and anthropogenic sources into environmental media: air, soil and water. When airborne mercury is deposited on land or in water, biological transformations can occur that converts some of the mercury to methylmercury. The amount of mercury transformed to methylmercury varies from one water body to another. 


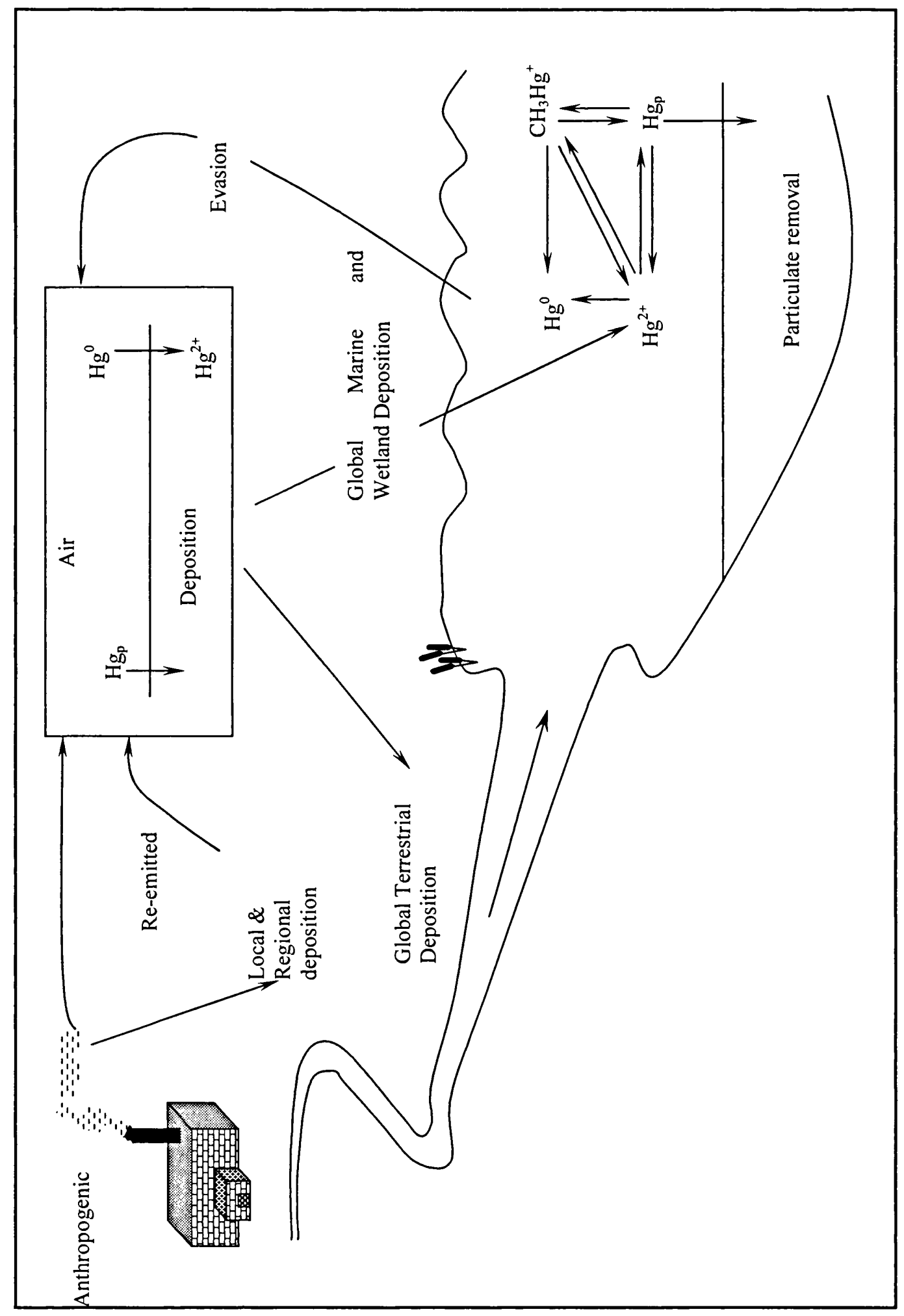

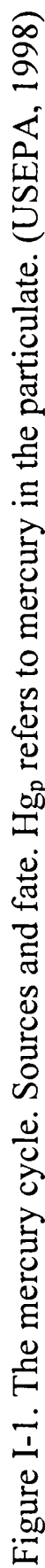


Beyond mercury loading, the environmental setting (i.e. climate, geology, land use, land cover), water chemistry and wetland density (Cleckner et al., 1999) are the most important factors controlling methylmercury production. However, these factors seem very complex and variable, and not altogether predictable. The exact mechanism by which mercury enters the food chain is largely unknown. However, EPA reported that bacteria that process sulfate in the environment places an important role by taking up the mercury in its inorganic form and through metabolic processes, converting it to methylmercury (USEPA, 1997). Dimethyl- and methylmercury, $\mathrm{Hg}^{2+}$ and elemental mercury may interchange in a general biochemical cycle. This accounts for the formation of methylmercury in remote areas where it has not been directly introduced to the environment, but where $\mathrm{Hg}^{2+}$ may have been used. A scheme with a summary of the biogeochemical cycling of mercury is presented in Figure I-2.

In lakes, rivers and reservoirs methylmercury is taken up by fish, resulting in significant methylmercury bioaccumulation in fish tissue. Nearly all the mercury that accumulates in fish tissue is methylmercury. Inorganic mercury is less efficiently absorbed and eliminated to a higher extent. In some instances the concentration of methylmercury in fish may be several orders of magnitude greater than the concentrations in the surrounding water or sediment. Research in mercury transport, transformations and fate will improve our understanding of the complexity of mercury processes once it enters the environment, and allow improved future regulatory efforts. 

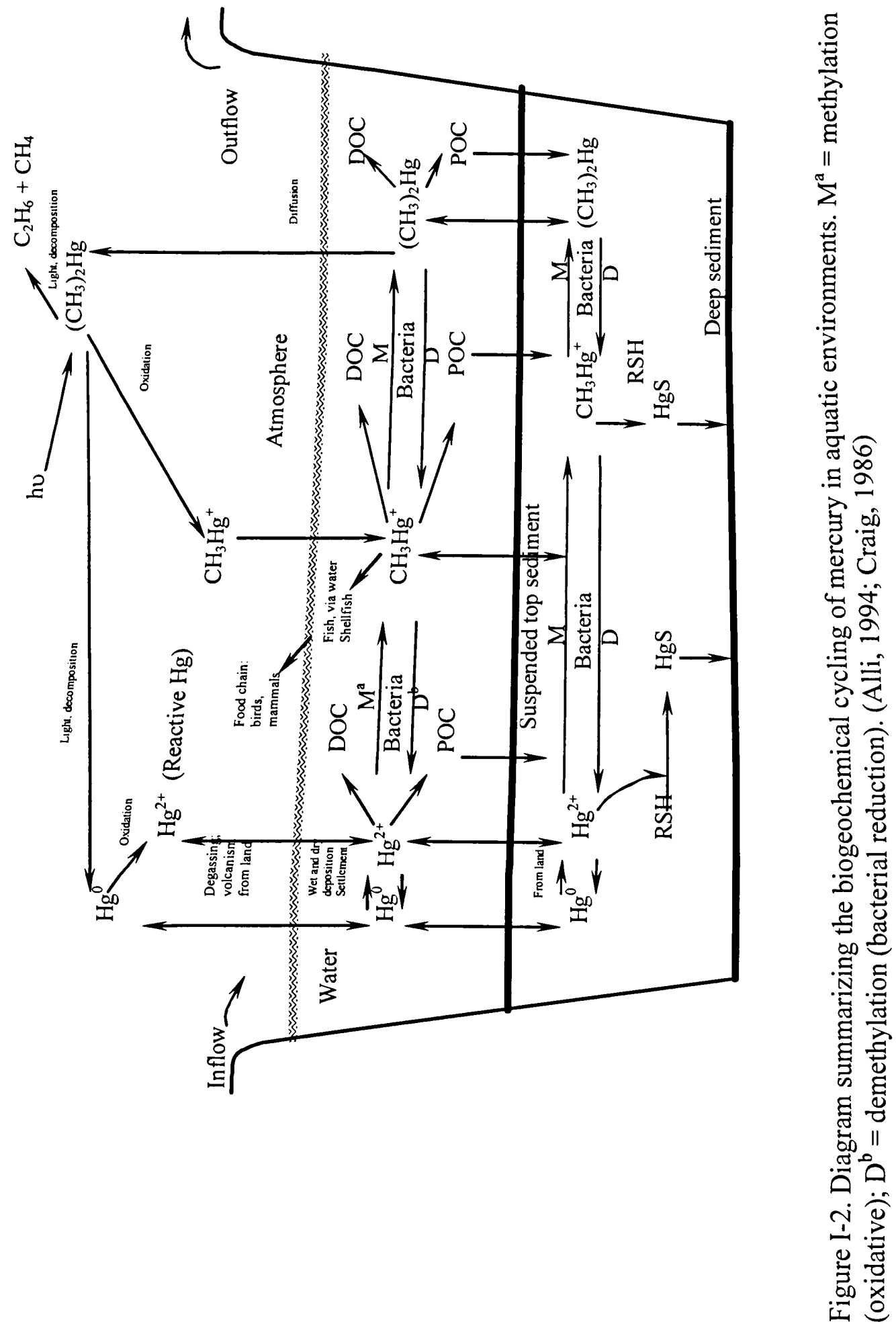


\section{Mercury in the Everglades}

The Florida Everglades is among the largest freshwater wetlands in the world. It covers a region about $60 \mathrm{Km}$ wide by $160 \mathrm{Km}$ long and extends south of Lake Okeechobee to Florida Bay (Stober et al., 1995). The Everglades ecosystem has been greatly altered during the last century to provide for urban and agricultural development, which has severely impacted this ecosystem. In 1948, the Central and Southern Florida Flood Control Project was created by federal legislation in response to periods of drought in the 1930s and 1940s, and severe flooding with loss of human life in the 1920s and 1940s. This project is one of the most intensive public water management systems constructed that effectively provides flood control and water supply to facilitate urban and agricultural growth, as intended. The canal system quickly drains water from developed areas and the wetlands that remain. The result is that some areas are too wet while other areas are too dry. Historically, most water slowly flowed across or soaked into the region's vast wetlands. Today, over one-half of the region's wetlands have been irreversibly drained. South Florida's population of about six million continues to grow and compete for the land and water of the Everglades ecosystem. One-fourth of the historic Everglades are now in agricultural production: sugar cane and vegetables are grown on the peat soils of drained sawgrass marshes. An extensive system of canals, levees, and water control structures have modified the Everglades water conditions and it is thought to provide a conduit for pollutant transport from urban and agricultural areas (e.g. a pump station discharges untreated stormwater from an urban basin into the Everglades). 
In the last two decades there has been an increased awareness of mercury contamination of game fish and wildlife in the Florida Everglades. About one million acres of the Everglades system reportedly contained large mouth bass with mercury concentrations above $2 \mathrm{mg} / \mathrm{Kg}$ (Ware et al., 1990; Florida DEP, 1994), double the FDA limit for human consumption. In addition, mercury accumulation may reduce the breeding success of fish-eating birds (Frederick and Spalding, 1994) and an endangered Florida panther was found dead with a high liver methylmercury concentration of 110 ppm (Roelke et al., 1991). In response, fish consumption advisories have been issued for almost the entire Everglades system (USEPA, 2000b).

To understand the biogeochemical cycling of mercury in the Everglades ecosystem, it is necessary to understand the processes and factors influencing the flux of mercury through this system. The mercuric ion is the predominant species in the Everglades aquatic environment. However, sulfate-reducing bacteria can transform inorganic mercury into methylmercury. Various hypotheses have been formulated to account for the apparent susceptibility of the Everglades to mercury impacts (SFMSP, 1996), including a high rate of net methylation of mercury and a high bioavailable fraction of methylmercury.

The sources, distribution, transport, transformations and pathways of mercury through the Everglades are not well understood. Among the possible mercury sources are natural mineral and peat deposits, atmospheric deposition, local emission sources such as medical and municipal waste incinerators, regional air emissions sources such as power plants, and local water sources such as agricultural runoff (US Dept. of Int., 1994). Although there are multiple interactions among these sources and several possible 
pathways for mercury transport and bioaccumulation through the Everglades ecosystem, none of these individual sources appears to explain the vast Everglades' area apparently contaminated.

In 1993, USEPA Region IV and the Florida International University Southeast Environmental Research Center (FIU-SERC) began the South Florida Ecosystem Assessment Project to monitor the condition of the South Florida Everglades ecosystem in order to provide timely ecological information that contributes to environmental management decisions on the Everglades and its restoration (USEPA, 2000b). Statistical results from the Environmental Monitoring and Assessment Program (EMAP), lead by USEPA, indicate that the Everglades Agricultural Area canals are loading the public Everglades with excess phosphorus, carbon and sulfate. The phosphorus, carbon and sulfate concentrations progressively decrease downstream from Lake Okeechobee to the Southern part of the Everglades (USEPA, 2000a). These significant gradients from north to south correlate well with mercury and methylmercury contamination in the Everglades. It appears that the canal system is an effective way for the transport of the degraded water into and through the Everglades marsh system. However, the highest mercury concentrations were found in the Everglades marshes, not in the canals. On the other hand, gradients for total mercury in sediment and fish were reversed from south to north (Stober et al., 1995). High concentrations of methylmercury were found not only in fish and birds, but also in algae in the marsh between Alligator Alley and Tamiami Trail. In this particular area, the environmental conditions for the microbial transformation of inorganic mercury to methylmercury seem to be optimal. 


\section{Interactions of mercury and dissolved organic matter}

Dissolved organic matter (DOM) consists of a heterogeneous mixture of organic compounds. DOM found in natural aquatic systems can be roughly divided in two groups: solutes belonging to well-known classes of organic compounds, such as proteins, carbohydrates, phenols, fats, waxes, resins, simple organic acids, etc. and complex heterogeneous mixtures of organic solutes, generally called humic substances (Maie et al., 2002). The major pathway for the production of humic substances appears to be through condensation reactions involving polyphenols and quinones (Stevenson, 1982). Humic substances can be defined operationally with the aid of the miscellaneous procedures applied for their isolation. Under all environmental conditions humic substances play a very important and essential role in the carbon cycle in nature (Stevenson, 1992). In general, aquatic humic matter in fresh water ecosystems accounts for the major part of the DOC.

DOM is ubiquitous in aquatic environments and is known to bind trace metals strongly, affecting their speciation, solubility, mobility and toxicity (Buffle, 1988). The association DOM- trace metal is found to be partially controlled by the molecular size distribution of the dissolved organics (Cai, 1999). Traditionally, DOM is defined as the portion passing through a $0.45 \mu \mathrm{m}$ or $0.2 \mu \mathrm{m}$ filter and POM as the particulate phase retained portion by the filter. Particles and the processes associated with their formation can act as either a mechanism to remove mercury from the water column by settling, or as carriers of mercury by transport as suspended material. The waters of the Everglades are typically rich in dissolved organic matter. The humic substances present in these waters are expected to play an important role in the transport and ultimate fate of mercury 
in this aquatic system, since they are extremely reactive and generally have short residence times (Martin et al., 1995). Many metals in natural waters have solubilities much higher than expected from calculations based on complexation with inorganic ligands. The enhanced solubility is due to the complexation and/or adsorption of these metals with DOM that therefore may play an important role in the biogeochemistry of mercury in aquatic environments (Watras et al., 1995a). Cai et al. (1999) developed an ultrafiltration procedure to study the interactions between organic carbon and mercury species revealing a different distribution pattern in the suspended particulate, colloidal and truly dissolved phases. Significant binding of mercury by natural DOM in surface waters is suggested by the positive correlation between concentrations that have frequently been observed in both lake and river waters (Mierle and Ingram, 1991; Driscoll et al., 1995; Watras et al.,1995b; Watras et al., 1998 and Babiarz et al., 1998). Although co-transport of mercury and DOM from watersheds can contribute to the mercury load in a water body, this association may also decrease the bioaccumulation of mercury in food webs by lowering the bioavailability of mercuric ion to methylating organisms.

The binding between mercury and humic substances is so strong that the speciation of both inorganic and methylated mercury in freshwater may be largely dominated by humic complexes (Mantoura and Riley, 1975; Allard and Arsenie, 1991; Hintelmann et al., 1995, 1997 and Meili, 1997). Lu and Jaffe (2001) studied the interaction between $\mathrm{Hg}(\mathrm{II})$ and DOM using fluorescence spectroscopy, including the conditional stability constants and the percentage of fluorophores participating in the complexation. The 
strength of mercury- DOM complexes has been reported in terms of conditional stability constants for aquatic humic substances as indicated in Table I-1.

Table I-1. Stability constants for Hg-DOM complexes reported in literature

\begin{tabular}{lll}
\hline Type of organic matter & $\log \mathrm{K}$ & Reference \\
\hline Bog water concentrated organic matter & 10.4 & Lovgren and Sjoberg, 1989. \\
\hline Lake and river humic substances & $18.4-21.1$ & $\begin{array}{l}\text { Mantoura and Riley, 1975. } \\
\text { Mantoura et al., 1978. }\end{array}$ \\
\hline
\end{tabular}

Methylmercury is formed in the aquatic environment depending on several factors that include availability of mercury and organic carbon, sulfate levels, and extent of anoxic conditions (Hurley et al., 1998). Sjöblom et al. (2000) concluded that dissolved humic substances decreased the bioavailability of dissolved inorganic mercury and methylmercury in the aquatic environment. Therefore, information regarding the interactions between DOM and methylmercury, as well as total mercury, is critical to understand the biogeochemical cycling and the bioavailability of mercury in the aquatic environment. This is especially important for the Everglades ecosystem since the waters of the Everglades are typically high in organic matter and methylmercury accounts for about $10 \%$ of the total mercury found in Everglades surface waters (USEPA 2000a).

\section{Mercury and sulfur interactions}

Because of the soft metal (low-oxidation-state metal with excess electron density) character of $\mathrm{Hg}^{2+}$ and $\mathrm{RHg}^{+}(\mathrm{R}=$ alkyl), mercury species have a high affinity towards thiol groups, resulting in increased biotransport, distribution and toxicity of mercury species. It is well known that the reactivity of thiol to mercury is strong compared to 
other transition metal ions (Cestari and Airoldi, 1997). It is not known in which way the mercury species are bound to organic matter, but we could assume that the association of mercury to the DOM via reduced organic sulfur-type binding functional group play an important role. Model calculations with thiol-type binding instead of carboxylic and phenolic (Guentzel et al., 1996) were successfully applied to explain mercury behavior in the Ochlockonee river estuary, Florida, USA. Humic substances may contain reduced organic sulfur-type species such as thiol $(-\mathrm{SH})$, or disulfide $(-\mathrm{S}-\mathrm{S})$ groups from sulfurcontaining amino acids (Strohal and Huljev, 1971). Such sulfur-containing groups are also involved in the very strong binding or complexation of mercury to humic substances (Dyrssen and Wedborg, 1991; Jackson, 1993; Lee and Hultberg, 1990; Schuster, 1991; Hintelmann et al., 1995 and 1997), as also suggested by Cai et al. (1999).

Recently, information on the sulfur speciation in humic substances has been obtained using X-ray absorption near edge structure (XANES) spectroscopy (Morra et al., 1997; Vairavamurthy et al., 1997; Xia et al., 1998). The organic sulfur species present in the DOM can be divided into three groups based on their oxidation states (Vairavamurthy et al., 1997): reduced sulfur, slightly oxidized sulfur, and highly oxidized sulfur. The reduced sulfur species contain sulfur in oxidation states between 0 and -2 including thiols (R-SH), organic sulfides (R-SR), organic polysulfides, and thiophenes. Given the high affinity of mercury for thiol groups (Dyrssen and Wedborg, 1991; Schuster, 1991, and Xia et al., 1998), Benoit et al. (2001) hypothesized that the complexation reaction can be written as:

$$
\mathrm{Hg}^{2+}+\mathrm{RSH}^{\mathrm{n}-}=\operatorname{HgRS}^{(\mathrm{n}-1)-}+\mathrm{H}^{+}
$$


The reactions of mercury species with reduced sulfur species are important for the environmental chemistry of mercury and its speciation, due to the marked difference in toxicity between organomercury compounds, $\mathrm{Hg}^{2+}$ compounds and elemental mercury.

\section{Rationale and Objectives}

The Everglades mercury problem has been extensively investigated, however, many questions still remain to be answered. One of such questions is that the importance of DOM in the biogeochemical cycling of mercury. Although the importance of DOM in mercury fate and transport has long been recognized, little is known about the nature of the mercury-DOM and particularly methylmercury-DOM interactions. While it is important to understand the distribution of mercury species, it is also necessary to examine the processes by which different mercury compounds are formed, mobilized and transported through the Florida Everglades ecosystem, particularly particles and organic matter. Environmental mercury is frequently associated with natural organic matter in aquatic environments. A study by Loux (1998) assesses the potential binding of mercury species with natural organic matter by hydrophobic and ionic mechanisms. The findings suggest that binding with organic matter occurs probably through ionic reactions with sulfhydryl-binding sites. Potential hydrophobic binding with natural organic matter will likely occur in the following sequence $\left(\mathrm{CH}_{3}\right)_{2} \mathrm{Hg}>\mathrm{Hg}^{0}>\mathrm{CH}_{3} \mathrm{HgX}$ (where $\mathrm{X}=\mathrm{OH}^{-}$or $\mathrm{Cl}^{-}$) Loux (1998), but none of these species appear to be strongly hydrophobic and hence, hydrophobic processes cannot explain observed organic matter-mercury associations in low-solids-content aquatic systems; additionally, hydrophobic binding mechanisms of the various mercury species are insufficient to explain observed environmental 
bioconcentration factors. On the other hand, ionic mercury binding with carboxyl-type sites on natural organic carbon is not sufficiently energetic to explain observed mercuryorganic matter associations in the environment. Therefore, environmental mercury binding with organic matter probably occurs through ionic reactions with naturally occurring sulfhydryl binding sites. Because reduced organic sulfur species are commonly found in porewaters and surface waters of the Florida Everglades (Gilmour et al., 1998), it is very important to determine the effect of organic matter and reduced organic sulfur (ROS) in mercury speciation. The binding of mercury with organic matter cannot be explained by any single listed factor.

This work will target the interactions of mercury species with DOM and suspended particulate and the effects of such phase interactions on the fate, transport and bioavailability of mercury in this system. The major goals are:

1. Investigate the interactions between mercury species (total mercury and methylmercury), DOM, and dissolved total sulfur (DTS), by analyzing their distributions among different molecular weight size fractions. This investigation will provide an indication of the processes that lend to mercury and methylmercury enrichment in the Everglades related to DOM and DTS.

2. Determine the functional groups and chemical characteristics of the DOM in different fractions. This allows and assessment of the influence of functional groups of the DOM on mercury behavior, by the identification of possible binding groups.

3. Investigate the identity of some of the reduced organic sulfur species present in freshwaters DOM and determine their concentration. The application of a 
thiol analytical technique for environmental analysis will help in the evaluation of ROS in the biogeochemistry of mercury in the Everglades ecosystem. 


\section{Chapter II. Characterization of mercury species and their interactions with dissolved organic carbon and sulfur in surface waters of the Florida Everglades}

\section{Introduction}

Interactions between mercury species and natural organic matter (e.g. humic and fulvic acids) appear to be important in controlling the fate and transport of mercury in the water column (Cai et al., 1999; Lu and Jaffe, 2001; Sjoblom et al., 2000). Mercury associates with DOC in water. Generally, this increases the concentration of mercury that can be maintained in water. Depending on the local conditions, DOC-mercury binding can either increase or reduce mercury uptake by organisms (Aiken and Reddy, 1998; Ravichandran 1999). The importance of mercury associated with colloids were evaluated in estuaries by Stordal et al. (1996a, b), however, these studies dealt only with total mercury and not methylmercury. Cai et al. (1999) reported the distribution profiles for methylmercury between different-sized fractions of DOC in natural waters.

Information regarding the interactions between DOC/colloids and methylmercury, as well as total mercury, is important to understand the bioavailability of mercury in the aquatic environment. Recent evaluations of the ultrafiltration technique for studies of total mercury and methylmercury at trace levels in freshwater systems (Babiarz et al., 2000; Cai et al., 1999; Benoit and Rozan, 1999) have been conducted. Also the major trace and elements associated with colloids in organic-rich river waters have been studied previously by ultrafiltration of natural and spiked solutions (Burba et al., 1998; Buffle et al., 1982; Buffle and Leppard, 1995a, b; Dupre et al., 1999; Hoffmann et al., 2000; 
Nifant'eva et al., 1999). The distribution of bioactive metals in natural waters has been studied as well (Wells et al., 2000).

There are sulfur-containing groups in DOC that may be involved in the very strong binding or complexation of mercury (Hintelmann et al., 1997 and Xia et al., 1999). However, the role of sulfur in controlling the toxicity and/or bioavailability of methylmercury is poorly understood. Additional work is required to explain the nature of interaction between sulfur species and organic matter. The geochemistry of sulfur in the Everglades is particularly important because of its link to the production of methylmercury through processes mediated by sulfate reducing bacteria (Bates et al., 2000). The interaction between DOC-organic sulfur species with mercury species in the Everglades was described by Gilmour et al. (1998). They correlated methylmercury concentrations with sulfate concentrations in surface waters. Although sulfate is not a good indicator of the possible interaction of mercury with reduced sulfur species (Driscoll et al., 2000), it is rather related to the mediation of sulfate reducing bacteria on mercury methylation.

The reduced sulfur species contain sulfur in oxidation states between 0 and -2 including thiols (R-SH), organic sulfides (R-SR), organic polysulfides, and thiophenes. Among different species of organic sulfur present in water samples, reduced organic sulfur compounds are mostly responsible for the strong binding to mercury (Ravichandran, 1999; Xia et al., 1999). The presence of organic sulfur species, including disulfides, has been reported in peat cores of the Florida Everglades (Bates et al., 1998). Sulfur in freshwater wetland soils is typically present as organic rather than inorganic sulfur, with reduced organic sulfur much more abundant than oxidized sulfur 
(Rennenberg and Dudas, 2001). To date, the available information on the extent of thiol groups in water and its impact on the fate, transport and methylation of mercury have not been studied. The binding constants for mercury species-humic substance are very large. Benoit et al. (2001) reported $\log \mathrm{K}=11.4$ to 13.2 for mercury-humic substance and methylmercury-humic substance $\log K=12.15$ to 14.48 for different binding sites (Hintelmann et al., 1997). The magnitude of these binding constants indicates that mercury or methylmercury/humic substance complexes could occur in aerobic (low sulfide) surface freshwaters.

While a number of studies have reported on the relationship between mercury and aqueous concentrations of DOC, little is known about the exact mechanism responsible for such interaction. Cai et al. (1999) studied the interaction between DOC and mercury species in natural waters using an ultrafiltration procedure. Their results showed that the most abundant fraction of methylmercury was found in the truly dissolved fraction $(<3 \mathrm{KDa})$. Unfortunately, no sulfur information was included in this investigation. Even in aerobic conditions the mercury compounds could complex with reduced sulfur species. The objective of this study is to extend this research to include dissolved sulfur compounds using a simple, non-destructive, reagent-free ultrafiltration technique to isolate mercury species from freshwaters.

The purpose of this study is to determine the concentrations of total mercury, methylmercury, DOC and total sulfur in surface waters at two selected sites in the Florida Everglades to determine the significance of the interaction between species, natural colloidal materials and sulfur. In addition, the ability of complexation between DOC/Hg species will be determined by using distribution coefficients in different phases. 


\section{Experimental}

\subsection{Materials and chemicals}

Argon - Zero grade; Mercury-free deionized water (DIW); $12 \mathrm{~N}$ hydrochloric acid; $12 \%(\mathrm{v} / \mathrm{v})$ hydroxylamine hydrochloride; mixed brominating reagent $(0.05 \mathrm{M}$ potassium bromide : $0.1 \mathrm{M}$ potassium bromate (1:1)); $0.1 \mathrm{M}$ potassium bromate; $0.05 \mathrm{M}$ potassium bromide; and $2 \%(\mathrm{w} / \mathrm{v})$ stannous chloride were prepared following the standard operation procedures used in the Mercury Laboratory at FIU-SERC. A calibration total mercury primary standard (1000 ppm) was bought from Fisher and used before expiration date. A second source primary total mercury standard (1000 ppm) was bought from Spex . All standards were prepared in a $1 \% \mathrm{HCl}$ solution.

The following reagents were prepared and used for methylmercury analysis: $36 \%$ $(\mathrm{v} / \mathrm{v})$ acetic acid, $0.2 \mathrm{M}$ acetic acid, acetic anhydride (glacial), $1 \mathrm{M}$ copper sulfate : acidic potassium bromide $(1: 2)$ mixture, $20 \%(\mathrm{v} / \mathrm{v})$ hydrochloric acid, methanol (Optima Grade), methylene chloride (Optima Grade), $6 \mathrm{~N}$ potassium hydroxide, $20 \%(\mathrm{w} / \mathrm{v})$ potassium hydroxide, $0.2 \mathrm{M}$ sodium acetate, sodium sulfate anhydrous (10-60 mesh), sulfuric acid (trace-metal grade), thioglycolic acid (glacial), $12 \mathrm{~N}$ hydrochloric acid, $12 \%$ (v/v) hydroxylamine hydrochloride and mixed brominating reagent $0.05 \mathrm{M}$ potassium bromide : $0.1 \mathrm{M}$ potassium bromate. The synthesis of sulfhydryl cotton fiber adsorbent (SCF) followed the procedure used by Lee and Mowrer (1989).

The primary standards of methyl- and ethylmercury chlorides were prepared by dissolving approximately $20 \mathrm{mg}$ of $\mathrm{CH}_{3} \mathrm{HgCl}$ or $\mathrm{C}_{2} \mathrm{H}_{5} \mathrm{HgCl}$ (Ultra Scientific) in $20 \mathrm{~mL}$ of methanol (optima grade) to yield an approximate mercury concentration of 800 and 760 ppm of $\mathrm{CH}_{3} \mathrm{HgCl}$ or $\mathrm{C}_{2} \mathrm{H}_{5} \mathrm{HgCl}$, respectively. Methyl- and ethylmercury chloride 
secondary standards $(10 \mathrm{ppm})$ were prepared by using an appropriate volume of methyl and ethylmercury chloride primary standards and brought to a total volume of $5 \mathrm{~mL}$ with methanol. Methyl- and ethylmercury chloride working standards (200 ppb) and spiking standard (5 ppb) were prepared in methanol and water respectively. Methyl- and ethylmercury chloride calibration standards were prepared in $7 \mathrm{~mL}$ vials. $0,50,100,150$ and $200 \mu \mathrm{L}$ of the methyl- and ethylmercury chloride spiking standard were spiked into the vials where $5 \mathrm{~mL}$ of acidic $\mathrm{KBr} / \mathrm{CuSO}_{4}(2: 1)$ and $1 \mathrm{~mL}$ of DIW were previously added. Then these standards were subjected to the extraction steps of the water sample preparation procedure.

Primary standard for sulfur analysis was prepared by dissolving $4.749 \mathrm{~g}$ of thiourea (Fisher Scientific, certified ACS grade) in $100 \mathrm{~mL}$ of DIW to yield a sulfur concentration of $20,000 \mathrm{ppm}$. Second source primary standard was prepared by dissolving $7.863 \mathrm{~g}$ of sodium sulfate (Fisher Scientific, certified ACS grade) in $100 \mathrm{~mL}$ of DIW to yield a sulfur concentration of $20,000 \mathrm{ppm}$. These standards were kept in $20 \mathrm{~mL}$ sealed injection vials in the refrigerator. The secondary sulfur standard $(1000 \mathrm{ppm})$ was prepared from the primary standard solution. Total sulfur working standards were prepared in $20 \mathrm{ml}$ by weighting in analytical balance or in $100 \mathrm{~mL}$ glass volumetric flasks, depending on the standard concentration. Table II-1 shows the vial volume used for each standard, as well as the volumes of secondary standard used. The standards were distributed into $2 \mathrm{~mL}$ glass vials, sealed and kept in the refrigerator until needed. 
Table II-1. Calibration standards (and second source standards) for total sulfur determination in water samples.

\begin{tabular}{l|l|l}
\hline $\begin{array}{l}\text { Total Sulfur } \\
(\mathrm{ppm})\end{array}$ & $\begin{array}{l}\text { Volume of } 1000 \mathrm{ppm} \\
\text { primary standard }(\mu \mathrm{L})\end{array}$ & $\begin{array}{l}\text { DIW volume } \\
(\mathrm{mL})\end{array}$ \\
\hline \hline 0 & 0 & 100 \\
\hline 0.5 & 50 & 100 \\
\hline 1.0 & 100 & 100 \\
\hline 2.0 & 200 & 100 \\
\hline 2.5 & 250 & 100 \\
\hline 5.0 & 100 & 20 \\
\hline 10 & 200 & 20 \\
\hline 15 & 300 & 20 \\
\hline 20 & 400 & 20 \\
\hline
\end{tabular}

\subsection{Instrumentation}

A Merlin mercury fluorescence detector (AFS), Model 10.023, from P.S. Analytical Ltd. (UK) was used for total mercury analysis. Organomercury analyses were performed using the P.S. Analytical mercury speciation system model PSA 10.723. Details concerning this GC/AFS system can be found elsewhere (Alli et al., 1994; Jones et al., 1995; Cai et al., 1996). Total sulfur concentrations were determined by using a Sulfur Analyser, ANTEK 9000S (Houston, TX). A Hewlett Packard HP 4500 plus ICP-MS system was used for metal analysis. The HP-4500 Chemstation allows automatic corrections for isobaric interferences and correction for internal standard responses. All critical argon flows, including nebulizer argon, were under mass flow control and a peristaltic pump was used for sample introduction.

An Amicon ultrafiltration system (Amicon, MA) was used for all ultrafiltration experiments. The system consists of a 20 -L reservoir, a 2.85 -L stirred cell, an ultrafiltration membrane and a filtrate collection container. The sample was added to an 
acid-cleaned polyethylene sample bag placed inside the reservoir, to avoid the sample direct contact with the stainless steel wall of the tank.

\subsection{Sampling}

A major characteristic of a water sample containing colloids is its intrinsic instability caused by continuing coagulation processes and microbial activity (Buffle and Leppard, 1995a). As a result, sampling, sample storage, sample processing and fractionation are key steps that should be shortened and simplified as much as possible.

\subsubsection{Site selection}

Surface waters were sampled over the course of six months at two sampling sites from canals located in Water Conservation Areas (WCA) 1A and 3A. Site selection was based on results obtained from the project "South Florida Ecosystem Assessment: phase I/II - Everglades Stressors Interactions: Hydropatterns, Eutrophication, Habitat Alteration and Mercury Contamination" supported by U.S.EPA. One of the sites is located in the northern Everglades, WCA-1A, and the other in the central part of the system, WCA-3A, as marked in Figure II-1. In both sites, mercury levels are known to be relatively high. The concentration distribution patterns at these two sites that support the selection of the two sampling stations are presented in Table II-2. 


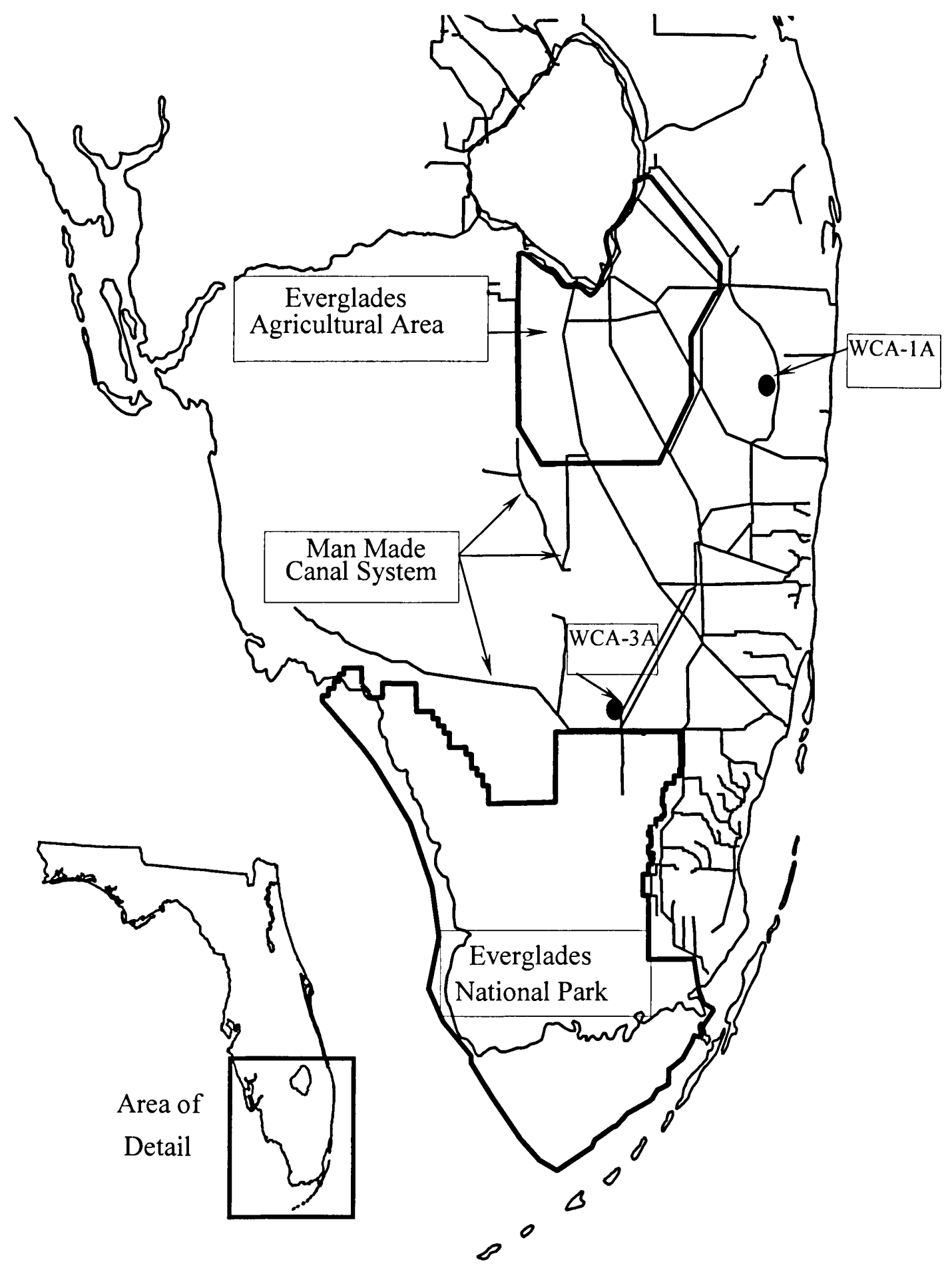

Figure II-1. Schematic map of South Florida showing the sampling locations (marked as •), as well as the Everglades Agricultural Area (EAA), Water Conservation Areas (WCA) and Everglades National Park. 
Table II-2. Comparisons of analyte mean concentrations in water (from US EPA, 2000a).

\begin{tabular}{l|l|l}
\hline Analyte & $\begin{array}{l}\text { North of } \\
\text { Alligator Alley }\end{array}$ & $\begin{array}{l}\text { Alligator Alley - } \\
\text { Tamiami Trail }\end{array}$ \\
\hline $\mathrm{TP}(\mu \mathrm{g} / \mathrm{L})$ & 79 & 24 \\
\hline $\mathrm{TOC}(\mathrm{mg} / \mathrm{L})$ & 26 & 18 \\
\hline $\mathrm{TSO}_{4}(\mathrm{mg} / \mathrm{L})$ & 27 & 7 \\
\hline $\mathrm{CH}_{3} \mathrm{Hg}(\mathrm{ng} / \mathrm{L})$ & 0.2 & 0.2 \\
\hline $\mathrm{THg}$ fish $(\mu \mathrm{g} / \mathrm{Kg})$ & 33 & 83 \\
\hline $\mathrm{THg}(\mathrm{ng} / \mathrm{L})$ & 1.6 & 1.2 \\
\hline
\end{tabular}

WCA-1A is the Arthur R. Marshall Loxahatchee National Wildlife Refuge, a $547 \mathrm{Km}^{2}$ diked marsh in the northern portion of the Everglades. Nearly $60 \%$ of the inflow water to WCA-1A is derived from the Everglades Agricultural Area (EAA), a $2900 \mathrm{Km}^{2}$ region of farmland. Consequently, water in the Hillsboro canal is enriched in nutrients (SFWMD, 1995). Canal water is discharged into WCA-1A from a distribution canal, which receives water from the S-10 control structures located along the northern perimeter levee in the Hillsboro Canal and is dependent upon the volume delivered through floodgates. WCA1A waters discharge into WCA-2A through a distribution canal. Site WCA-1A was chosen to evaluate the occurrence of mercury species in a eutrophic environment where high DOC concentrations have been reported. The water discharged to the WCA-1A marsh creates a strong north to south gradient with associated ecological changes. The Southern sampling site is located on the L67 canal, in WCA-3A, and serves as comparison to the eutrophied Hillsboro distribution system. Site WCA-3A is located at the southern terminus of the L67 canal and the Tamiami Trail. The Everglades National Park lies south of the Tamiami Trail and receives water directly from the L67 canal. 


\subsubsection{Sampling procedures}

The samples collected in the field were subjected to the experimental procedures described below. No sample preservation was used in order to minimize possible alterations in the sample, and therefore changes in the distribution of mercury and DOC. Large volumes of water were needed for the analytical procedure, and $20 \mathrm{~L}$ polyethylene carboys were used for sampling. The Teflon bottles and tubing used for water analyses and the polyethylene sampling carboys were rinsed three times with DIW and filled with $625 \mathrm{ml}$ of $1 \% \mathrm{HCl}$. Then $12.5 \mathrm{~mL}$ of mixed brominating reagent were added. This mixture remained in the bottles until they were used. Prior to using these bottles, $2.5 \mathrm{~mL}$ of hydroxylamine hydrochloride were added to remove all free bromine. The bottle, bottle mouth and cap were then rinsed three times with DIW. Previous experience demonstrates that these materials and cleaning steps provide extremely low trace metal blanks $(<10 \mathrm{pM})$ for all the metals of interest in this study (Cai et al., 1999; Wells et al., 2000).

Prior to collection, the bottles were rinsed three times with the freshwater sample. Surface water samples were collected directly with a $10 \mathrm{~L}$ acid-cleaned polyethylene carboy, screened with a $105 \mu \mathrm{m}$ nylon filter to prevent the collection of large particles, and then transferred to other carboys or Teflon bottles (acid-cleaned). The depth of the water at the sampling locations is about 1 to $2 \mathrm{~m}$. Care was taken not to disturb the sediments. Physico-chemical parameters (temperature, $\mathrm{pH}$, conductivity and dissolved oxygen) were measured in the field.

Samples were transported to the laboratory within 2 hours of collection. Sample processing was done in a mercury-free clean room maintained at positive pressure with 
respect to the outside environment. $8 \mathrm{~L}$ of the unfiltered water sample were distributed into four 2 liter acid-cleaned Teflon (Nalgene) bottles, acidified for preservation with $12 \mathrm{~N}$ trace-metal grade $\mathrm{HCl}$ for further total mercury and methylmercury analysis $(0.5$ and $1 \%$, respectively), and stored in the dark until analysis (within 3 days).

The rest of the unfiltered sample was filtered in a clean bench by nitrogen overpressure ( $55 \mathrm{psi})$ through an acid-cleaned $0.2 \mu \mathrm{m}$ nitrocellulose membrane of 150 mm diameter cut from a plain white membrane (Advantech MFS, CA) in an acid-cleaned filtration system (Amicon, MA), with a $20 \mathrm{~L}$ sample tank. Filtration was stopped when filtrate rates slowed greatly (after approximately 10L). A $5 \mathrm{~L}$ portion of the filtrate was used for determination of total mercury, methylmercury and DOC in the filtered sample $(<0.2 \mu \mathrm{m})$. The remaining filtered sample was subjected to ultrafiltration.

\subsection{Ultrafiltration}

\subsubsection{Procedure}

The collected surface waters samples were filtered using a $0.2 \mu \mathrm{m}$ nitrocellulose filter. Then the samples were processed by ultrafiltration using two membranes with different molecular weight cut off. All membranes were cleaned by a series of soaking, rinsing and flushing steps. Cleaning took place over 1 hour period consisting of:

1) soaking the membrane in $0.1 \mathrm{M} \mathrm{KOH}$ for 30 minutes, to eliminate any organic matter residues from the membrane surface and pores,

2) rinsing and soaking with DIW for 30 minutes, changing the water three times, to eliminate the excess hydroxide, and 
3) flushing with $2 \mathrm{~L}$ of $0.1 \mathrm{M}$ trace-metal grade $\mathrm{HCl}$ and $2 \mathrm{~L}$ of $\mathrm{DIW}$ in the filtration system, prior to the sample filtration.

For reuse, the membranes were rinsed with DIW and stored in $10 \%$ ethanol/DIW solution in the refrigerator (Amicon, 1999).

When membrane blanks were evaluated, THg was initially detected, requiring procedural modifications to reduce this background $\mathrm{THg}$ concentrations. The ultrafiltration system was found to contribute significant blank levels to the filtered sample, with variable concentrations depending on the membrane and the plastic bag (placed inside the reservoir to avoid direct contact of the sample with the stainless steel reservoir). To clean the plastic bags, they were filled with $1 \% \mathrm{HCl}$ for one week before use. The solution was changed each day for one week. $0.2 \mu \mathrm{m}$ nitrocellulose membranes were cleaned by soaking in $1 \% \mathrm{HCl}$ in a similar manner. Finally, the analysis of periodically collected fractions was pursued to find the minimum volume necessary to achieve low blank levels in the filtered sample and it is shown in Figure II-2. The previously soaked nitrocellulose membrane was presumably mercury free after placing it in the ultrafiltration stirred cell and flushing with at least $375 \mathrm{ml}$ of $1 \% \mathrm{HCl}$ and then rinsing and flushing with DIW (500 ml). Different membranes were subject to this cleaning procedure and the corresponding DIW procedural blanks analyzed for all parameters already mentioned. As reported previously by others (Cai et al., 1999; Babiarz et al., 2000) $\mathrm{CH}_{3} \mathrm{Hg}$ was not found in the procedural blanks. 


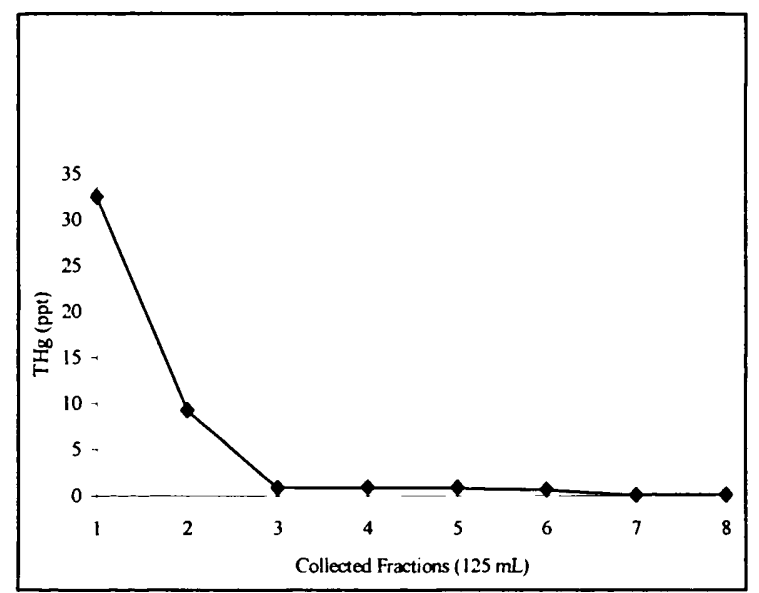

Figure II-2. Data showing the minimum volume of solvent $(1 \% \mathrm{HCl})$ necessary to achieve low blank levels in the filtered sample.

Two molecular weight cutoff membranes were used that provided the nominal molecular weight cutoff of $>30 \mathrm{KDa}$ and $>3 \mathrm{KDa}$, respectively. The schematic diagram of the ultrafiltration system and the associated nomenclature used in this work is shown in Figure II-3.

A sample of known volume $(9.0-11 \mathrm{~L})$ was introduced in an acid-cleaned polyethylene plastic bag placed inside the 20 -L sample reservoir for each ultrafiltration, and the system was pressurized with nitrogen to $55 \mathrm{psi}$. The filtrate was collected in a 10L polyethylene carboy and part of this volume was then transferred to two 2-L Teflon bottles. When the sample volume was reduced to approximately $2.75 \mathrm{~L}$ of retentate, the system was depressurized, and the retentate volume was measured and transferred to two 2L Teflon bottles. The concentrations of total mercury, methylmercury, DOC and sulfur 
were determined in these solutions. An outline of the filtration procedure is shown in Figure II-4.

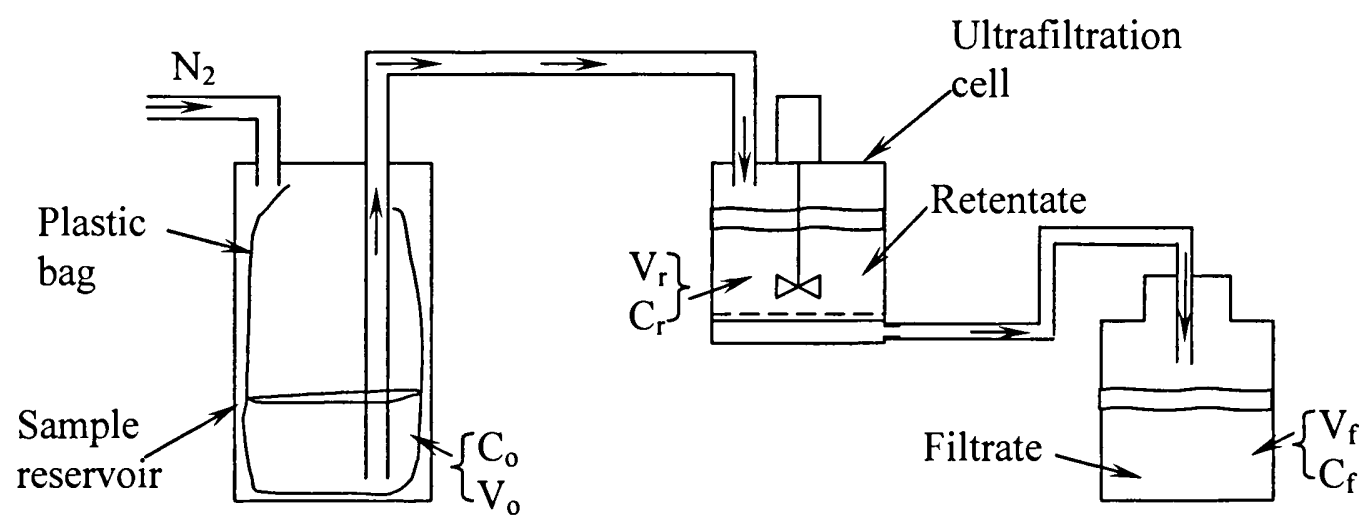

Collection

container

Figure II-3. Schematic diagram of the ultrafiltration system for determination of the initial concentration of an analyte from its retentate concentration $\left(\mathrm{V}_{\mathrm{r}}\right.$, retentate volume; $\mathrm{C}_{\mathrm{r}}$, retentate concentration; $\mathrm{V}_{\mathrm{f}}$, filtrate volume; $\mathrm{C}_{\mathrm{f}}$, filtrate concentration).

\subsubsection{Ultrafiltration mode}

The ultrafiltration method applied to the fractionation of DOC was conducted in a parallel mode and by monitoring of the retentate concentrations. Solutes with molecular size larger than the membrane MWCO were retained in the ultrafiltration cell and collected for analysis. The concentration of molecules having sizes larger than the MWCO will increase over time in the ultrafiltration cell (Cai, 1999) due to sample volume reduction, while solutes with molecular size smaller than the MWCO were removed by the filtration process. It has been reported that losses of $\mathrm{THg}$ and $\mathrm{CH}_{3} \mathrm{Hg}$ can be minimized by using a parallel ultrafiltration mode (Cai et al., 1999), in which handling of the filtrate is not required, therefore avoiding the significant $\mathrm{CH}_{3} \mathrm{Hg}$ adsorption losses 


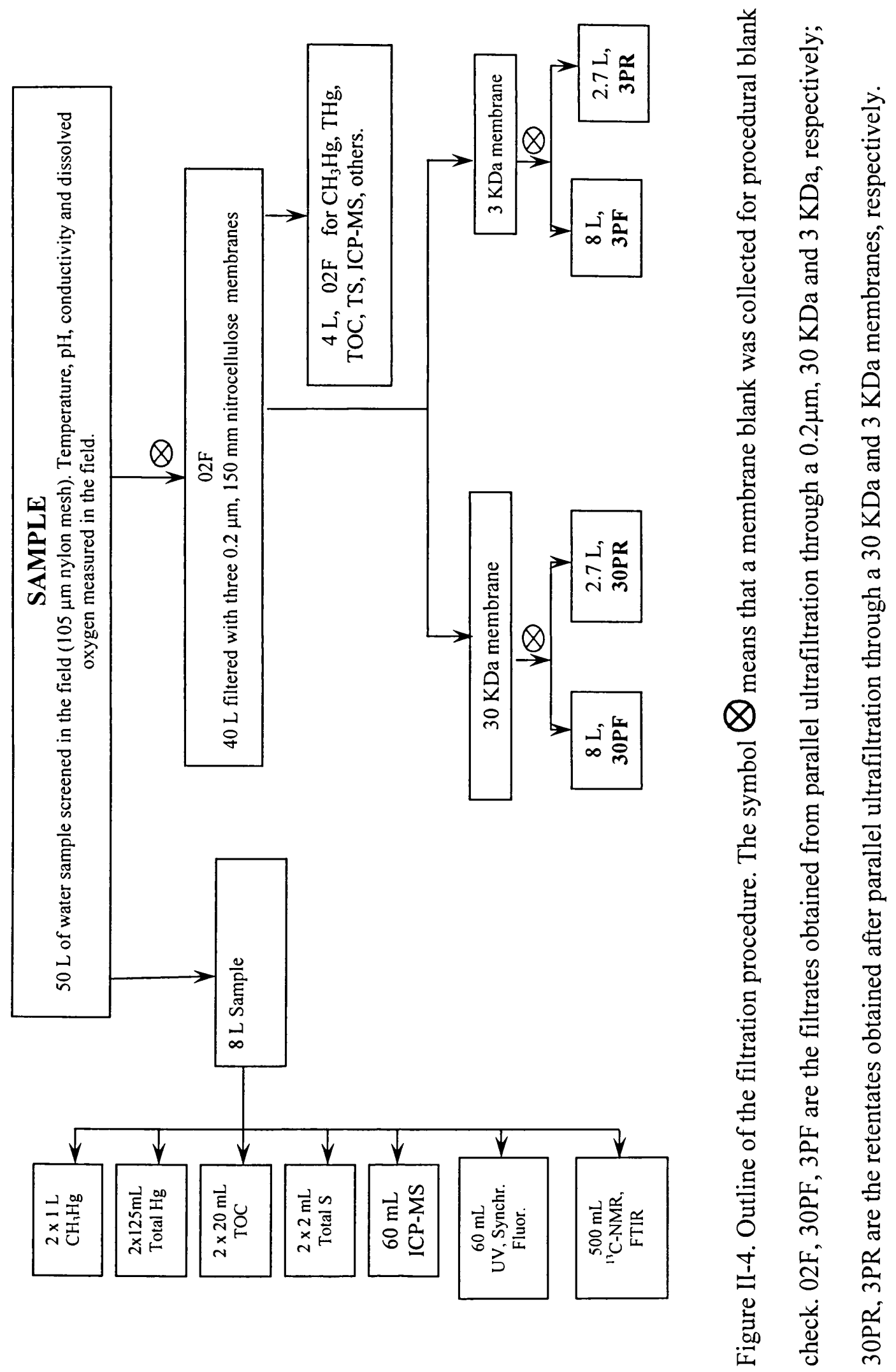


Table II-3. Mathematical calculations for solute permeation from retentate concentration.

A) Concentrations of analyte measured

\begin{tabular}{l|c|c|c}
\hline Filter size & $0.2 \mu \mathrm{m}$ & $30 \mathrm{KDa}$ & $3 \mathrm{KDa}$ \\
\hline Feed concentration, volume & $\mathrm{C}_{\mathrm{o}}$ & $\mathrm{C}_{0.2 \mathrm{~F}}, \mathrm{~V}_{30 \mathrm{i}}$ & $\mathrm{C}_{0.2 \mathrm{~F}}, \mathrm{~V}_{3 \mathrm{i}}$ \\
\hline Retentate concentration, volume & $\mathrm{N} / \mathrm{A}$ & $\mathrm{C}_{30 \mathrm{R}}, \mathrm{V}_{30 \mathrm{R}}$ & $\mathrm{C}_{3 \mathrm{R}}, \mathrm{V}_{3 \mathrm{R}}$ \\
\hline Permeate concentration & $\mathrm{C}_{0.2 \mathrm{~F}}$ & $\mathrm{C}_{30 \mathrm{~F}}, \mathrm{~V}_{30 \mathrm{~F}}$ & $\mathrm{C}_{3 \mathrm{~F}}, \mathrm{~V}_{3 \mathrm{~F}}$ \\
\hline
\end{tabular}

Where $C$ is the concentration of analyte in the original sample $\left(C_{0}\right) ;<0.2 \mu \mathrm{m}\left(\mathrm{C}_{0.2 \mathrm{~F}}\right) ; 30 \mathrm{KDa}$ retentate $\left(\mathrm{C}_{30 \mathrm{R}}\right) ; 30 \mathrm{KDa}$ filtrate $\left(\mathrm{C}_{30 \mathrm{~F}}\right) ; 3 \mathrm{KDa}$ retentate $\left(\mathrm{C}_{3 \mathrm{R}}\right) ; 3 \mathrm{KDa}$ filtrate $\left(\mathrm{C}_{3 \mathrm{~F}}\right)$. Also, $\mathrm{V}$ is the volume of the initial ultrafiltration $30 \mathrm{KDa}$ feed $\left(\mathrm{V}_{30 \mathrm{i}}\right)$ and $3 \mathrm{KDa}$ feed $\left(\mathrm{V}_{3 \mathrm{i}}\right)$; the volume of the retentate $30 \mathrm{KDa}\left(\mathrm{V}_{30 \mathrm{R}}\right)$ and $3 \mathrm{KDa}$ $\left(\mathrm{V}_{3 \mathrm{R}}\right)$; and the volume of the filtrate $30 \mathrm{KDa}\left(\mathrm{V}_{30 \mathrm{~F}}\right)$ and $3 \mathrm{KDa}\left(\mathrm{V}_{3 \mathrm{~F}}\right)$

B) Concentration of analyte in fractions larger than MWCO

\begin{tabular}{c|l}
\hline $\begin{array}{l}\text { Concentration of analyte in fractions } \\
\text { larger than MWCO }\end{array}$ & $\begin{array}{l}\text { Mathematical definition, based on } \\
\text { permeation model }\end{array}$ \\
\hline $\mathrm{C}_{\mathrm{L} 30 \mathrm{KDa}}$ & $\left(\mathrm{C}_{30 \mathrm{R}} \cdot \mathrm{V}_{30 \mathrm{R}}-\mathrm{C}_{0.2 \mathrm{~F}} \cdot \mathrm{V}_{30 \mathrm{R}}\right) /\left(\mathrm{V}_{30 \mathrm{i}}-\mathrm{V}_{30 \mathrm{R}}\right)$ \\
\hline $\mathrm{C}_{\mathrm{L} 3 \mathrm{KDa}}$ & $\left(\mathrm{C}_{3 \mathrm{R}} \cdot \mathrm{V}_{3 \mathrm{R}}-\mathrm{C}_{0.2 \mathrm{~F}} \cdot \mathrm{V}_{3 \mathrm{R}}\right) /\left(\mathrm{V}_{3 \mathrm{i}}-\mathrm{V}_{3 \mathrm{R}}\right)$ \\
\hline $\mathrm{C}_{\mathrm{L} 0.2 \mathrm{~m}}$ & $\mathrm{C}_{\mathrm{o}}-\mathrm{C}_{0.2 \mathrm{~F}}$ \\
\hline
\end{tabular}

Where $\mathrm{C}_{\mathrm{L} 30 \mathrm{KDa}}, \mathrm{C}_{\mathrm{L}}{ }_{3 \mathrm{KDa}}$ and $\mathrm{C}_{\mathrm{L} 0.2 \mu \mathrm{m}}$ are the concentrations of analytes larger than $30 \mathrm{KDa}, 3 \mathrm{KDa}$ and $0.2 \mu \mathrm{m}$, respectively.

C) Concentration of analyte in different fractions

\begin{tabular}{c|c|c|c|c|c}
\hline Sample & $>0.2 \mu \mathrm{m}$ & $<0.2 \mu \mathrm{m}$ & $0.2 \mu \mathrm{m}-30 \mathrm{KDa}$ & $30 \mathrm{KDa}-3 \mathrm{KDa}$ & $<3 \mathrm{KDa}$ \\
\hline $\mathrm{C}_{\mathrm{o}}$ & $\mathrm{C}_{\mathrm{L} 0.2 \mu \mathrm{m}}$ & $\mathrm{C}_{0.2 \mathrm{~F}}$ & $\mathrm{C}_{\mathrm{L} 30 \mathrm{KDa}}$ & $\mathrm{C}_{\mathrm{L} 3 \mathrm{KDa}}-\mathrm{C}_{\mathrm{L} 30 \mathrm{KDa}}$ & $\mathrm{C}_{0.2 \mathrm{~F}}-\mathrm{C}_{\mathrm{L} 3 \mathrm{KDa}}$ \\
\hline
\end{tabular}

in mass concentration between retentates of organic matter with different MWCO

obtained by parallel filtration. The concentrations of DOC, TS and mercury species in the fractions larger than a certain MWCO membranes were calculated as shown in Table II-3.

\subsection{Analytical procedures}

\subsubsection{Determination of total mercury in water samples}

The Southeast Environmental Research Center Standard Operation Procedure, SERC SOP-001-99, 'Determination of Total Mercury in Water Samples' was followed. 
Three $125 \mathrm{~mL}$ bottles were filled to the $125 \mathrm{~mL}$ line with the water sample. The samples were placed in an ultraviolet cabinet for 12 hours and allowed to cool. $0.6 \mathrm{~mL}$ of $12 \mathrm{~N}$ $\mathrm{HCl}$ (to complete $1 \% \mathrm{HCl}$ ) and $2.5 \mathrm{~mL}$ of $\mathrm{KBrO}_{3} / \mathrm{KBr}$ mixed brominating agent were added to each bottle. After one hour, $0.5 \mathrm{~mL}$ of $(2 \% \mathrm{v} / \mathrm{v})$ hydroxylamine hydrochloride, previously purged with argon for 20 minutes, were added to inhibit any further reaction. Samples were allowed to settle for at least 10 minutes before analysis.

The determination of total mercury in water samples was carried out using an analytical procedure based on a bromination $/ \mathrm{SnCl}_{2}$ reduction method followed by cold vapor atomic fluorescence spectrometry (CVAFS) (Bloom and Fitzgerald, 1988; Jones et al., 1995). The instrument detection limit for total mercury was $0.03 \mathrm{ng} / \mathrm{L}$. All total mercury samples were analyzed in duplicate

\subsubsection{Determination of methylmercury in water samples}

The SERC Standard Operating Procedure for the 'Determination of Organomercury in Water' was followed as described by Cai et al. (1996). KOH (6N, 8 $\mathrm{mL}$ ) were added to the previously acidified $1000 \mathrm{~mL}$ of water sample stored into a $1 \mathrm{~L}$ Teflon bottle. The $\mathrm{pH}$ of the water sample was further adjusted to 3.0 (2.9-3.1) using $20 \%$ $\mathrm{HCl}$ and $20 \% \mathrm{KOH}$ solutions (or diluted). Then $10 \mathrm{~mL}$ of the $\mathrm{pH} 3.0$ buffer acetic/acetate were added to the sample. A sulfhydryl cotton (SCF) fiber column was made of a $5 \mathrm{~mL}$ screening column (Fisher Scientific) containing $160 \mathrm{mg}( \pm 5)$ of SCF medium packed (with a glass stirring rod) $1 \mathrm{~cm}$ high (to the mark). A system consisting of Teflon tubing, stoppers, a disposable pipette tip, and the SCF column was setup in a test tube rack and connected to a 12 channel peristaltic pump, as shown in Figure II-5. The system (without 
the screening column) was first washed with $500 \mathrm{~mL}$ of $1 \% \mathrm{HCl}$ by using the peristaltic nalysis. One of the samples in a given sample set was prepared in duplicate.

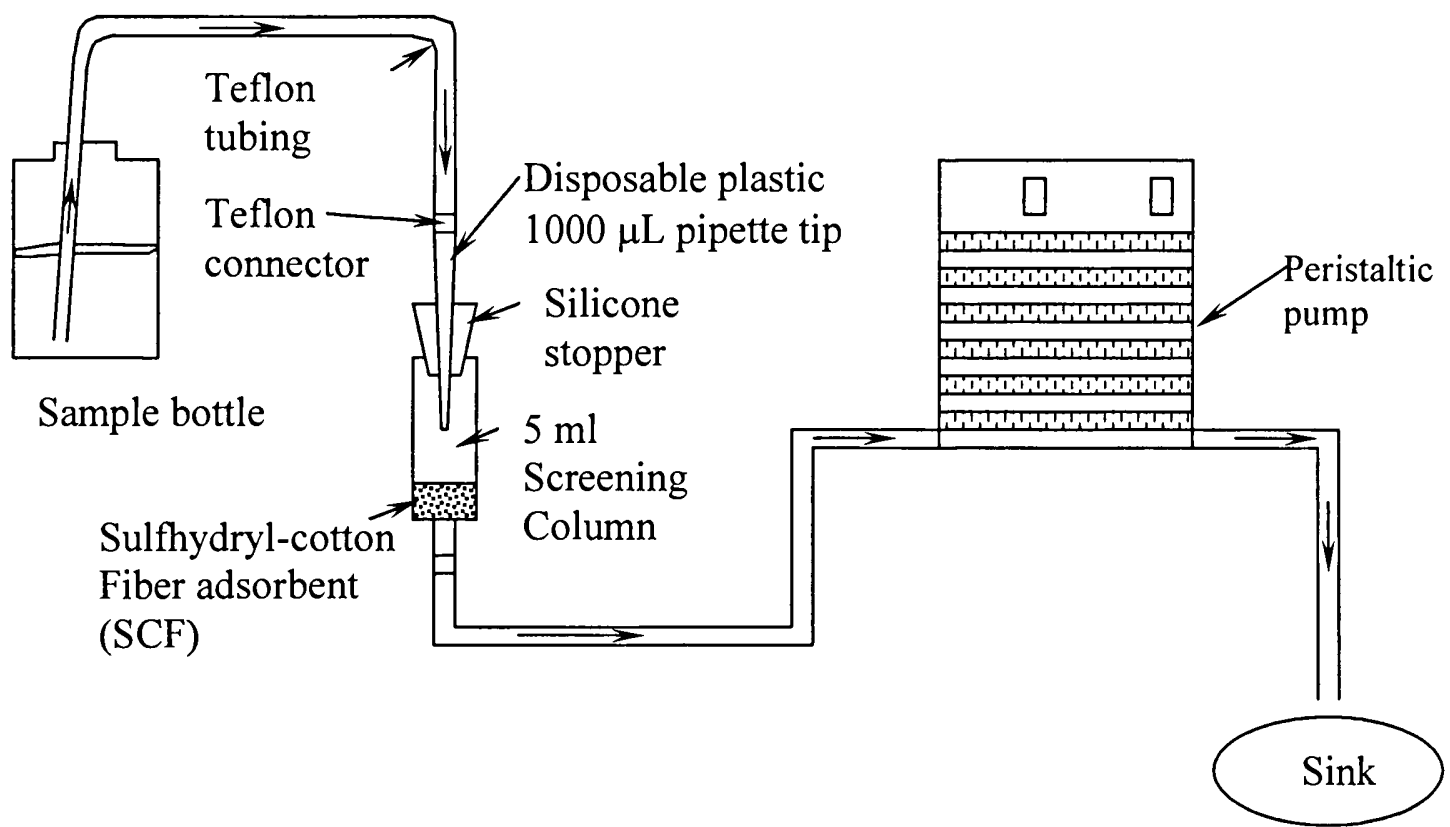

Figure II-5. Schematic diagram for the organomercurial column pre-concentration apparatus.

pump (pump setting: 5). The column was then incorporated in the system and washed with $500 \mathrm{~mL}$ of DIW (pump setting: 40). The water sample was then passed through the column. After the sample had passed through the column, $15 \mathrm{~mL}$ of DIW ( $5 \mathrm{~mL}$ at a time, 3 times) were pipetted onto the adsorbent surface. $6 \mathrm{~mL}(1 \mathrm{~mL}$ at a time, 6 times) of the acidic potassium bromide and $1 \mathrm{M}$ copper sulfate mixture $(2: 1)$ were then pipetted on the surface of the adsorbent, and the eluate collected in a $7 \mathrm{~mL}$ glass vial. The eluate was extracted with $300 \mu \mathrm{L}$ of methylene chloride on a shaker for 15 minutes and gyratory shaker (model G2) for 30 seconds, and centrifuged for 10 minutes at $5000 \mathrm{~g}$ in a refrigerated centrifuge (Dupont, Sorvall Model RC-5). $200 \mu \mathrm{L}$ of the methylene chloride 
layer were then transferred through a small layer of anhydrous $\mathrm{Na}_{2} \mathrm{SO}_{4}$ (packed in a pipette tip) to a $2 \mathrm{~mL}$ glass sampling vial with a low volume glass insert and subject to GC-AFS. Organomercury concentrations were determined as described by Cai et al. (1996) by capillary gas chromatography coupled with atomic fluorescence spectrometry (GC-AFS). The detection limit for methylmercury by this method was $0.02 \mathrm{ng} / \mathrm{L}$, expressed as three times the mean baseline noise.

\subsubsection{Determination of total sulfur in water samples}

Water samples were introduced into $2 \mathrm{~mL}$ glass vials, sealed and kept in the refrigerator until analysis. Because the concentration of sulfur in the sample was expected to be low, care was taken to handle samples properly, avoiding touching the injection needle or sampling vials because this way sulfur compounds may be introduced into the system and produce erroneous results.

Total sulfur was determined in water samples by using an analytical procedure based on a quantitative high temperature oxidation method. The complete high temperature oxidation of the entire sample matrix occurs at $1100^{\circ} \mathrm{C}$ following the reaction:

$$
\text { S-compound }+\mathrm{O}_{2} \rightarrow \mathrm{CO}_{2}+\mathrm{H}_{2} \mathrm{O}+\mathrm{SO}_{2}+\mathrm{MO}_{\mathrm{x}}
$$

The conversion of chemically bound sulfur was quantitative (Antek 9000NS Manual, 1999). The dried combustion gases were routed directly to the UV sulfur detector. A sheath gas (also oxygen) constrained the $\mathrm{SO}_{2}$ vapor to a small stream as it passed by a light source and a photomultiplier tube. The total sulfur concentration was determined by UV (Meixner and Jaeschke, 1981 and Maser et al., 1991). The detection limit for sulfur 
by using this technique was $500 \mathrm{ppb}$ with a $25 \mu \mathrm{L}$ injection, expressed as 3 times the baseline noise.

\subsubsection{Total organic carbon analysis}

DOC concentrations were measured by acidifying the water sample to $\mathrm{pH}<2$ with $3 \mathrm{~N} \mathrm{HCl}$, purging the sample with $\mathrm{CO}_{2}$-free air, and analyzing for total carbon using a hot platinum catalyst direct injection analyzer (Shimadzu TOC 5000).

\subsection{Method for determining the distribution coefficient, $K_{d}$}

Commonly the distribution coefficient, $\mathrm{K}_{\mathrm{d}}$, is defined as (Stumm, 1992):

$$
\mathrm{K}_{\mathrm{d}}=\frac{(\text { mass of filter retained metal)/mass of macroparticles }}{(\text { mass of filter passing metal)/volume of water }}=\mathrm{C}_{\mathrm{s}} / \mathrm{C}_{\mathrm{w}}
$$

$\left(\right.$ Units $\left.=\mathrm{L} \mathrm{Kg}^{-1}\right) . \mathrm{K}_{\mathrm{d}}$ is site specific, but readily calculable from widely measured parameters. In this formulation, the metal present in each size fraction is normalized to the total quantity of its carrier phase. Since this study refers to the distribution of metals across all size classes from truly dissolved $(<3 \mathrm{KDa})$ to macroparticulate, the use of the traditional $\mathrm{K}_{\mathrm{d}}$ would require the introduction of modifications in its definition to account for the presence of colloids in the dissolved phase. The colloid-corrected distribution coefficient, $\mathrm{K}_{\mathrm{d}}^{\mathrm{c}}$, was calculated according to the following relation:

$$
\mathrm{K}_{\mathrm{d}}^{\mathrm{c}}=\mathrm{K}_{\mathrm{p}} /\left(1+\mathrm{K}_{\mathrm{c}} \mathrm{C}_{\mathrm{c}}\right)
$$

where: $\quad K_{p}=$ distribution coefficient between particle phase and dissolved phase excluding the colloidal fraction, defined here as the truly dissolved fraction $(<3 \mathrm{KDa})$. 
$\mathrm{K}_{\mathrm{c}}=$ distribution coefficient between the colloidal fraction and the truly dissolved fraction.

$$
\mathrm{C}_{\mathrm{c}}=\text { concentration of colloids }[\mathrm{Kg} / \mathrm{L}]
$$

To assess the distributions of total mercury and $\mathrm{CH}_{3} \mathrm{Hg}$ among different fractions in the Everglades samples, a variety of distribution coefficients were calculated according to the method by Stordal et al. (1996a,b) and Cai et al. (1999):

$$
\begin{aligned}
& \mathrm{K}_{\mathrm{d}}=\left(\mathrm{M}_{\mathrm{p}} / \mathrm{SPM}\right) / \mathrm{M}_{\mathrm{fp}} \\
& \mathrm{K}_{\mathrm{p}+\mathrm{c}}=\left[\left(\mathrm{M}_{\mathrm{p}}+\mathrm{M}_{\mathrm{c}}\right) /(\mathrm{SPM}+\mathrm{COC})\right] / \mathrm{M}_{\mathrm{d}} \\
& \mathrm{K}_{\mathrm{p}}=\left(\mathrm{M}_{\mathrm{p}} / \mathrm{SPM}\right) / \mathrm{M}_{\mathrm{d}} \\
& \mathrm{K}_{\mathrm{c}}=\left(\mathrm{M}_{\mathrm{d}} / \mathrm{COC}\right) / \mathrm{M}_{\mathrm{d}}
\end{aligned}
$$

where:

$-\mathrm{M}_{\mathrm{p}}=$ concentration of $\mathrm{THg}$ or $\mathrm{CH}_{3} \mathrm{Hg}$ in the particulate fraction $(>0.2 \mu \mathrm{m}),[\mathrm{ng} / \mathrm{L}]$.

- SPM = concentration of suspended particulate matter $[\mathrm{Kg} / \mathrm{L}]$.

$-\mathrm{M}_{\mathrm{fp}}=$ concentration of $\mathrm{THg}$ or $\mathrm{CH}_{3} \mathrm{Hg}$ in the dissolved phase $(<0.2 \mu \mathrm{m}),[\mathrm{ng} / \mathrm{L}]$.

$-\mathrm{M}_{\mathrm{d}}=$ concentration of $\mathrm{THg}$ or $\mathrm{CH}_{3} \mathrm{Hg}$ in the truly dissolved fraction $(<3 \mathrm{KDa})[\mathrm{ng} / \mathrm{L}]$.

$-\mathrm{M}_{\mathrm{c}}=$ concentration of $\mathrm{THg}$ or $\mathrm{CH}_{3} \mathrm{Hg}$ in the colloidal fraction $(0.2 \mu \mathrm{m}-3 \mathrm{KDa})[\mathrm{ng} / \mathrm{L}]$.

$-\mathrm{COC}=$ concentration of organic carbon in the colloidal fraction $(0.2 \mu \mathrm{m}-3 \mathrm{KDa})$ $[\mathrm{kg} / \mathrm{L}]$ as $\mathrm{C}$.

\section{Results and Discussion}

\subsection{Ultrafiltration procedure}

Because inorganic mercury and $\mathrm{CH}_{3} \mathrm{Hg}$ are present at trace level in the surface waters, large volumes of sample needed to be filtered. A major advantage of the 
ultrafiltration technique is its ability to process large volumes of sample (Logan and Jiang, 1990). Conventionally the discrimination between the "dissolved" phase and the "particulate" phase in aquatic environments is made with $0.45 \mu \mathrm{m}$ or $0.2 \mu \mathrm{m}$ filters (Burba et al., 1998). A $0.2 \mu \mathrm{m}$ nitrocellulose membrane was used as the cut-off molecular size for dissolved phase. Ultrafiltration was used to separate organic matter into various molecular sizes for obtaining the distribution of organic matters in various fractions and to isolate every fraction for subsequent analysis of partitioned metals into soluble and colloidal size classes.

\subsubsection{Procedural blanks}

One of the principal analytical concerns in this study was the risk of contamination during ultrafiltration.. All the procedures (sampling, filtration and storage) were carried out in a manner that minimized contamination. To evaluate the membrane blanks of $\mathrm{THg}$, DOC, TS and major and minor elements, blanks levels were determined by processing DIW under the same protocol as the natural sample. It is noteworthy that ultrafiltration by means of the above mentioned washing technique yields very low procedural blanks levels (DOC, THg, TS) (Table II-4).

Table II-4. Concentrations of THg, DOC and TS found in the blanks.

\begin{tabular}{l|l|l|l}
\hline \multicolumn{2}{c}{ 0.2 B } & 30 B & 3 B \\
\hline THg ng/L & 0.01 & 0.01 & 0.17 \\
\hline DOC mg/L & 0.95 & 0.93 & 0.82 \\
\hline TS mg/L & 0.52 & 0.35 & 0.24 \\
\hline
\end{tabular}

Procedural blank for different membranes are as noted: $0.2 \mathrm{~B}=0.2 \mu \mathrm{m}$ membrane blank; $30 \mathrm{~B}=30 \mathrm{KDa}$ membrane blank; $3 \mathrm{~B}=3 \mathrm{KDa}$ membrane blank. $\mathrm{n}=8$. 


\subsubsection{Ultrafiltration mass balance}

In order to ensure of the filtration procedure used, mass balance calculations were performed. The results of these calculations for $\mathrm{THg}, \mathrm{CH}_{3} \mathrm{Hg}$, DOC and $\mathrm{TS}$ are reported in Figure II-6. The quantity of each measured analyte in the original sample was compared with the total sum of the same element in the filtrate and in the retentate. It can be seen that the analyte content of the $3 \mathrm{KDa}$ filtration generally differs by less than \pm $30 \%$ from the corresponding analyte content measured in the $0.2 \mu \mathrm{m}$ filtrate. This result suggests that ultrafiltration mass balance is difficult to obtain if the filtrate is used for the analyses since the losses of these analytes are believed to occur mainly in the membrane (see also Cai et al., 1999). Use of the retentate as analytical matrix can substantially reduced these losses (Cai, et al., 1999). For natural water samples, naturally present complexing agents in DOM may lower the residual adsorptive losses in the membrane, improving the recovery of mercury compared to the recoveries obtained in DDIW where such ligands may be present in lower amounts (Cai, et al., 1999). 


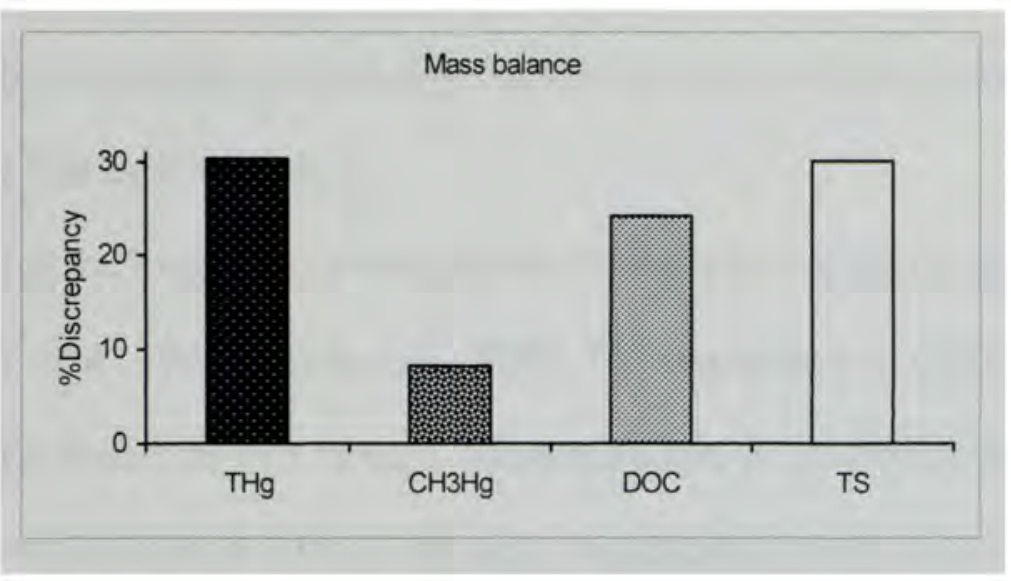

Figure II-6. Results of the mass balance calculated by difference (expressed in wt $\%$ ) between the input and output of analyte quantities through the $3 \mathrm{KDa}$ filtration membrane $(\mathrm{n}=8)$. The mass balance was calculated as $\left\{\left[\mathrm{V}_{3 \mathrm{~F}} \bullet \mathrm{C}_{3 \mathrm{~F}}\right]+\left[\mathrm{V}_{3 \mathrm{R}} \bullet \mathrm{C}_{3 \mathrm{R}}\right]-\left[\mathrm{V}_{\mathrm{o}} \bullet \mathrm{C}_{0.2 \mathrm{~F}}\right] /\left[\mathrm{V}_{\mathrm{o}} \bullet \mathrm{C}_{0.2 \mathrm{~F}}\right]\right\} \bullet 100 \%$ where $V_{3 F}, V_{3 R}, V_{0}$ are the volumes of filtrate, retentate and initial volume respectively and $C_{3 F}, C_{3 R}, C_{0.2 F}$ are the analyte concentrations in the filtrate, retentate and original, respectively.

\subsection{Distributions of mercury species, TS and DOC between different size fractions}

For the convenience of discussion, the different molecular weight size fractions obtained by ultrafiltration are defined as shown in Table II- 5 .

Table II-5. Operational definitions of the molecular weight size fractions.

\begin{tabular}{l|l}
\hline Molecular weight size fraction & Definition \\
\hline$>0.2 \mu \mathrm{m}$ & Suspended particulate matter (SPM) \\
\hline$<0.2 \mu \mathrm{m}$ & Dissolved fraction \\
\hline $0.2 \mu \mathrm{m}-3 \mathrm{KDa}$ & Colloidal fraction \\
\hline$<3 \mathrm{KDa}$ & Truly dissolved fraction \\
\hline
\end{tabular}

\subsubsection{Suspended particulate matter and DOC}

TOC was determined in the original natural water sample as well as in the dissolved phase $\left(<0.2 \mu \mathrm{m}, \mathrm{DOC}_{\text {total }}\right)$. The organic carbon content corresponding to the suspended particulate matter (SPM) was calculated by difference. Table II-6 presents the data for 
TOC in the SPM and different size fractions of the dissolved phase, along with other water quality parameters measured in the field for every collection event, in two different sites in the Florida Everglades.

SPM in the Everglades water has been found to be composed of mostly organic matter (Cai et al., 1999, Benoit et al., 1999). The concentrations of SPM found in this study ranged from 0.01 to $3.16 \mathrm{mg} / \mathrm{L}$. Concentrations of DOC found in the sample analyzed ranged from 14.59 to $37.56 \mathrm{mg} / \mathrm{L}$, in agreement with reported values by others (Cai et al., 1999; Benoit et al., 2001). Therefore, SPM was only a small contribution compared to the organic carbon from dissolved phases.

DOC in the small colloidal forms $(30 \mathrm{KDa}-3 \mathrm{KDa})$ varies in a range of average concentrations from 11.7 to $9.89 \mathrm{mg} / \mathrm{L}$ in WCA-1A and WCA-3A, respectively; and represents 45.9 and $47.1 \%$ of the total DOC present in these natural waters. DOC in the truly dissolved fraction $(<3 \mathrm{KDa})$ contributed 47.6 to $49.8 \%$. It can be further observed from Table II-6 that most of DOC has a molecular weight smaller than 30KDa. These results suggest that the composition of DOC in the Everglades waters is mostly less than $30 \mathrm{KDa}$ molecular weight. These results were also observed in the experiments carried out by Cai et al. (1999). 


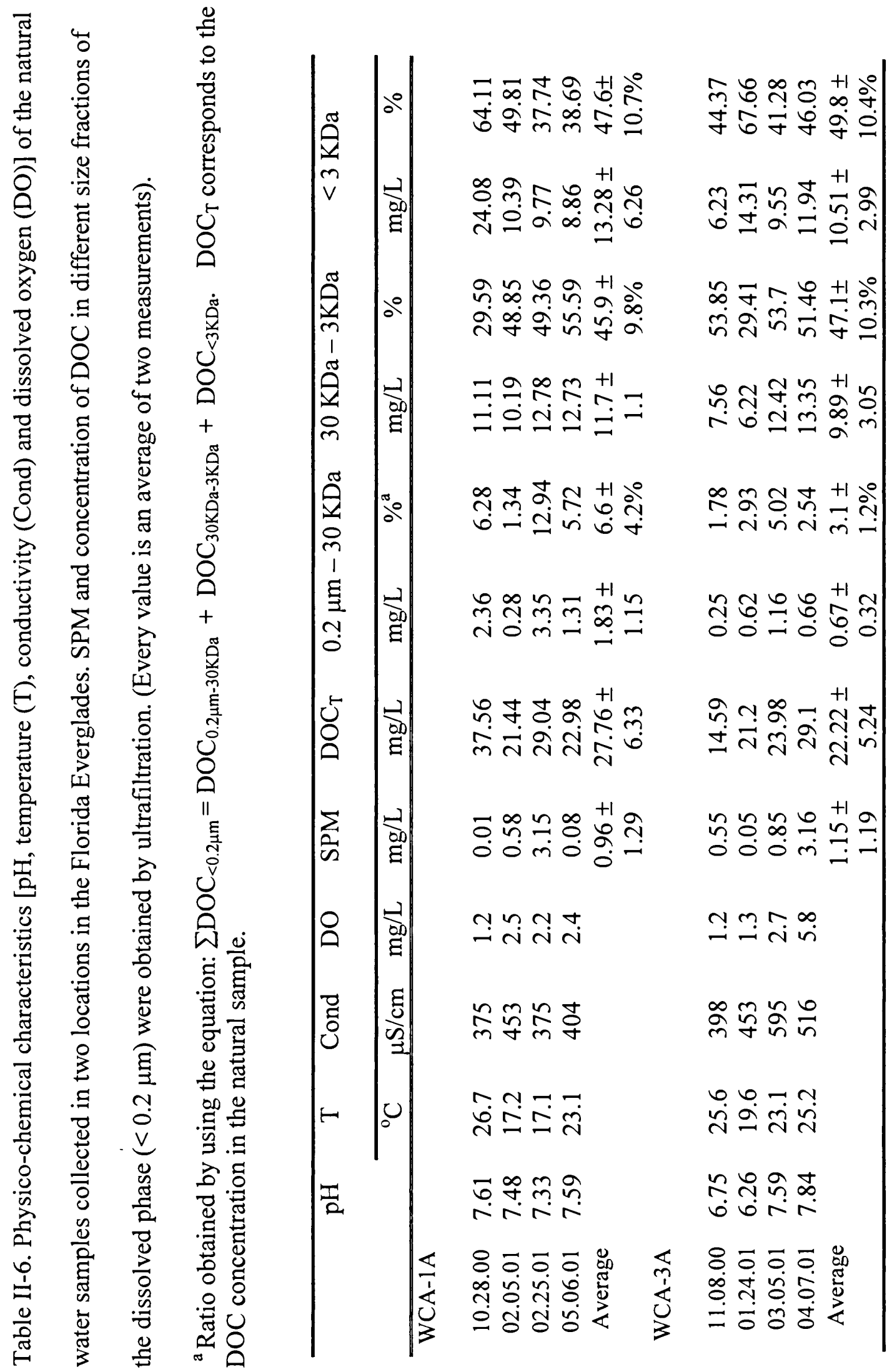




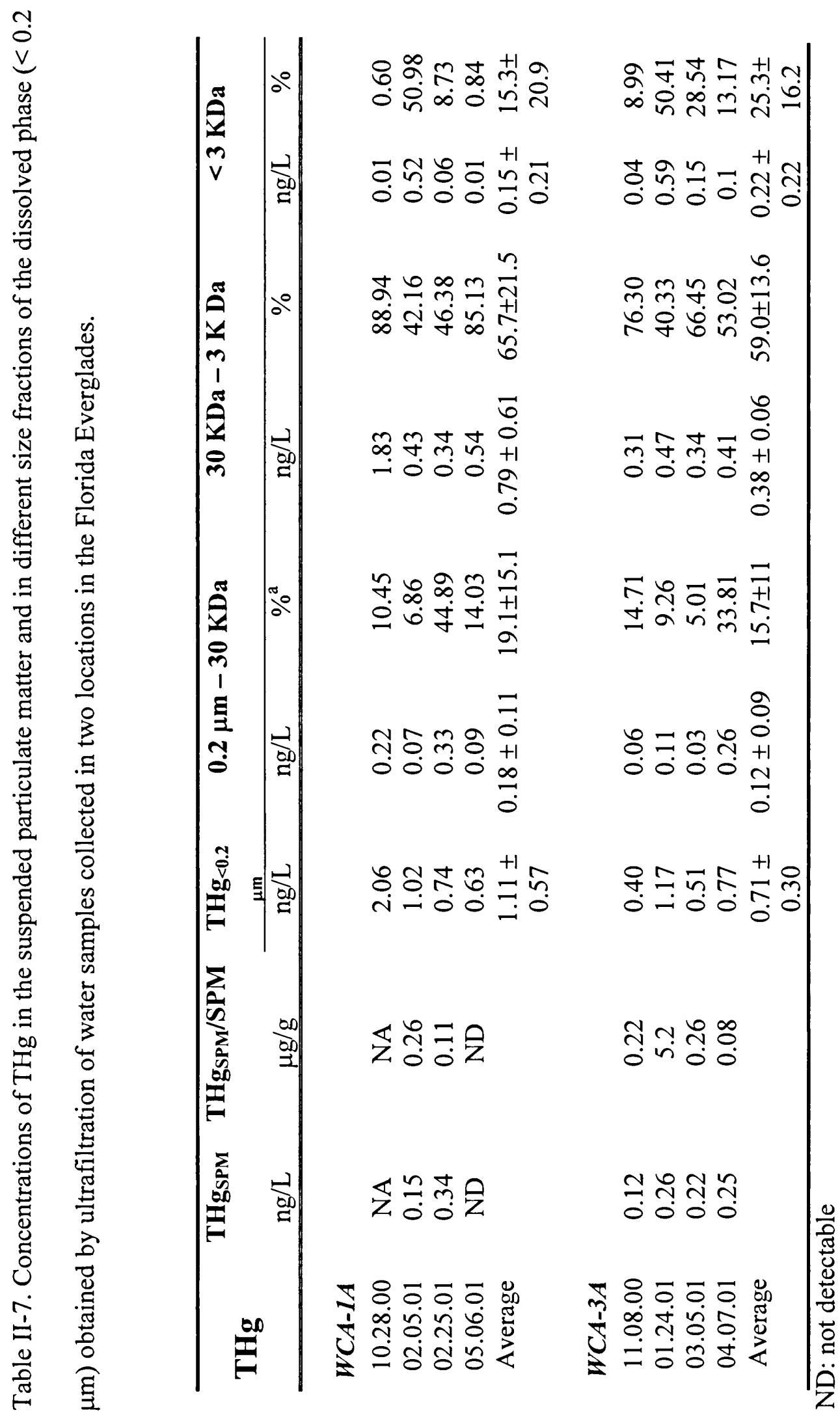




\subsubsection{Total mercury}

\subsubsection{Total mercury in the particulate phase $(>0.2 \mu \mathrm{m})$}

The concentrations of THg in the particulate were obtained by difference between the values obtained for the natural sample and its dissolved phase $(<0.2 \mu \mathrm{m})$ (Table II-7). The concentrations of THg in the particulate in the two locations (WCA-1A and WCA3A) ranged from 0.15 to 0.34 , and 0.12 to $0.26 \mathrm{ng} / \mathrm{L}$, respectively. The mass normalized $\left(\mathrm{Hg}_{\mathrm{SPM}} / \mathrm{SPM}\right)$ contents of particulate matter ranged from 0.12 to $0.26 \mu \mathrm{g} / \mathrm{g}$ for WCA-1A and 0.08 to 5.2 for WCA-3A. Average concentrations as reported earlier by Hurley et al. (1994) for mercury levels of particulate suspended in the water column in four northern Wisconsin seepage lakes had average concentrations ranging from 0.12 to $0.68 \mu \mathrm{g} / \mathrm{g}$. The particulate forms of mercury in the Everglades found by Cai et al. (1999) were smaller than those reported here (average concentrations ranged from 0.094 to $0.158 \mu \mathrm{g} / \mathrm{g}$ ). The difference in particulate mercury content may, in part, be attributed to the fluctuation in SPM content in the Everglades samples. Nevertheless, particulate THg makes a minor contribution to $\mathrm{THg}$ in the Everglades surface waters compared to those in the dissolved phase.

\subsubsection{Total mercury in the dissolved phases}

The distribution of dissolved THg in different molecular weight fractions is also presented in Table II-7. Concentrations of $\mathrm{THg}$ in the dissolved phase ranged from 2.06 to $0.4 \mathrm{ng} / \mathrm{L}$, This is consistent with the results observed previously for Everglades surface waters (Cai et al., 1999). It can be further observed that colloidal and truly 
dissolved THg play an important role in the distribution of mercury in the Everglades waters. The data showed that the majority of the dissolved THg is contained in the colloidal forms $(0.2 \mu \mathrm{m}-3 \mathrm{KDa})$, up to 86.6 and $74.7 \%$ on average for WCA-1A and WCA-3A respectively. As seen in Figure II-8, the average distribution of dissolved THg in the truly dissolved fraction $(<3 \mathrm{KDa})$ constitutes also an important portion of the $\mathrm{THg}$ for both sites, with 15.3 to $25.3 \%$ for WCA-1A and WCA-3A, respectively.

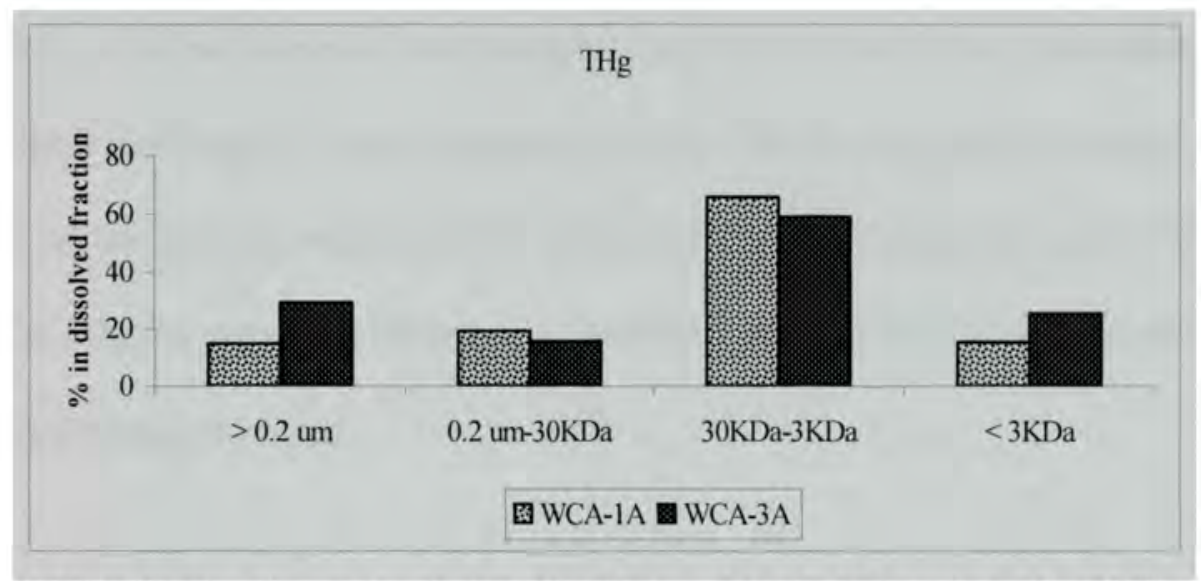

Figure II-7. Distribution in suspended particulate matter $(>0.2 \mu \mathrm{m})$ and in different colloidal fractions of dissolved total mercury for two locations in the Florida Everglades

Although surface waters are subject to different physico-chemical and microbial conditions at the two sites studied, they follow the same pattern in their relative percent distribution of total mercury. Additionally, the distribution of THg in different fractions obtained is supported by similar results obtained by Cai et al. (1999) and Santschi (1988) where the major fractions containing mercury (II) were colloidal. Furthermore, Stordal et al. (1996) reported that the colloidal forms of $\mathrm{THg}(1 \mathrm{KDa}-0.45 \mu \mathrm{m})$ represent a major portion of the total operationally defined dissolved mercury $(<0.45 \mu \mathrm{m})$ in the surface 
waters of three Texas estuaries. The present results for the Everglades waters are in good agreement with these reports.

\subsubsection{Methylmercury}

\subsubsection{Methylmercury in the particulate phase $(>0.2 \mu \mathrm{m})$}

In contrast to $\mathrm{THg}$, a smaller portion of $\mathrm{CH}_{3} \mathrm{Hg}$ was present in the particulate matter, as presented in Table II-8. The concentrations of $\mathrm{CH}_{3} \mathrm{Hg}$ in WCA-1A and WCA3A ranged from below detection to $0.04 \mathrm{ng} / \mathrm{L}$, which were very close to the method detection limit $(0.02 \mathrm{ng} / \mathrm{L})$. It was estimated that the $\mathrm{CH}_{3} \mathrm{Hg}$ associated with the particulate represents was less than $10 \%$ with respect to the concentration of $\mathrm{CH}_{3} \mathrm{Hg}$ found in the original samples (Table II-8). Therefore, most of the $\mathrm{CH}_{3} \mathrm{Hg}$ was found in the dissolved phase $(<0.2 \mu \mathrm{m})$.

\subsubsection{Methylmercury in the dissolved phase}

As shown in Table II-8, the small colloidal forms of $\mathrm{CH}_{3} \mathrm{Hg}(0.2 \mu \mathrm{m}-3 \mathrm{KDa})$ accounted for 44 and $54.1 \%$ of total $\mathrm{CH}_{3} \mathrm{Hg}$ present in average for samples from WCA$1 \mathrm{~A}$ and WCA-3A, respectively. Figure II-8 shows that the fraction $0.2 \mu \mathrm{m}-30 \mathrm{KDa}$ accounted only for 7.2 and $7.7 \%$ of the average dissolved $\mathrm{CH}_{3} \mathrm{Hg}$ in the WCA-1A and WCA-3A, respectively. 


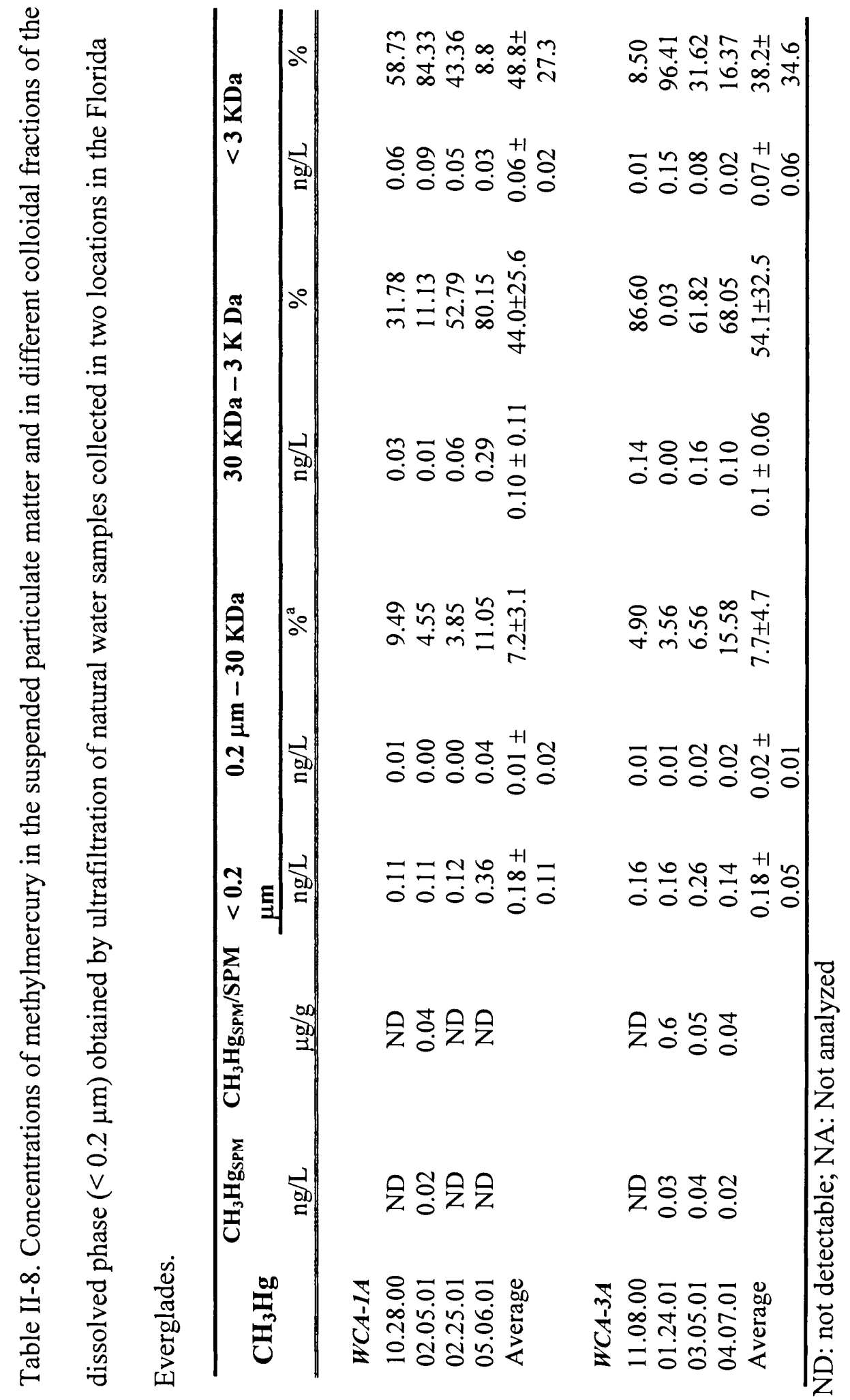




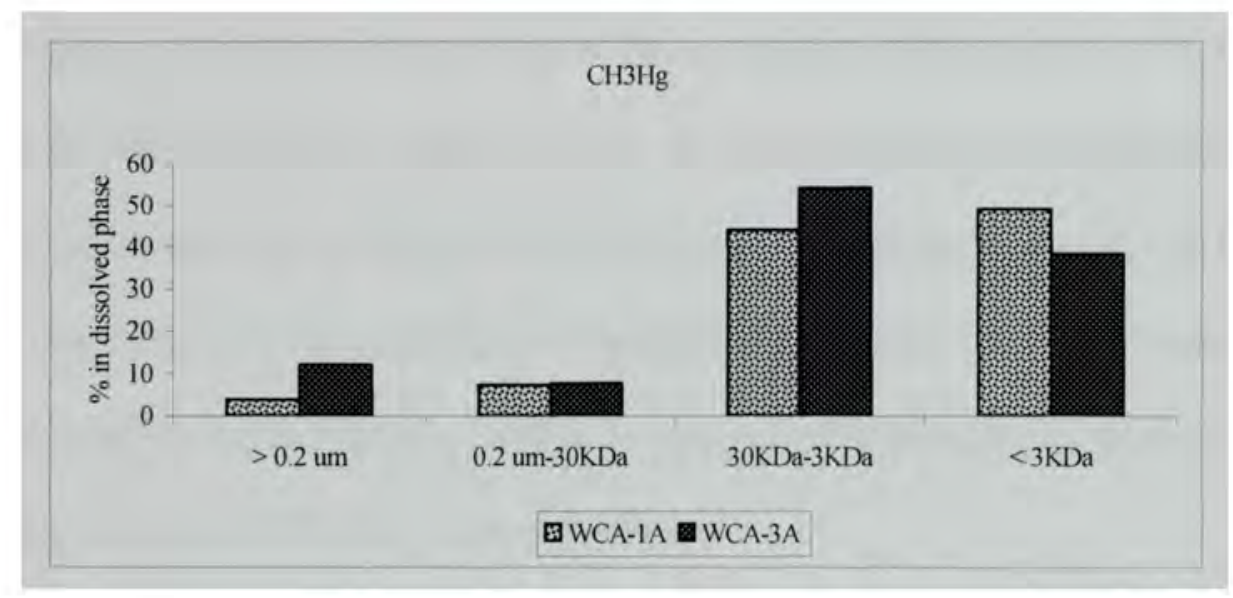

Figure II-8. Distribution of dissolved methylmercury in suspended particulate matter $(>0.2 \mu \mathrm{m})$ and in different colloidal fractions for two locations in the Florida Everglades.

This result agrees with the report by Cai et al. (1999) on the interactions between $\mathrm{CH}_{3} \mathrm{Hg}$ and DOC, where the $<10 \mathrm{KDa}$ fraction showed the highest $\mathrm{CH}_{3} \mathrm{Hg}$ abundance. $\mathrm{CH}_{3} \mathrm{Hg}$ found in the truly dissolved fraction $(<3 \mathrm{KDa})$ ranges from 48.8 to $38.2 \%$ in average for waters from WCA-1A and WCA-3A locations.

Concentrations of $\mathrm{CH}_{3} \mathrm{Hg}$ in the dissolved phase $(<0.2 \mu \mathrm{m})$ ranged from 0.11 to $0.36 \mathrm{ng} / \mathrm{L}$ (Table II-8), which is consistent with the results reported for this region (Stober et al., 1998). It is noteworthy that the truly dissolved fraction contains $43.5 \%$ (average of the two sampling sites) of the $\mathrm{CH}_{3} \mathrm{Hg}$ present in water samples, in contrast with total mercury, which was mostly present in the $30-3 \mathrm{KDa}$ colloidal fraction. This finding was initially reported by Cai et al. (1999), whose results clearly indicate that $\mathrm{CH}_{3} \mathrm{Hg}$ has a different distribution pattern from THg in the Everglades surface waters. The tools to 
isolate colloidal material have been only recently adapted for $\mathrm{Hg}$ research. Consequently, very little data about this important subject has been reported in the literature, and data on fresh water systems are particularly rare. The research by Babiarz et al. (2001) in fresh waters from the Florida Everglades and 13 other locations using tangential flow ultrafiltration, determined THg and $\mathrm{CH}_{3} \mathrm{Hg}$ in the colloidal phase $(0.4 \mu \mathrm{m}-10 \mathrm{KDa})$, and found that $\mathrm{THg}$ and $\mathrm{CH}_{3} \mathrm{Hg}$ partition to different subfractions of colloidal material, in natural waters of Lake Superior. Similar results were found by Hurley et al. (2001) where the major fractions of $\mathrm{CH}_{3} \mathrm{Hg}$ were colloidal.

\subsubsection{Total sulfur}

\subsubsection{Total sulfur in the particulate}

The concentrations of TS in the particulate phase $(>0.2 \mu \mathrm{m})$ and in different colloidal fractions of the dissolved phase $(<0.2 \mu \mathrm{m})$ are shown in Table II-9. The concentrations of TS in the suspended particulate matter $(>0.2 \mu \mathrm{m})$ ranged from below detection limit to 1.64 , and from 0.57 to $0.63 \mathrm{mg} / \mathrm{L}$ in WCA-1A and WCA-3A, respectively. The concentrations of TS in the dissolved phase $(<0.2 \mu \mathrm{m})$ ranged from 14.00 to $2.52 \mathrm{mg} / \mathrm{L}$ consistent with sulfate levels reported earlier (Bates et al., 2000). It can be observed from Figure II-10 that most of the dissolved TS has a molecular weight $<3 \mathrm{KDa}$, with a strong contribution of the colloidal forms $(30 \mathrm{KDa}-3 \mathrm{KDa})$. As shown in

Figure II-9, most of the TS was found in the truly dissolved phase $(<3 \mathrm{KDa})$, with an average concentration of 5.43 and $3.87 \mathrm{mg} / \mathrm{L}$ for WCA-1A and WCA-3A, respectively (Table II-9). 


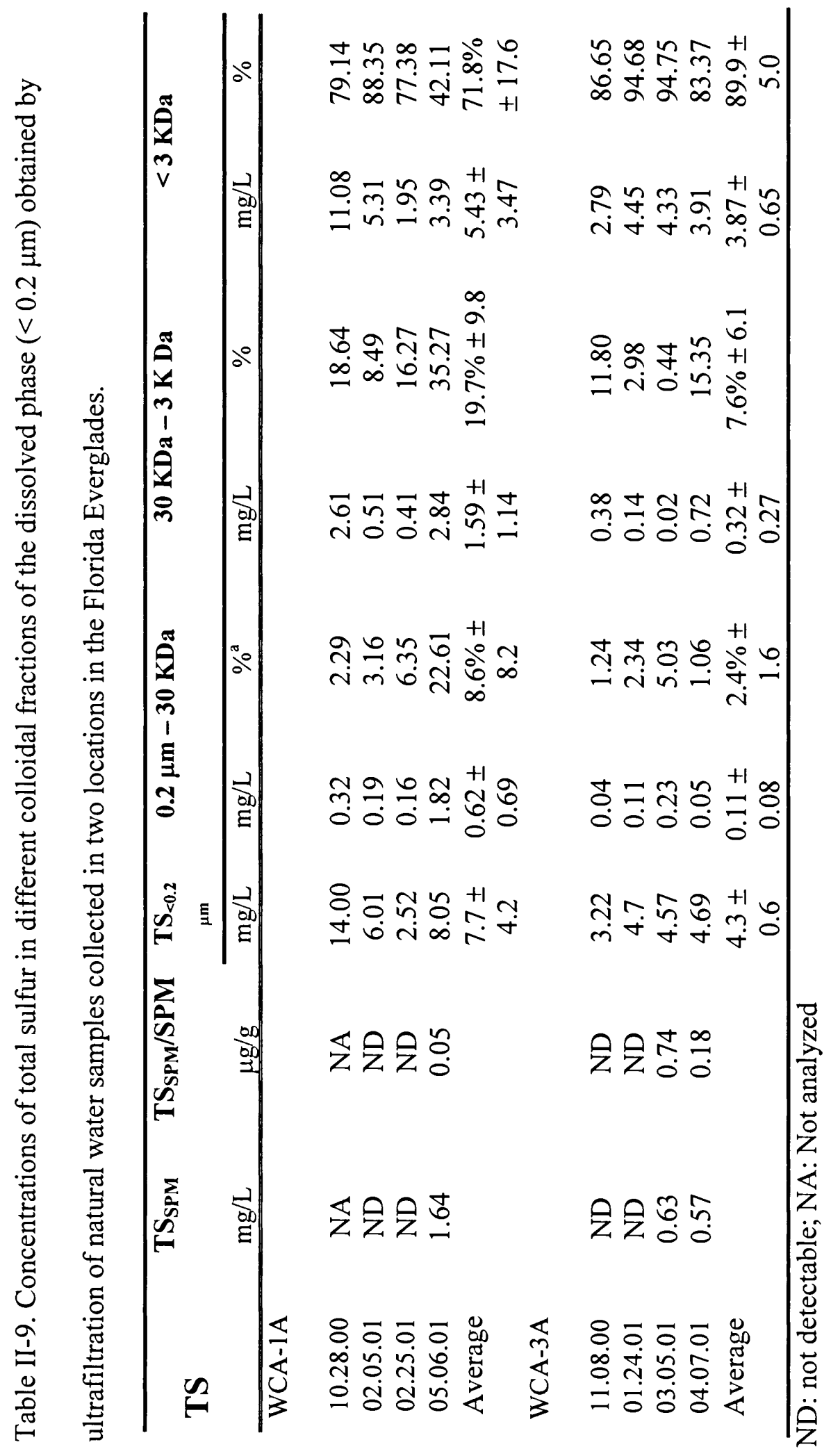




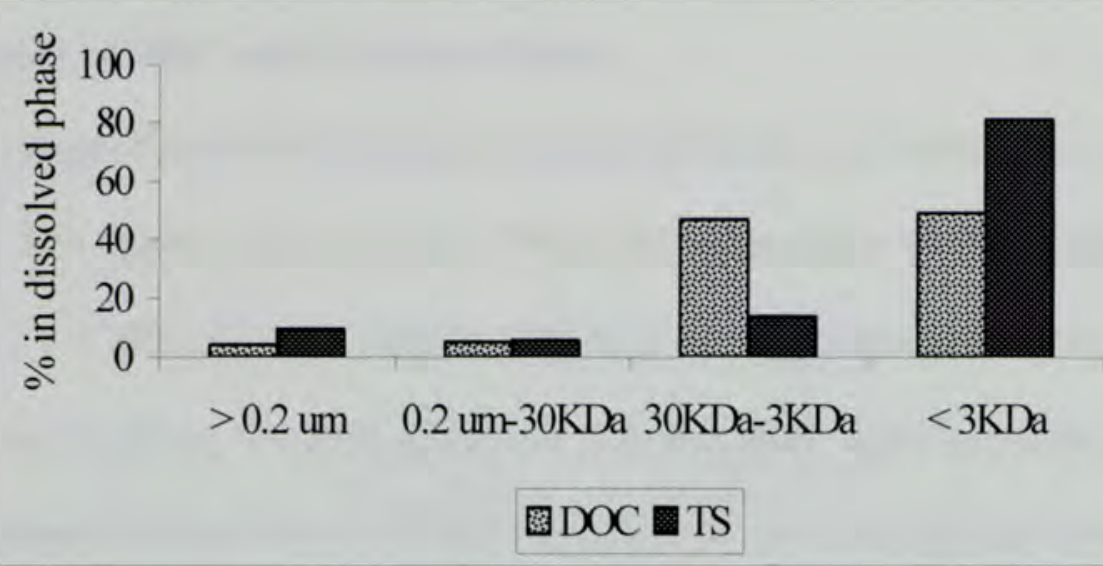

Figure II-9. Distribution in suspended particulate matter $(>0.2 \mu \mathrm{m})$ and in different colloidal fractions of TS and DOC for two locations in the Florida Everglades.

TS in the colloidal form (30KDa-3KDa) represents 19.7 and $7.6 \%$ of the sulfur present in the sample, while the TS in the truly dissolved fraction $(<3 \mathrm{KDa})$ contributed 71.8 and $89.9 \%$ in WCA-1A and WCA-3A, respectively. The high percentage of TS in the truly dissolved fraction is probably attributed to the sulfate content in the samples. However, the exact contribution of sulfate is not clear based on our current results. According to Ravichandran (1999), the reduced sulfur content contributes between 48.2 and $69.4 \%$ of the total sulfur in organic matter in the Everglades, and a correlation between TS and DOC could be expected. 


\subsection{Correlations between different chemical parameters}

\subsubsection{Interactions of $\mathrm{DOC}$ with $\mathrm{THg}$ and $\mathrm{CH}_{3} \mathrm{Hg}$}

The percentage of dissolved $\mathrm{THg}$ and $\mathrm{CH}_{3} \mathrm{Hg}$ in different size fractions are shown in Figure II-10. The figure shows that while THg in both locations is mainly associated with the $0.2 \mu \mathrm{m}-30 \mathrm{KDa}$ colloidal fraction, $\mathrm{CH}_{3} \mathrm{Hg}$ is mostly present in the truly dissolved fraction $(<3 \mathrm{KDa})$. In addition, the results of this study agree with previous studies where strong correlations were found between DOC and $\mathrm{CH}_{3} \mathrm{Hg}$ (Cai et al., 1999;

Driscoll et al., 1994). Our results are in agreement with those obtained by Driscoll et al. (1994) who showed that the correlation between $\mathrm{CH}_{3} \mathrm{Hg}$ and DOC was much stronger than that between $\mathrm{THg}$ and DOC concentration. It is also in agreement with results by Cai et al., (1999) who wereas the first to compare the different distribution patterns of $\mathrm{THg}$ and $\mathrm{CH}_{3} \mathrm{Hg}$ in the suspended particulate matter, colloidal and truly dissolved phases in surface waters of the Everglades.

In order to assess the effect of DOC on the distribution of $\mathrm{THg}$ and $\mathrm{CH}_{3} \mathrm{Hg}$ in the dissolved phase, the percentage of $\mathrm{THg}$ and $\mathrm{CH}_{3} \mathrm{Hg}$ in different molecular weight fractions were plotted vs. the percentage of DOC in each fraction. A strong correlation might exist between mercury species and DOC, similar to those observed in other regions (Andren and Harris, 1973; Mierle and Ingram, 1991; Hurley et al., 1995 and Watras et al., 1995a). 

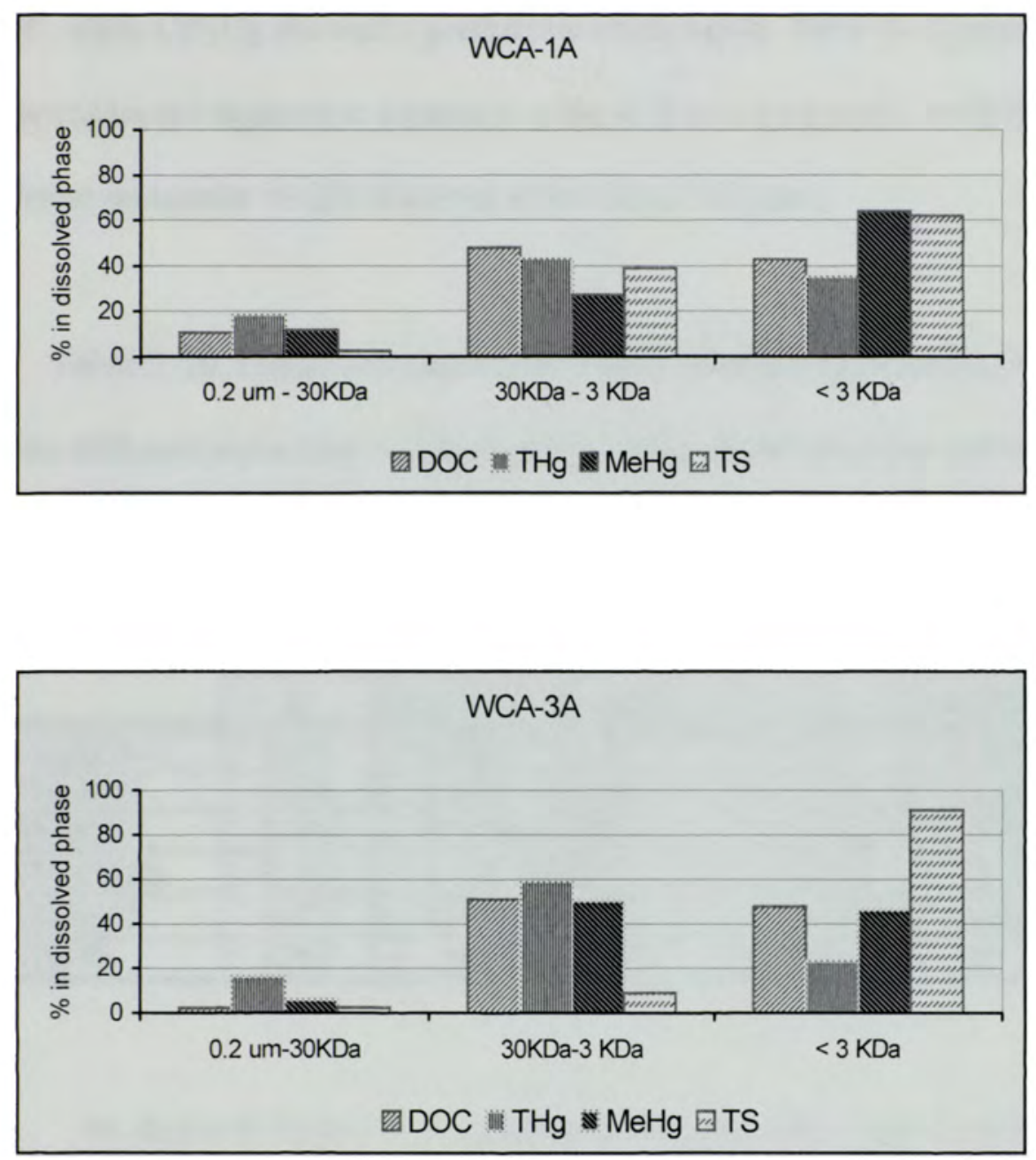

Figure II-10. Percent DOC, THg, $\mathrm{CH}_{3} \mathrm{Hg}$ and TS associated with different molecular weight fractions of the dissolved phase. Data was an average of four samples. 
The relationships between $\mathrm{THg}, \mathrm{CH}_{3} \mathrm{Hg}$ and $\mathrm{DOC}$ in surface waters of the Everglades was discussed by Cai et al. (1999) and showed no correlation for THg vs. DOC, while $\mathrm{CH}_{3} \mathrm{Hg}$ showed a good linear relationship. Table II-10 presents the linear correlations and regression equations of the different parameters analyzed for the different molecular weight fractions of the dissolved phase.

Table II-10. Linear correlations $\left(\mathrm{R}^{2}\right)$ and regression expressed as \%x vs. \%y (x-y), for the different molecular weight fractions of the dissolved phase equations of the different parameters analyzed in this study. $(n=12)$

\begin{tabular}{l|c|l|c|l}
\hline & \multicolumn{2}{|c|}{ WCA-1A } & \multicolumn{2}{c}{ WCA-3A } \\
\cline { 2 - 5 } & $\mathrm{R}^{2}$ & Linear regression equation & $\mathrm{R}^{2}$ & Linear regression equation \\
\hline \hline $\mathrm{CH} \mathrm{H}_{3} \mathrm{Hg}-\mathrm{DOC}$ & 0.612 & $\mathrm{y}=0.9782 \mathrm{x}+0.531$ & 0.4517 & $\mathrm{y}=0.7934 \mathrm{x}+5.1661$ \\
\hline $\mathrm{THg}-\mathrm{DOC}$ & 0.1899 & $\mathrm{y}=0.4623 \mathrm{x}+15.464$ & 0.3718 & $\mathrm{y}=0.3718 \mathrm{x}+15.705$ \\
\hline $\mathrm{TS}-\mathrm{DOC}$ & 0.3864 & $\mathrm{y}=0.7399 \mathrm{x}+6.4921$ & 0.9275 & $\mathrm{y}=0.9275 \mathrm{x}+1.8123$ \\
\hline $\mathrm{THg}_{\mathrm{NH}} \mathrm{CHg}_{3} \mathrm{Hg}$ & 0.2406 & $\mathrm{y}=0.4359 \mathrm{x}+14.103$ & 0.6131 & $\mathrm{y}=0.441 \mathrm{x}+13.975$ \\
\hline $\mathrm{CH}_{3} \mathrm{Hg}-\mathrm{TS}$ & 0.4726 & $\mathrm{y}=0.6698 \mathrm{x}+8.2548$ & 0.061 & $\mathrm{y}=0.4604 \mathrm{x}+21.87$ \\
\hline $\mathrm{THg}^{\mathrm{THS}}$ & 0.0023 & $\mathrm{y}=-0.0522 \mathrm{x}+26.303$ & 0.0139 & $\mathrm{y}=-0.0524 \mathrm{x}+26.309$ \\
\hline
\end{tabular}

As shown in Figure II-11 where data from two sites were combined, $\mathrm{CH}_{3} \mathrm{Hg}$ showed a better linear correlation with DOC $\left(\% \mathrm{CH}_{3} \mathrm{Hg}=1.006 \% \mathrm{DOC}-2.8751 ; \mathrm{R}^{2}=\right.$ $0.5664)$ than the correlation observed between THg and DOC $(\% \mathrm{THg}=0.4851 \% \mathrm{DOC}+$ $11.379 ; \mathrm{R}^{2}=0.2182$ ). A linear relationship could suggest that this compound is primarily associated with DOC. The better correlation between DOC- $\mathrm{CH}_{3} \mathrm{Hg}$ compared to DOCTHg indicates that $\mathrm{CH}_{3} \mathrm{Hg}$ is primarily associated with DOC. 

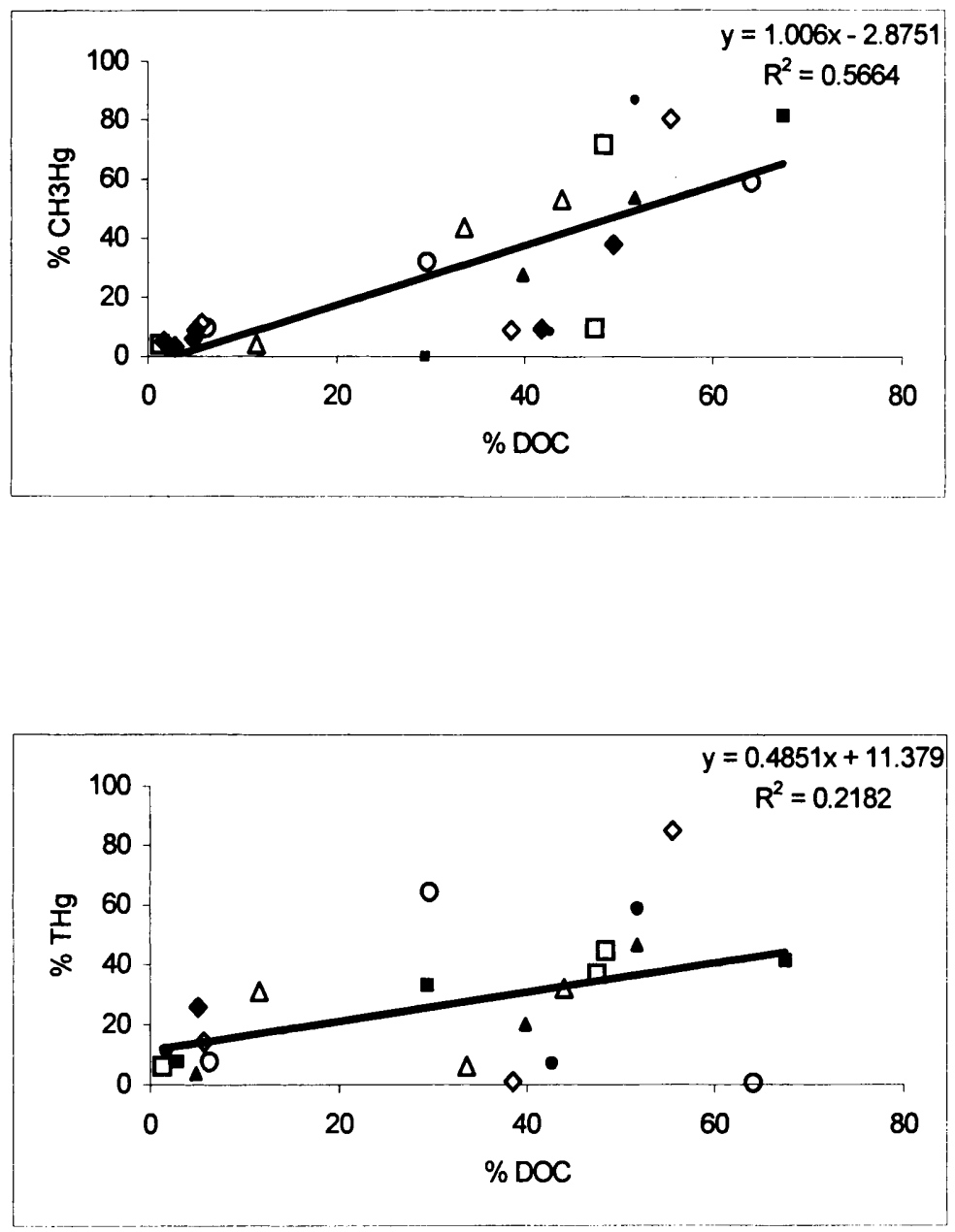

Figure II-11. A) Percent methylmercury and B) percent total mercury in different molecular weight fractions of the dissolved phase versus the percent dissolved organic carbon in each fraction. $\mathrm{n}=20$.
$\bigcirc \quad 10.28 .00 ; \square \quad 02.01 .01 ; \triangle \quad 02.25 .01 ; \diamond \quad 05.06 .01$ sampling in WCA-1A
- $11.08 .00 ; \quad 01.24 .01 ; \mathbf{\Delta} \quad 03.05 .01 ; \quad 04.07 .01$ sampling in WCA-3A 


\subsubsection{TS, THg, $\mathrm{CH}_{3} \mathrm{Hg}$, and DOC}

The effect of TS on the distribution of $\mathrm{THg}$ and $\mathrm{CH}_{3} \mathrm{Hg}$ in the dissolved phase can be assessed by plotting $\% \mathrm{TS}$ vs. $\% \mathrm{THg}$ or $\% \mathrm{CH}_{3} \mathrm{Hg}$ for both sampling sites. As shown in Figure II- 12 for the results from WCA-1A, the distribution of $\mathrm{CH}_{3} \mathrm{Hg}$ is clearly correlated with that of TS (Figure II-12A) while such relationship does not exist for THg (Figure II-12B). There is no correlation at all for both $\mathrm{THg}$ and $\mathrm{CH}_{3} \mathrm{Hg}$ at WCA-3A (Table II-9). A better correlation for the northernmost site indicates possibly different interactions of $\mathrm{CH}_{3} \mathrm{Hg}$ with TS at different sites. The correlation between DOC-TS is also very different in both sites, and could be related to differences in the composition of TS in the two sampling sites. TS measured included various sulfur species other than organic sulfur. WCA-1A shows a less significant correlation $\left(\% \mathrm{TS}=0.7399 \% \mathrm{DOC}+6.4921 ; \mathrm{R}^{2}\right.$ $=0.3864)$ between DOC and TS (Table II-10) compared with WCA-3A $(\% \mathrm{TS}=$ $\left.0.9275 \% \mathrm{DOC}+1.8123 ; \mathrm{R}^{2}=0.9275\right)$. The presence of different sulfate concentrations in the dissolved phase for both sites may cause an artifact in the correlations obtained with TS. Although sulfate doesn't complex mercury species (Branfireum et al. 1999), additions of sulfate to peat and peat pore water resulted in a significant increase of pore water $\mathrm{CH}_{3} \mathrm{Hg}$ concentrations in northwestern Ontario Lake waters.

\subsection{Distribution coefficients}

Partitioning between solids and solution plays a dominant role in the distribution, transport, behavior and fate of metals in the aquatic environment (Benoit and Rozan, 1999). The distribution coefficient $K_{d}$ indicates the sorption/binding capability of mercury species in a given DOM fraction. Such interactions can be described based on a 
A)

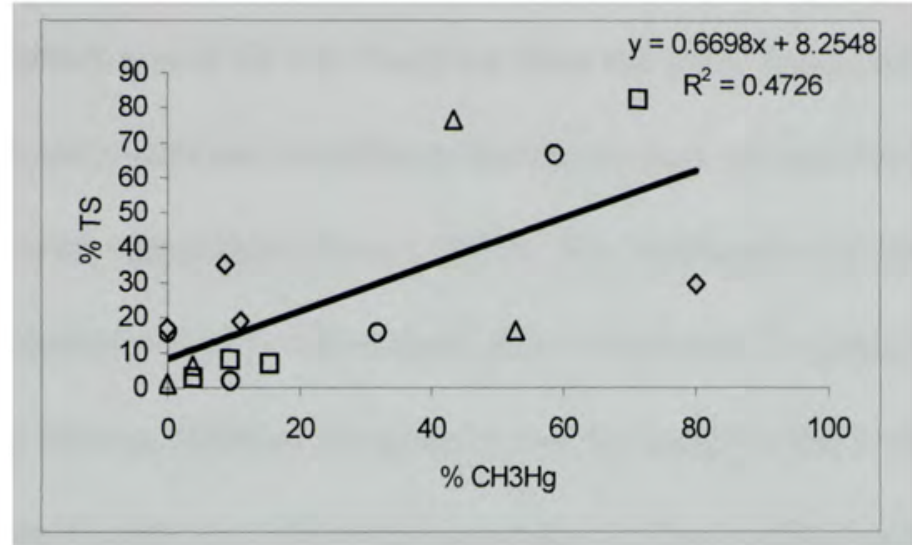

B)

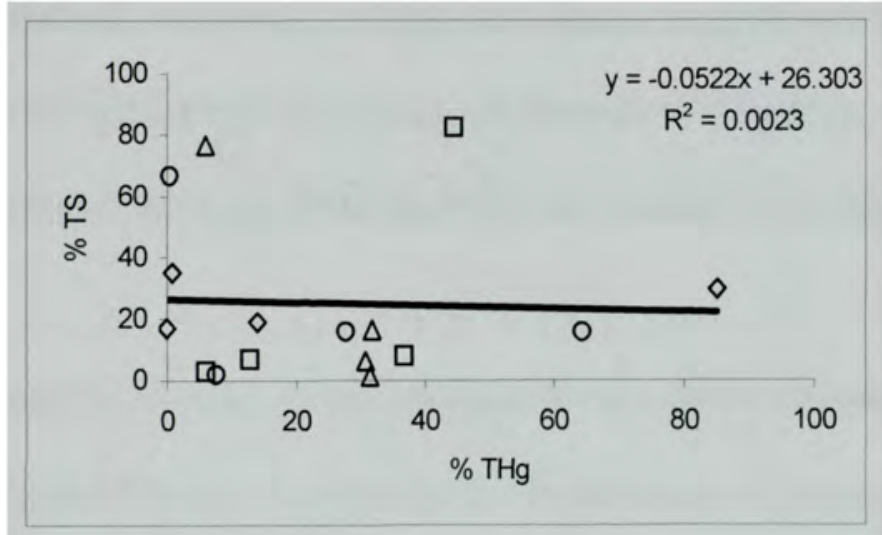

Figure II-12. A) Percent methylmercury and B) percent total mercury in different molecular weight fractions of the dissolved phase versus the percent total sulfur in each fraction. $\mathrm{n}=16$.

$\bigcirc \quad$ 10.28.00; $\square \quad 02.01 .01 ; \triangle \quad 02.25 .01 ; \diamond \quad 05.06 .01$ sampling in WCA-1A

- 11.08.00; $\quad 01.24 .01 ; \boldsymbol{\Delta} \quad 03.05 .01 ; \diamond \quad 04.07 .01$ sampling in WCA-3A. 
distribution coefficient. The distribution coefficient may be useful to understand the distribution of metals across all size fractions from the truly dissolved phase to particulate. Such tests were not possible in the recent past, at least for fresh waters, since trace metal data were unreliable (Benoit, 1995). The application of clean methods and ultrafiltration techniques finally allow these determinations. To assess the distributions of THg and $\mathrm{CH}_{3} \mathrm{Hg}$ among different fractions in two locations in the Everglades, a variety of distribution coefficients are calculated according to the method by Stordal et al. $(1996 a, b)$, as described previously (section 2.6.). Since the distribution coefficient is a conditional constant, it should be independent of the amount in the partitioning phases (Benoit, 1995). Therefore, the amount of mercury species in each size fraction is normalized to the total quantity of the carrier phase, and consequently, the distribution coefficient $\left(\mathrm{K}_{\mathrm{d}}\right)$ is related to the binding capability of mercury to the binding sites in each fraction.

Table II-11 shows the average values obtained for the different distribution coefficients for $\mathrm{THg}$ and $\mathrm{CH}_{3} \mathrm{Hg}$. $\mathrm{K}_{\mathrm{d}}$ refers to the distribution of mercury species in the particulate $(>0.2 \mu \mathrm{m})$ with respect to the dissolved fraction $(<0.2 \mu \mathrm{m})$. For THg the log $\mathrm{K}_{\mathrm{d}}$ had a range from 5.01 to 6.65 . This result is in good agreement with $\mathrm{K}_{\mathrm{d}}=5.4-5.7$ observed by Stordal et al. (1996a) in laboratory experiments and Hurley et al. (1994b) for Little Rock Lake (4.5 - 5.7), as well as with the results obtained by Cai et al. (1999) in Florida Everglades surface waters $(4.80-5.11)$.

Other distribution coefficients are also shown in Table II-11. These coefficients $\left(\mathrm{K}_{\mathrm{p}+\mathrm{c}}, \mathrm{K}_{\mathrm{p}}\right.$ and $\mathrm{K}_{\mathrm{c}}$ ) refer to the distribution of mercury species in the particulate $(>0.2 \mu \mathrm{m})$ and/or colloidal $(0.2 \mu \mathrm{m}-3 \mathrm{KDa})$ phases with respect to the truly dissolved fraction 


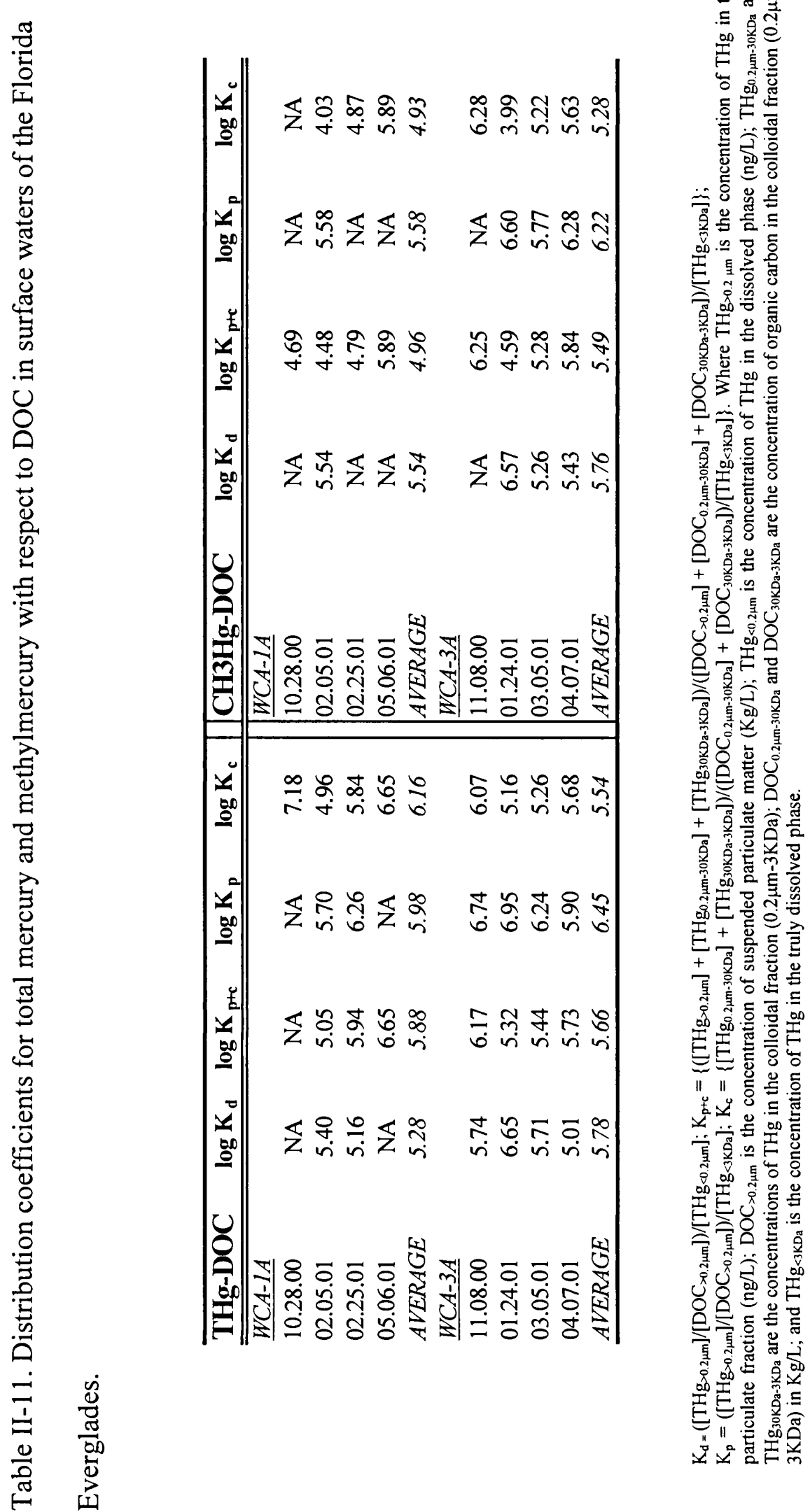


$(<3 \mathrm{KDa})$ (i.e. $\mathrm{K}_{\mathrm{p}+\mathrm{c}}$ includes the particulate and the colloidal fractions of mercury species in relation to the truly dissolved phase; $\mathrm{K}_{\mathrm{p}}$ and $\mathrm{K}_{\mathrm{c}}$ include only mercury species in the particulate and colloidal fractions respectively). Cai et al. (1999) reported that $K_{p+c}$, $K_{p}, K_{c}$ are larger than $K_{d}$. This seems to be true for WCA-1A, but not for WCA-3A.

\section{Conclusions}

Ultrafiltration is a useful method for the fractionation of DOC in water samples. The analytical concern of contamination during the ultrafiltration was avoided by procedural modifications to reduce the background THg concentrations. Blank levels processed in the clean laboratory were low for $\mathrm{THg}$, and $\mathrm{CH}_{3} \mathrm{Hg}$ was not found in the blanks. Retention of elements in the membrane during ultrafiltration by adsorptive losses was evaluated by calculating the mass balance. The element content calculated from the concentration measured in the filtrate and retentate generally differs by $< \pm 30 \%$. This proves that ultrafiltration mass balance closure is difficult to obtain if the filtrate is to be used. In order to obtain an adequate degree of fractionation with reasonable volumes of sample, a parallel ultrafiltration process based on monitoring the retentate concentration was used. The size distribution was calculated as a difference in mass concentration between retentates with different molecular weight cutoff.

Our results from two very different sites in the Florida Everglades indicate that certain fractions of the DOC are more reactive with mercury species. The determination of several specific parameters in selected molecular-size fractions of natural waters provided more detailed information about the occurrence of mercury species in relation to DOC and TS. The data shows that the majority of the dissolved THg is contained in the 
colloidal forms $(30 \mathrm{KDa}-3 \mathrm{KDa})$. In contrast with $\mathrm{THg}$, a very small portion of the $\mathrm{CH}_{3} \mathrm{Hg}$ was present in the particulate matter. In addition, the truly dissolved phase contains most of the $\mathrm{CH}_{3} \mathrm{Hg}$. This indicates that these two phases play a different role in the THg and $\mathrm{CH}_{3} \mathrm{Hg}$ fate and transport. TS was mostly found in the truly dissolved phase, this result is different than the distribution obtained for DOC, which is mainly associated with both the small colloidal and truly dissolved forms. $\mathrm{CH}_{3} \mathrm{Hg}$ showed better correlations than $\mathrm{THg}$ with DOC, this may suggest again different interactions of both mercury species with DOC.

The interaction of $\mathrm{THg}$ and $\mathrm{CH}_{3} \mathrm{Hg}$ with DOM across all size fractions, were represented by a variety of distribution coefficients. The distribution coefficients obtained for $\mathrm{CH}_{3} \mathrm{Hg}$ seem slightly smaller than those obtained for $\mathrm{THg}$. This could be attributed to the great complexation capability of the $<3 \mathrm{KDa}$ in its distribution, and may be due to the complexation of organomercury with functional groups of humic acids, particularly with organic material containing thiol groups.

In the next chapter, efforts will be made to better characterize the composition of the DOM and to determine the influence of functional groups on mercury behavior. In terms of mercury mobility, the character of every DOC fraction may serve as the primary control on mercury transport. 


\section{Chapter III. Spectroscopic studies of DOM size fractionated isolates from surface waters of the Florida Everglades.}

\section{Introduction}

The aquatic humic substances are present in water as dissolved molecules, as colloidal suspensions, and as particulate matter. In general, aquatic humic matter in freshwater ecosystems accounts for the major part of DOM (Peuravuori and Pihlaja, 1998). The reactivity of the natural organic matter is closely tied to its physicochemical properties such as molecular weight, aromaticity, elemental composition, and functional group content (Cabaniss et al., 2000). The filtered (through $0.2 \mu \mathrm{m}$ nitrocellulose membrane) water contains not only humic substances but also other biochemically important compounds of natural origin, such as very hydrophilic low molecular acids, carbohydrates, fatty acids, amino acids and hydrocarbons.

Ultraviolet and visible absorbance spectroscopy and fluorescence spectroscopy have been used to provide qualitative and quantitative information on the interaction between natural DOM and metal ions (Senesi, 1990; Cabaniss, 1992; Lu and Jaffe, 2001). Both methods provide similar information for the characterization of humic substances, revealing various spectral components present in the DOM. The advantage of synchronous fluorescence spectroscopy compared to UV spectra is the better resolution of the fluorescence spectra (Hautala et al., 2000; Senesi, 1990), since many environmental factors (type of solution, $\mathrm{pH}$, ionic strength, temperature, redox potential of the medium, and interactions with metal ions and organic substances) may affect fluorescence more than absorbance (Senesi, 1990). 
${ }^{13} \mathrm{C}$-Nuclear magnetic resonance $\left({ }^{13} \mathrm{C}\right.$ NMR), especially in solid-state (CPMAS, cross-polarization and magic angle spinning), has been extensively employed (Malcolm, 1990; Peuravuori and Pihlaja, 1998; Preston, 1996; Conte et al., 1997, 1999; Peuravuori, 2000) to obtain structural information of carbon nuclei in different humic substances isolates and on the relative amount of each type of carbon. Several developments in NMR technology have made possible its routine application to solid organic matter. These improvements include superconducting magnets with high fields (up to $800 \mathrm{MHz}$ for ${ }^{1} \mathrm{H}$ or 18.8 Tesla), Fourier Transform techniques for data acquisition and manipulation, and Cross-Polarization and Magic-Angle Spinning methods for obtaining well-resolved spectra of solids (Preston, 1996). All of these developments have made possible the routine application of NMR to samples which are structurally complex, heterogeneous, very dilute, solids or intermediate states such as colloids or gels (Jones and Bryan, 1998).

Since humic substances contain a large number of diverse chemical functionalities, there is no single analytical method to isolate and fractionate them. Therefore, humic substances from various environmental sources can be defined only operationally based on the procedure applied to their isolation (Malcolm, 1990). Ultrafiltration as natural organic matter isolation method has been reported (Buffle et al., 1978; Dupre et al., 1999; Burba et al., 1998; Peuravuori and Pihlaja, 1998) and can be combined with low temperature evaporation for the intended fractionation without natural organic matter alteration.

There is a great interest in the role of DOC in the transport of metals in aquatic environmental. A number of studies have reported on the relationship between mercury and aqueous concentrations of DOC (Buffle, 1988; Aiken and Reddy, 1998; Cai et al., 
1999; Benoit et al., 2001), but little is known about the exact mechanism responsible for such interaction. Characterization of DOM fractions could provide some important insight on the mercury/DOM interactions. In order to characterize the composition of the DOM size fractions obtained and to determine the influence of functional groups on mercury binding UV-Vis, fluorescence and ${ }^{13} \mathrm{C}-\mathrm{NMR}$ were used.

\section{Experimental}

\subsection{Water samples}

Fresh water samples were collected from two locations in the Florida Everglades as shown previously (Figure II-1). Detailed background information regarding the selection of these two sampling sites has been discussed in Chapter II, section 2.3.1. Briefly, water was collected from a northern site (WCA-1A) and a site located in the central part of the Everglades (WCA-3A) because these two sites have been reported (US EPA, 1997) to be impacted differently (DOC, $\mathrm{THg}, \mathrm{MeHg}$ and TS concentrations).

The collection of water samples followed the procedure previously described in Chapter II, section 2.3.2. Water samples (ca. $50 \mathrm{~L}$ ) were collected from $0.5 \mathrm{~m}$ below the surface using acid-cleaned polyethylene bottles covered with a $105 \mu \mathrm{m}$ nylon mesh between September and November 2000. The samples were filtered using a nitrocellulose filter, $0.2 \mu \mathrm{m}$ pore size (Advantech MFS, CA) immediately upon returning to the laboratory.

\subsection{Isolation of DOM}

The isolation procedure of the DOM fractions by ultrafiltration is outlined in the scheme shown in Figure II-4 and is described in detail in the literature (Cai, 1999). This 
ultrafiltration procedure divided organic solutes into three operationally defined molecular size fractions: $<0.2 \mu \mathrm{m}$ (dissolved fraction), $0.2 \mu \mathrm{m}-30 \mathrm{KDa}$ and $30-3 \mathrm{KDa}$ (colloidal fraction) and $<3 \mathrm{KDa}$ (truly dissolved fraction). $\mathrm{THg}, \mathrm{CH}_{3} \mathrm{Hg}, \mathrm{TS}, \mathrm{DOC}$, UV/Vis and fluorescence analyses were performed in the aqueous fractions of the DOM isolates.

$500 \mathrm{ml}$ aliquots of these fractions were rotary evaporated at $40^{\circ} \mathrm{C}$ under reduced pressure and reduced to approximately $50 \mathrm{ml}$. The concentrated aqueous samples were then freeze-dried to obtain dried DOM samples. The solid isolates of the aquatic DOM fractions obtained were analyzed by ${ }^{13} \mathrm{C}$-NMR CPMAS and FTIR and subjected to CHN elemental analysis as well.

\subsection{Apparatus}

DOC in water samples was measured using a Shimadzu TOC-5050 Carbon Analyzer (Shimadzu Co., MD). UV/Vis measurements of DOM were carried out using a Shimadzu UV-Visible double beam spectrophotometer (UV-2101 PC). Doubly distilled MilliQ water was used as a reference scanned from 600 to $200 \mathrm{~nm}$ at $100 \mathrm{~nm} \mathrm{~min}{ }^{-1}$. Fluorescence spectra were obtained using a Perkin-Elmer LS50B spectrofluorometer equipped with a 150-W Xenon arc lamp as the light source. Fluorescence emission spectra were obtained at wavelengths ranging from 300 to $700 \mathrm{~nm}$ with an excitation wavelength of $335 \mathrm{~nm}$. Synchronous fluorescence spectra were recorded as well, with a constant offset $(\delta \lambda=30 \mathrm{~nm})$ between excitation and emission wavelengths and $10 \mathrm{~nm}$ slit widths. The analyses of the carbon and nitrogen were performed on a Flash EA1112 CE

elemental analyzer (Carlo Erba, Milan, Italy). ${ }^{13} \mathrm{C}$-CPMAS NMR spectra were recorded 
at $50.3 \mathrm{MHz}$ on a Bruker ASX200 NMR spectrometer at the Macromolecular Technology Research Center (Japan). A 7 mm (o.d.) zirconia rotor with Kel-F cap was used with $5.0 \mathrm{kHz}$ spinning rate, relaxation delays of $2 \mathrm{~s}$ were used throughout the measurements. Sample size was ca. $200 \mathrm{mg}$. Typically $10-20 \mathrm{k}$ transients were required to obtain acceptable spectra. The spectral width was $25 \mathrm{kHz}(500 \mathrm{ppm})$ and 512 points were collected. The total experiment time for each spectrum was ca. $5 \mathrm{~h}$. The spectra were zero-filled once, Fourier transformed with $100 \mathrm{~Hz}$ line broadening and baseline corrected before analysis. All measurements were made at room temperature. The chemical shift scale is referenced to carboxyl carbons of glycine $(\mathrm{C}=\mathrm{O} ; \mathrm{C}=176.5 \mathrm{ppm})$.

\section{Results and Discussion}

\subsection{Chemical composition}

Table III-1 shows some characteristic properties for three freshwater samples: two of them from WCA-1A and one from WCA-3A. The parameters measured for these samples include $\mathrm{pH}$, temperature, conductivity and DOC concentrations in different size fractions of the original liquid samples. Note that higher concentrations of DOC are observed in WCA-1A with majority of the DOC present in the truly dissolved phase $(<3 \mathrm{KDa})$. For WCA-3A, DOC is mainly present in both colloidal $(30-3 \mathrm{KDa})$ and truly dissolved phases.

Table III-2 shows the elemental carbon/nitrogen compositions $(\mathrm{C} / \mathrm{N})$ obtained for two sub samples of solid DOM material after acidification. The exposure of the DOM isolates to $\mathrm{HCl}$ results in a measurable change in elemental composition, and shows a low percentage of inorganic carbon (0.03-4.24\%). Quality control concerning the removal of 


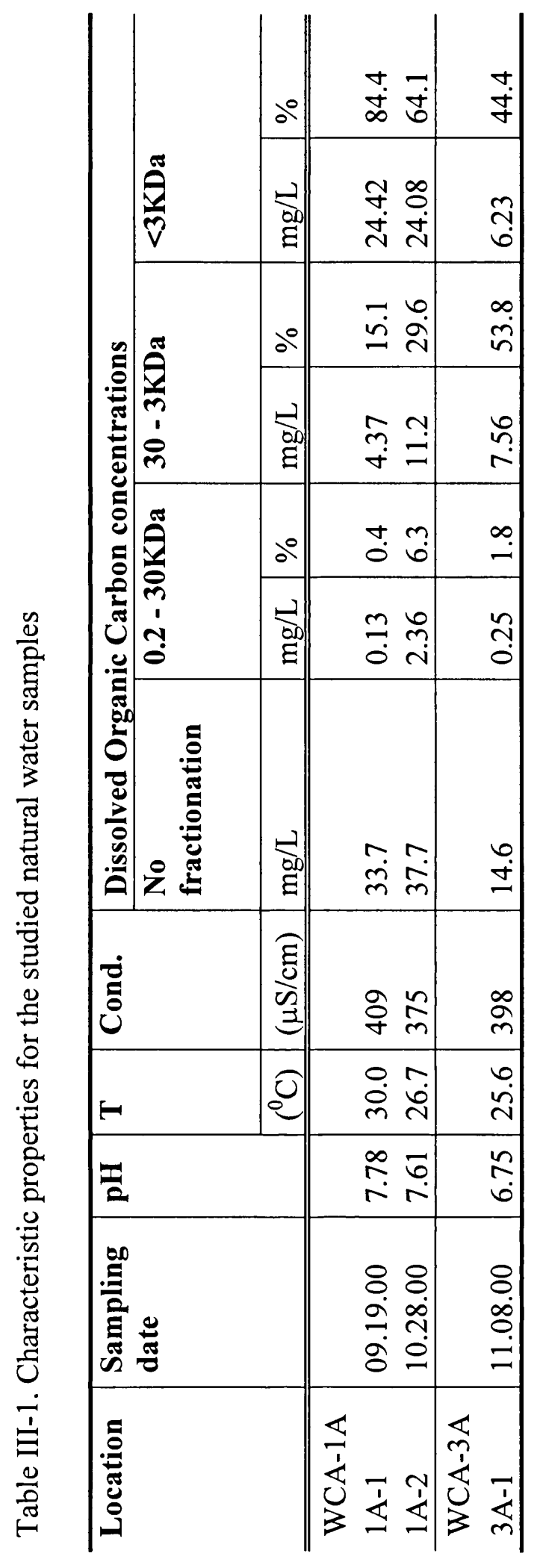


Table III-2. Elemental compositions of dissolved organic matter after acidification

\begin{tabular}{llllll}
\hline Water source & \%TN & \%C $^{\mathbf{a}}$ & $\mathbf{C : ~}^{\mathbf{b}}$ & \%IC $^{\mathbf{c}}$ & $\mathbf{( \% O C )}^{\mathbf{d}}$ \\
\hline WCA-1A & & & & & \\
1A-1 & & & & & \\
No fractionation & 0.22 & 5.29 & 28.05 & 4.24 & 1.92 \\
$<0.2$ um & 0.15 & 5.06 & 39.36 & 4.09 & 3.04 \\
0.2 um-30KDa & 0.01 & 0.10 & 11.67 & 0.03 & 0.30 \\
30KDa-3KDa & 0.06 & 0.38 & 7.39 & 0.23 & 0.44 \\
$<3 \mathrm{KDa}$ & 0.1 & 4.39 & 51.22 & 4.60 & 3.07 \\
\hline 1A-2 & & & & & \\
0.2 um-30KDa & 0.06 & 1.63 & 31.69 & 1.40 & 0.81 \\
30KDa-3KDa & 0.12 & 1.88 & 18.28 & 0.19 & 2.35 \\
$<3 \mathrm{KDa}$ & 0.1 & 2.07 & 24.15 & 3.64 & 2.07 \\
\hline WCA-3A & & & & & \\
3A-1 & & & & & \\
0.2 um-30KDa & NA & NA & ND & ND & ND \\
30KDa-3KDa & 0.16 & 3.83 & 27.93 & 2.20 & 4.07 \\
$<3 \mathrm{KDa}$ & 0.07 & 3.43 & 57.17 & 1.76 & 0.00 \\
\hline
\end{tabular}

${ }^{\mathrm{a}} \mathrm{C}$ Organic carbon.

${ }^{b} \mathrm{C}: \mathrm{N}$ calculated as $(\% \mathrm{C} / 12) /(\% \mathrm{~N} / 14)$

$\%$ IC calculated as $\% \mathrm{C}_{0}-\% \mathrm{C}_{\mathrm{f}}$

${ }^{d} \% \mathrm{OC}$ in the original sample; $(\% \mathrm{OC})_{0}=\left[(\% \mathrm{TN})_{0} \times(\mathrm{C}: \mathrm{N})_{\mathrm{f}}\right] / 1.167$ (Hedges and Stern, 1984), where o and f indicate original and final (post acidification) values.

$\mathrm{NA}=$ Not analyzed

ND Not determined, not possible to calculate 
total nitrogen (TN) or organic carbon (OC) present in the sample was not performed, but the procedure by Hedges and Stern (1984) was followed. Additional precautions were taken such as avoiding the use of silicone grease on the lid of the desiccator, as recommended by Schubert and Nielsen (2000). Complete carbonate removal is fast, therefore facilitating the measurement of carbon and nitrogen in solid natural DOM samples (Schubert and Nielsen, 2000). Then, according to Hedges and Stern (1984) the $\mathrm{C} / \mathrm{N}$ ratio can be calculated as:

$$
(\% \mathrm{OC})_{\mathrm{o}}=\left[(\% \mathrm{TN})_{\mathrm{o}} \times(\mathrm{C}: \mathrm{N})_{\mathrm{f}}\right] / 1.167
$$

where the subscripts $o$ and $f$ indicate original and final (post-acidification) values.

$\mathrm{C} / \mathrm{N}$ ratios determined from elemental analyses of organic matter have been used as bulk source identifiers, to distinguish between algal and land-plant origins of sedimentary organic matter (Meyers, 1997). Table III-3 shows the assignment of C/N ratios to possible sources of organic matter.

Table III-3. Assignment of $\mathrm{C} / \mathrm{N}$ ratios to possible sources of organic matter.

\begin{tabular}{l|l|l}
\hline C/N ratio & Possible source & Reference \\
\hline $8-15$ & Algal imputs & Meyers, 1994 \\
\hline $14-18$ & Humin & Krishnamurthy et al., 1995 \\
\hline $18-45$ & Lipid-rich algal organic matter & Meyers et al, 1986 \\
\hline
\end{tabular}

The values obtained for the size fraction isolates from natural waters of the Everglades are comparatively high to those presented in Table III-3. This could be due to a lipid-rich 
algal organic matter origin of the DOM, or to the degradation of nitrogen -containing compounds present in the DOM; or a combination of both processes could be taking place in organic rich surface waters, where partial preservation of algal organic matter occurs by selectively favoring carbon-rich components, while degrading nitrogen-rich components, thereby elevating $\mathrm{C} / \mathrm{N}$ ratios. As reported previously (Meyers, 1997), partial degradation of organic matter can selectively diminish proteinaceous components and thereby raise $\mathrm{C} / \mathrm{N}$.

The effect of the different size reflects that the type of macromolecules and the mineral compositions vary with particle size. In general, the $\mathrm{C} / \mathrm{N}$ ratios of organic matter in the truly dissolved phase are larger than $\mathrm{C} / \mathrm{N}$ ratios of colloidal phases. Colloidal fractions contain a larger proportion of intact macromolecules than the truly dissolved fraction, with smaller $\mathrm{C} / \mathrm{N}$ ratios. The truly dissolved fraction contains a larger proportion of carbon-rich components, with a degraded nitrogen portion.

A summary of the major chemical analyses of the different aquatic fractions $(\mathrm{THg}$, $\mathrm{MeHg}, \mathrm{TS}, \mathrm{C} / \mathrm{N}, \mathrm{DOC}$ and IC) is given in Table III-4. It does not appear to be a linear relationship between the $\mathrm{C} / \mathrm{N}$ ratio and the group of parameters considered previously in Chapter II. Instead, the $\mathrm{C} / \mathrm{N}$ ratio refers to the organic origin and potentially to the degree of degradation of the DOC found in these waters.

\subsection{Spectrophotometric measurements}

\subsubsection{UV-Vis}

UV-Vis has been used to measure the aquatic humus content and to estimate the humic properties by measuring the absorbance at different wavelengths (Hautala et al., 


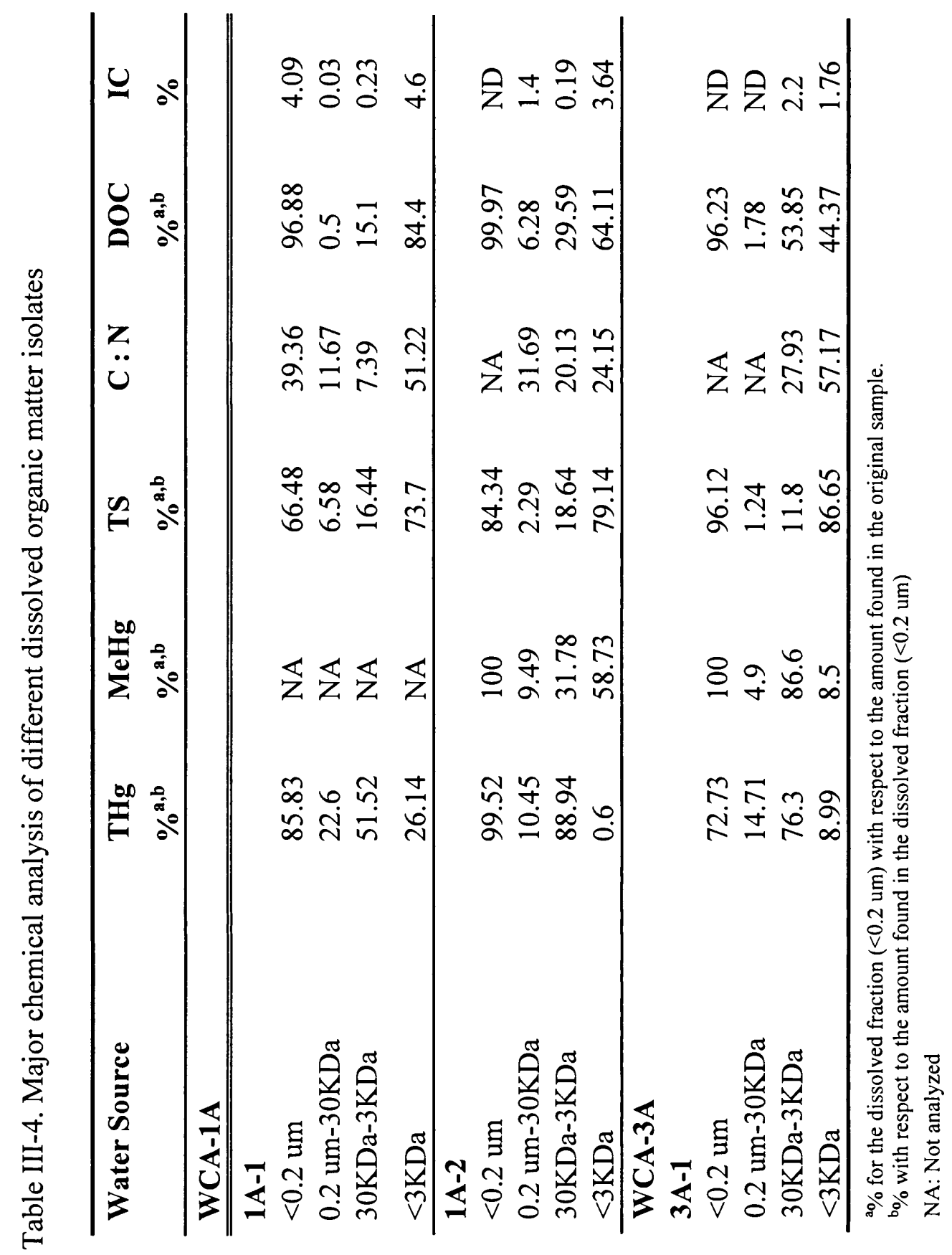


2000). Chromophores responsible for the absorbance consist of conjugated double bonds and unbonded electrons like those associated with oxygen, sulfur and halogen atoms (MacCarthy and Rice, 1985). Absorbance is probably mainly due to the aromatic ring structure (Bloom and Leenheer, 1989). In addition, internal vibration and rotation of the molecules and intermolecular interactions affect the spectra (Korshin et al., 1997). However, the UV-Vis spectra of humic solutes are featureless with absorptivities increasing toward shorter wavelengths.

Absorptivities of different DOM solutions at 250 and $436 \mathrm{~nm}$ are presented in Table III-5 for two locations in the Florida Everglades. Notice that due to the lower amounts of DOC present in WCA-3A, the values obtained for absorption are lower. $\pi \rightarrow \pi^{*}$ electron transition (e.g. aromatic compounds) occurs close to the $250 \mathrm{~nm} \mathrm{UV}$ region. The wavelength of $436 \mathrm{~nm}$ in the visible region is associated with the determination of color (Chen et al., 1977), and it is also close to the peak (440 nm) of the blue absorption band of chlorophyll a and has the potential to relate to algal biomass (Battin, 1998). The ratio of the absorbance at 254 and $436 \mathrm{~nm}$ (Table III-5) has been used to determine the origin of the organic matter in solution. DOM compounds derived from terrestrial vegetation and soils have a significant content of aromatic carbon, whereas microbially derived DOM is lower in aromaticity (Battin, 1998). The values found for terrestrial organic matter in the Surumoni and Orinoco river ranged from 9.70 to 8.53 . In this study the ratios found are larger than 20 . The measurement of the absorbance in the visible region is difficult owing to the low absorption coefficient in this region, therefore limiting the accuracy of the measurement. Because of this limitation, the usefulness of this ratio is limited. 
Table III-5. UV absorption measured at the indicated wavelength for different samples and the corresponding fractions obtained by parallel ultrafiltration. (Path length of the cell $=1 \mathrm{~cm}$ )

\section{\begin{tabular}{|l|l|l|l}
\hline $254 \mathrm{~nm}$ & $300 \mathrm{~nm}$ & $436 \mathrm{~nm}$ & $254 / 436$ \\
\hline
\end{tabular}}

WCA-1A

1A-1

\begin{tabular}{|c|c|c|c|c|}
\hline $\begin{array}{l}\text { Original } \\
\text { sample }\end{array}$ & 1.49 & 0.738 & 0.064 & 23.28 \\
\hline$<0.2$ um & 1.475 & 0.728 & 0.058 & 25.43 \\
\hline $0.2 \mathrm{um}-30 \mathrm{KDa}$ & 1.467 & 0.725 & 0.057 & 25.74 \\
\hline$<30 \mathrm{KDa}$ & 1.462 & 0.72 & 0.057 & 25.65 \\
\hline$<3 \mathrm{KDa}$ & 1.311 & 0.63 & 0.044 & 29.80 \\
\hline \multicolumn{5}{|l|}{ 1A-2 } \\
\hline $\begin{array}{l}\text { Original } \\
\text { sample }\end{array}$ & 1.5 & 0.739 & 0.03 & 50.00 \\
\hline$<0.2 \mathrm{um}$ & 1.499 & 0.737 & 0.059 & 25.41 \\
\hline $0.2 \mathrm{um}-30 \mathrm{KDa}$ & 1.501 & 0.742 & 0.061 & 24.61 \\
\hline$<30 \mathrm{KDa}$ & 1.492 & 0.736 & 0.059 & 25.29 \\
\hline$<3 \mathrm{KDa}$ & 0.386 & 0.176 & 0.01 & 38.60 \\
\hline
\end{tabular}

WCA-3A

3A-1

\begin{tabular}{l|l|l|l|l}
\hline $\begin{array}{l}\text { Original } \\
\text { sample }\end{array}$ & 0.449 & 0.222 & 0.019 & 23.63 \\
\hline$<0.2 \mathrm{um}$ & 0.444 & 0.217 & 0.017 & 26.12 \\
\hline $0.2 \mathrm{um}-30 \mathrm{KDa}$ & 0.503 & 0.246 & 0.019 & 26.47 \\
\hline$<30 \mathrm{KDa}$ & 0.429 & 0.209 & 0.016 & 26.81 \\
\hline$<3 \mathrm{KDa}$ & 0.12 & 0.053 & 0.001 & 120.00 \\
\hline
\end{tabular}


Phenolic and benzene carboxylic groups play an important role on the value of the absorbance at $300 \mathrm{~nm}$. It was experimentally found that the absorption of surface waters at this wavelength is primarily dependent on the molecular absorption of the organic substances (Buffle et al., 1982). Particularly phenolic, benzene carboxylic and condensed polycyclic aromatic functional groups of humic substances are the most important absorbing groups at this wavelength. Notice that the values corresponding to the truly dissolved fraction $(<3 \mathrm{KDa})$ are considerably smaller than for the rest of the fractions (Figure III-1). This could signify a smaller proportion of phenolic and benzene carboxylic groups in the truly dissolved phase.

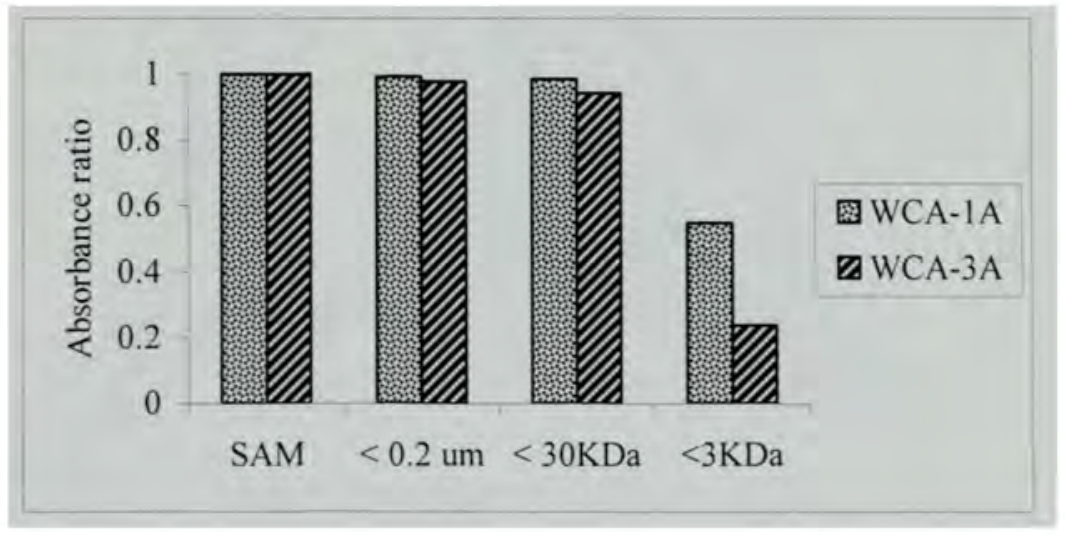

Figure III-1. Absorbance ratio $\left(\mathrm{A}_{\text {fraction }} / \mathrm{A}_{\mathrm{SAM}}\right.$ at $\left.300 \mathrm{~nm}\right)$ of different size fractions with respect to the absorbance of the unfractionated sample (data from WCA1A-1).

\subsubsection{Fluorimetric measurements}

Figure III-2 shows the synchronous spectra of the different size fractions for a WCA-1A sample. Two bands around 300 and $370 \mathrm{~nm}$ and a shoulder at around $470 \mathrm{~nm}$ are common in the synchronous spectra of the natural DOM because of the presence of fulvic acids (Senesi et al., 1991). These spectra show: peak I @ 285 nm, due to 
proteinaceous materials (Lombardi and Jardim, 1999); peak II @350 nm; peak III @385 nm due to the presence of fulvic acids; and peak IV @ $460 \mathrm{~nm}$, due to the presence of humic substances (Miano and Senesi, 1992). The different peaks observed are shifted to longer wavelengths from the lower molecular weight fraction $(<3 \mathrm{KDa})$, to the higher molecular weight fraction $(<0.2 \mu \mathrm{m})$. This shift in the maxima of fluorescence intensity

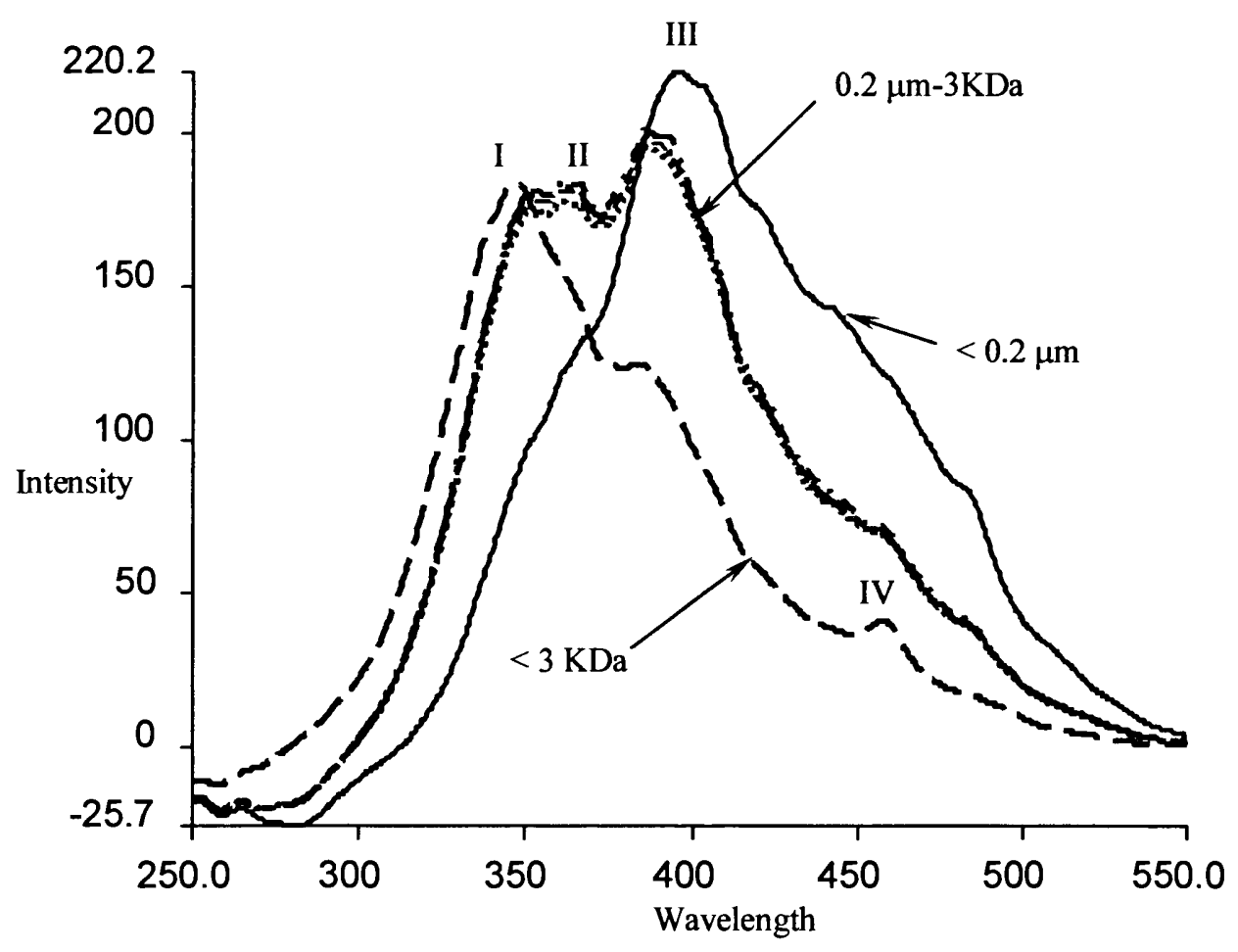

Figure III-2. Synchronous fluorescence spectra of a natural sample from the Florida Everglades. Assignments for peaks I, II, III and IV are explained in the text.

from shorter to longer wavelengths is associated with an increasing number of highly substituted aromatic nuclei (Senesi, 1990; Miano and Senesi, 1992) with a higher content of conjugating groups (such as carbonyl and carboxyl groups), and with possible 
reabsorption of the emitted radiation by other absorbing centers of the molecule or neighboring molecules (McGarry and Baker, 2000). Ideally, the dissolved fraction $(<0.2$ $\mu \mathrm{m})$ should have a pattern result of the addition of its different size fractions spectra. The actual spectrum is close but does not evolve all of them; this could be due to differences in DOC concentration in different fractions or non-perfect size discrimination.

\subsection{3. ${ }^{13} \mathrm{C}-\mathrm{CPMAS}$ NMR}

Figure III-3 shows the ${ }^{13}$ C-CPMAS NMR spectra of various DOM fractions in dissolved phase $(<0.2 \mu \mathrm{m})$ obtained in a sequential manner by using two different ultrafiltration membranes $(30 \mathrm{KDa}$ and $3 \mathrm{KDa})$. The spectra of the isolates from WCA1A and WCA-3A show that all the size fractions were similar with each other by visual comparison (Figure III-3). DOM contains mostly a wide variety of functionalities; therefore, line widths are inevitably broad, this is due to the many overlapping resonances from the heterogeneous mixture of organic compounds present in the DOM. Due to this very heterogeneous macromolecular nature, the nuclei can experience a variety of chemical environments thus producing a wide range of ${ }^{13} \mathrm{C}$ NMR chemical shifts. This fundamental characteristic interferes somewhat with the exact assignments and interpretations of specific resonance regions of different kinds of carbons since they can resonate within a wide shift range with numerous overlaps. (Malcolm, 1990; Peuravuori et al., 1998; Preston, 1996; Conte et al., 1997, 1999; Peuravuori, 2000).

The ${ }^{13} \mathrm{C}$ NMR spectra of Figure III-3 were assigned into four chemical shift ranges (Malcolm, 1990; Peuravuori and Pihlaja, 1998; Preston, 1996; Conte et al., 1997, 1999; Peuravuori, 2000) (ppm, relative to tetramethylsilane), as shown in Table III-6. These conventional labels for regions of the ${ }^{13} \mathrm{C}$-NMR spectrum are only approximate. 


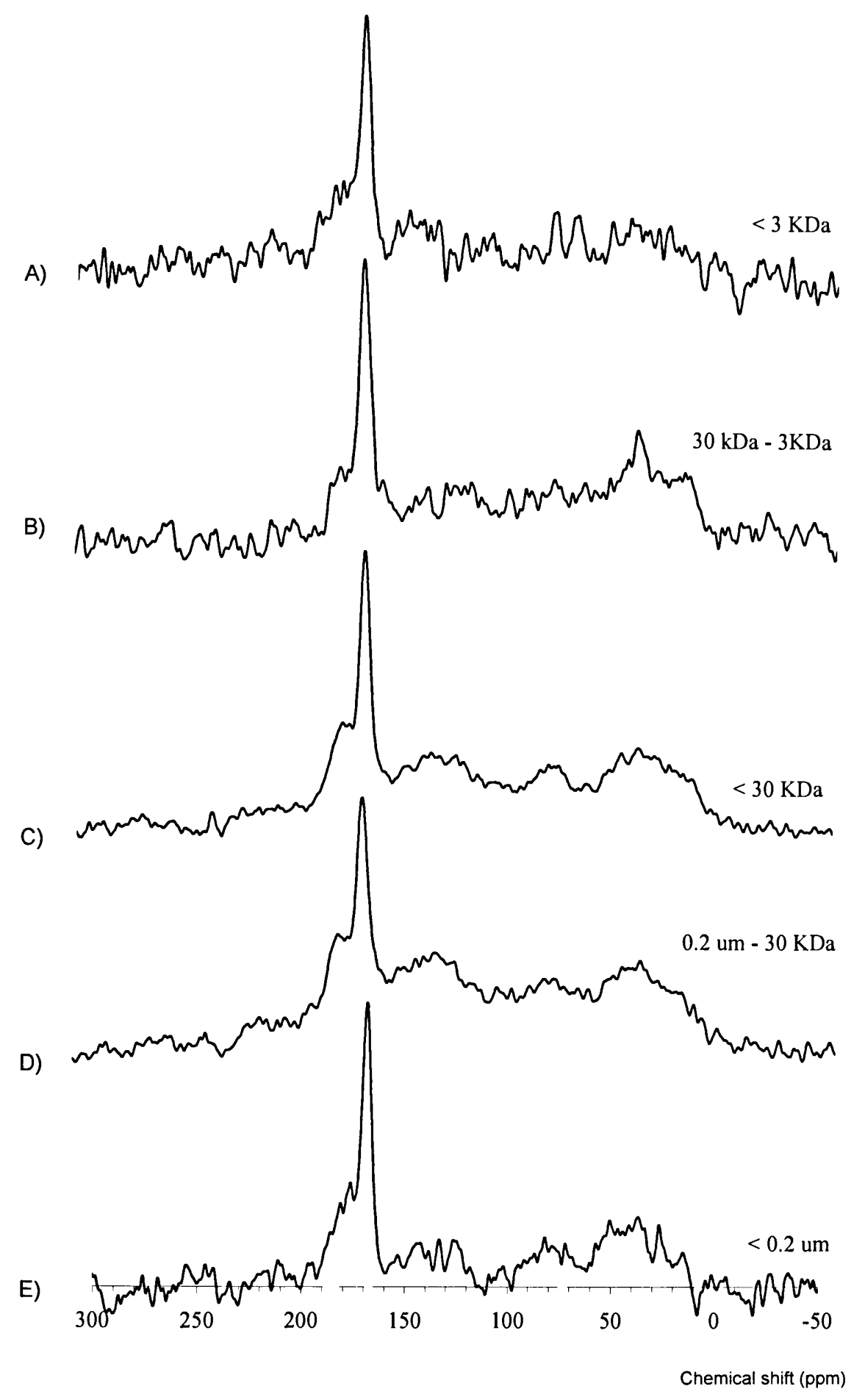

Figure III-3. ${ }^{13} \mathrm{C}$-CPMAS NMR spectra of various DOM size fraction isolates obtained by sequential ultrafiltration. A) $<3 \mathrm{kDa}$; B) $30 \mathrm{KDa}-3 \mathrm{KDa}$; C) $<30 \mathrm{KDa}$; D) $0.2 \mathrm{um}-30 \mathrm{KDa}$; E) $<0.2$ um. 
Table III-6. ${ }^{13} \mathrm{C}-\mathrm{NMR}$ spectra chief chemical shift ranges (ppm relative to tetramethylsilane)

\begin{tabular}{ll}
\hline Region & Chemical shift \\
\hline \hline Alkyl C, aliphatic & $0-45 \mathrm{ppm}$ \\
& $30 \mathrm{ppm}$ \\
\hline O-alkyl & $45-110 \mathrm{ppm}$ \\
& $55 \mathrm{ppm}$ \\
& $60-90 \mathrm{ppm}$ \\
& $90-110 \mathrm{ppm}$ \\
\hline Aromatic & $110-160 \mathrm{ppm}$ \\
& $100-105 \mathrm{ppm}$ \\
\hline Carbonyl C & $160-210 \mathrm{ppm}$ \\
& $195-220 \mathrm{ppm}$ \\
\hline
\end{tabular}

Integration of the ${ }^{13} \mathrm{C}-\mathrm{NMR}$ spectral regions of Figure III-3 for assessing relative percentages (\%) of different types of carbon atoms representing the four different spectral regions [alkyl-carbon (0-45 ppm), O-alkyl (45-110 ppm), aromatic (110-160 ppm) and carbonyl-carbon (160-210 ppm)] was based on the assumption of straight baselines in areas of spectral intensity. The two samples from WCA-1A collected in different dates show some differences in the phenolic region, the reason may be decomposition that modifies the aromatic rings of lignin and causes the decrease of the phenol peaks. The aromatic region becomes dominated by a single broad peak with its maximum at 130ppm, as previously observed by Newman and Tate (1991).

Table III-7 shows the relative abundance of different types of carbons for the various DOM isolates obtained from the different size fraction isolates for both sites. This comparison shows that the different fractions of a given sample have a contribution to the 


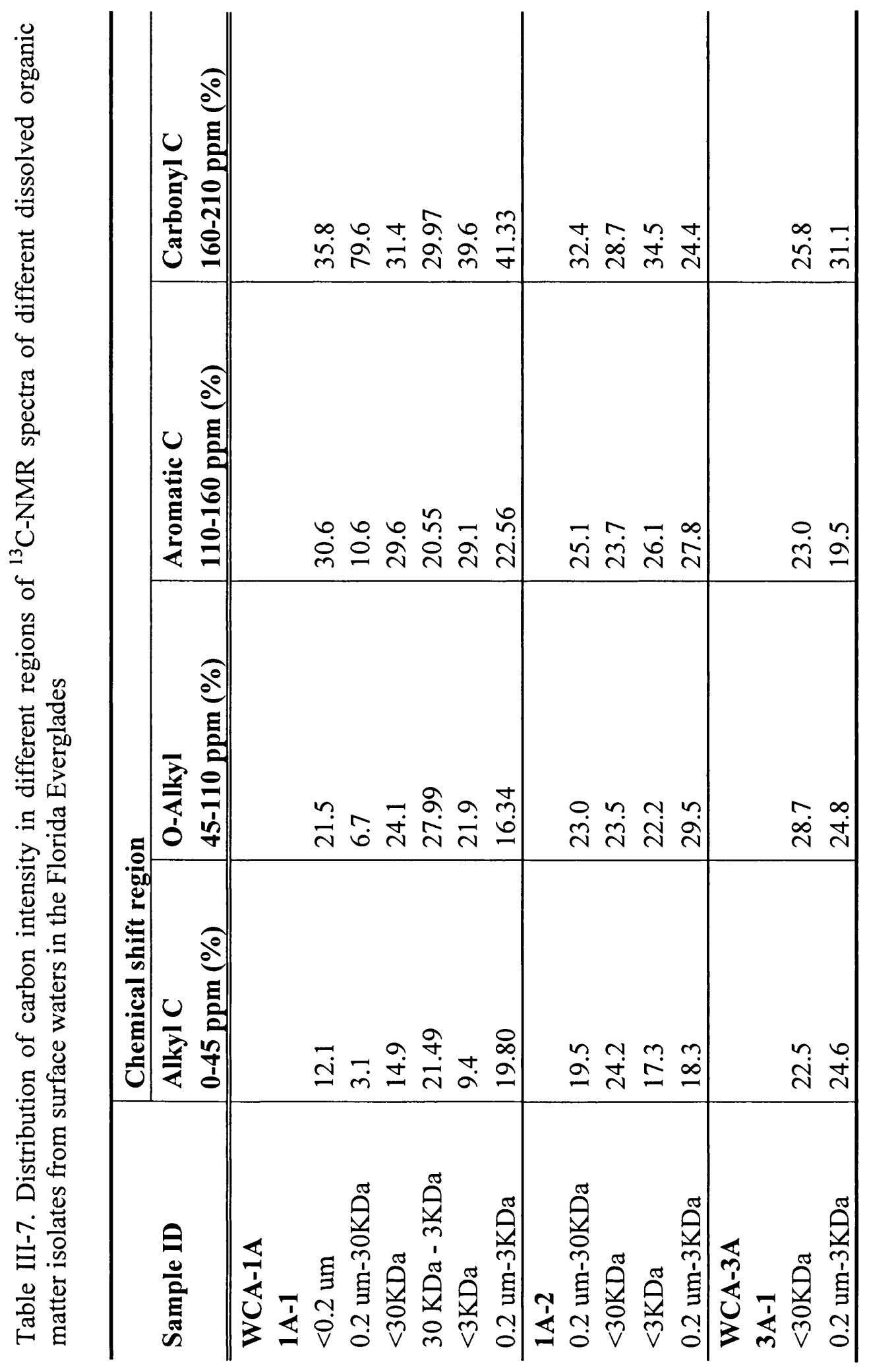


total composition of the structurally different types of carbon present in the whole water sample. Unfortunately, this distribution was not determined for several fractions in the WCA-3A sample due to lack of a larger amount of isolate, since the DOC content of this location is lower. Therefore, some comparisons could be made only for two of the fractions for which data was available for this sample.

\section{Conclusions}

Several DOC fractions were studied using several spectroscopic techniques. The results indicate that the studied size fraction isolates exhibit some structural differences. For example, the variation from aliphatic to aromatic characteristics was noted by using ${ }^{13} \mathrm{C}$ CPMAS NMR. The spectra showed a progressive decrease in bands associated with the aromatic moiety of the molecules for those fractions containing lower molecular weight DOM.

The previous characterization of mercury species and their interaction with DOC revealed that $\mathrm{THg}$, and especially $\mathrm{MeHg}$, were associated with the low molecular weight fraction (especially truly dissolved, $<3 \mathrm{KDa}$ ). Although some useful information has been gained in terms of charactering the DOC, from our very limited data of spectroscopic studies, conclusions about the interactions between different DOC fractions and mercury interactions, as well as the effects of different functional groups cannot be drawn. 


\section{Low molecular weight thiol-containing compounds in natural water and suspended particulate from the Florida Everglades}

\section{Introduction}

Dissolved organic matter may contain reduced organic sulfur (ROS), such as thiol (-SH), or disulfide (-S-S) groups from sulfur-containing amino acids (Strohal and Huljev, 1971; Dyrssen and Wedborg, 1991). It is believed that such sulfur-containing groups are involved in the very strong binding or complexation of mercury to humic substances (Jackson et al., 1980; Lee and Hulberg, 1990; Schuster, 1991; Hintelmann et al., 1995 and Hintelmann et al., 1997). The reactivity of thiol to mercury is strong compared to other transition metal ions (Cestari and Airoldi, 1997). The way the mercury species are bound to organic matter is not known, but we could assume that mercury is most likely associated with the DOM via ROS-type binding functional groups.

The Everglades mercury problem has been extensively investigated (US EPA, 1997; US EPA, 1998), however little is known about the mercury-ROS interactions and particularly $\mathrm{CH}_{3} \mathrm{Hg}$ - $\mathrm{ROS}$ interactions in these waters, the bioavailability of these complexes and the effect of the chemical characteristics of the ROS on these interactions. Driscoll et al. (2000) have shown that total sulfur is not a good estimate of $\mathrm{CH}_{3} \mathrm{Hg}$ - $\mathrm{ROS}$ binding and that its use would result in underestimation of mercury biomagnification in food chains. The lack of data on the mercury-ROS interaction is partially attributed to the limitation of analytical techniques that can be used for the determination of ROS at concentration levels in environmental samples. Accordingly, the development of a convenient and reliable method for the direct determination of the concentrations of 
naturally occurring thiol groups in natural freshwater is necessary to provide more specific information, to clarify its environmental role in relation to mercury binding.

High performance liquid chromatography (HPLC) with fluorescent detection appears to be the most promising method with respect to convenience, resolution, sensitivity and versatility for thiol analysis. Several assay methods based on HPLC for thiols have been developed. Most of these techniques were developed for analyzing biological samples where relatively high concentrations of thiols are expected. Labeling of plasma thiols with a thiol-specific fluorogenic reagent followed by HPLC and fluorescence detection has been previously reported (Ubbink et al., 1991; Fermo et al., 1992; Jacobsen et al., 1994; Araki and Sako, 1987). At least three thiol-specific reagents, o-phthaldaldehyde (OPA), monobromobimane (MBrB) and ammonium 7-fluorobenzo-2oxa-1,3-diazole-4-sulphonate (SBD-F) are commercially available, all of them previously used for thiol-containing amino acids (cysteine, glutathione, homocysteine) analyses.

One of the procedures available for the determination of analytes with a primary amino group is the Roth's fluorimetric method (Roth, 1971). Under basic conditions, the derivatization reaction of the fluorogenic reagents, o-phthalaldehyde (OPA) and a primary amino compound, with a thiol-containing species yields a 1-(2hydroxyethyl)thio-2-N-alkyl-substituted isoindole [eq.1] whose fluorescence is proportional to the thiol concentration. The OPA fluorophore rapidly links the primary amino groups and the thiol group at normal ambient temperatures, giving derivatized products that can be detected with high sensitivity. This method was found to be suitable for the determination of total homocysteine in plasma (Fermo et al., 1992) with very good sensitivity (10 pmol per injection). The primary limitation of this method is that the 
derivatives formed were found to be unstable, and can produce non-fluorescent adducts (Jacobs et al., 1986) in a rapid, time-dependent degradation (Dai et al., 1997). Also, the OPA reaction is highly $\mathrm{pH}$ dependent and at $\mathrm{pH}<9$ no reaction occurs (Svedas et al., 1980).<smiles>O=Cc1ccccc1C=O</smiles>

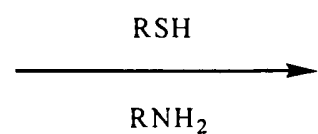

OPA

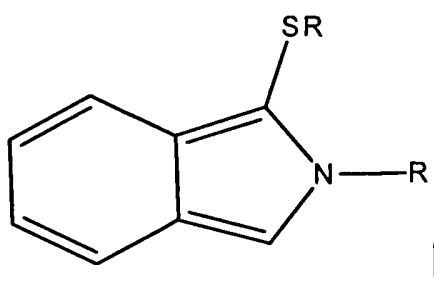

[1]

The second fluorogenic thiol-specific reagent used for precolumn labeling of low molecular weight thiols is monobromobimane $(\mathrm{MBrB})$. The compound itself is weakly fluorescent, it selectively reacts with thiols [eq. 2] to yield highly fluorescent and stable thioethers (MBSR) that can be detected at the picomole level.<smiles>Cc1c(C)n2c(CBr)c(C)c(=O)n2c1=O</smiles><smiles>[R5]Cc1c(C)c(=O)n2c(=O)c(C)c(C)n12</smiles>

The bimane derivatives can be separated by HPLC. Unfortunately, this derivatization is characterized by the formation of interfering adducts. Time consuming clean-up steps are required to remove the MBrB hydrolysis products (Jacobsen et al., 1989). More recently Jacobsen et al. (1994) have prepared beads with sepharose-SH groups used to scavenge excess $\mathrm{MBrB}$ during the preparation of the thiol-bimane 
derivatives. The assay easily detects serum and plasma total homocysteine concentrations of $10 \mathrm{pmol}$, despite the background fluorescence and the formation of fluorescent degradation products.

Finally, ammonium 7-fluoro-2,1,3-benzoxadiazole 4-sulfonate (SBD-F) has proved useful for the assay of biological thiols in trace amounts (Toyo'oka and Imai, 1983). SBD-F is a thiol-specific, fluorogenic reagent. This reagent has some excellent features with respect to fluorescence characteristics (excitation maxima at $385 \mathrm{~nm}$, emission maxima at $515 \mathrm{~nm}$ ), soluble in water, and high stability of the fluorescence derivatives compared to other derivatization reagents (Toyo'oka and Imai, 1984a, b). Because of these stability characteristics, SBD-F can be used as pre-column derivatization reagent for thiols (and disulfides after reduction) followed by chromatographic separation. Thiols derivatized with SBD-F have been reported to show high fluorescence and high stability (Toyo'oka and Imai, 1983, 1984a). The reaction between the fluorescent tag (SBD-F) and the organic thiols is shown [eq. 3] (Imai and Toyo'oka, 1987).<smiles>[NH3+]S(=O)(=O)c1ccc(F)c2nonc12</smiles>
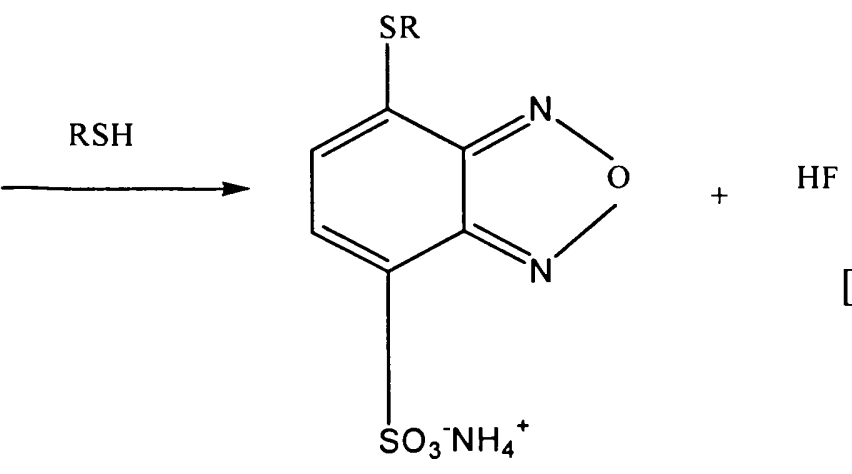
The fluorogenic-tagging reagent SBD-F has a benzo-furazan (2,1,3-benzoxadiazole) structure that increases its fluorescence. The fluorescence depends on the functional groups at the 4- and 7-position in the 2,1,3-benzoxadiazole, as well as the emission wavelength (Toyo'oka et al., 1991). The SBD-thiol derivatives can be separated by HPLC column and detected fluorimetrically. This derivatization yields very clean chromatograms in comparison with the MBrB reaction (Fermo et al., 1998). SBD-F itself is non-fluorescent, and no-fluorescent by-products are formed during the derivatization procedure. From the original method proposed by Araki and Sako (1987) several modifications have been proposed as improvements, as it would be explained later. This method is a simple and relatively inexpensive assay for thiols. Ubbink et al. (1991) reported a rapid isocratic HPLC method to separate SBD-derivatized thiols within six minutes.

SBD-F adducts have high fluorescence, give rise to a low detection limit and have excellent stability which is favorable for precolumn labeling (Imai et al., 1983). The selectivity of SBD-F derivatization technique is superior to that of other reagents such as the o-phthalaldehyde (Mopper and Delmas, 1984) and the monobromobimane (Fahey and Newton, 1987) because SBD-F is highly specific to sulphyhydryl groups and does not react with alcohols, phenols or amino groups (Araki et al., 1987). Due to this high reactivity to thiol compounds low detection limits can be attained. Additionally SBD-F does not have fluorescence itself, and has a negligible fluorescence blank (Toyo'oka and Imai, 1983) and has biological buffer solubility.

The SBD-F method has been used to determine low-molecular weight thiols, such as cysteine, homocysteine and glutathione, in plasma (Araki and Sako, 1987; Rizzo et al., 
1998; Oe et al., 1998) and high-molecular weight metallothioneins (Miyairi et al., 1998). A study has been performed for thiols in the particulate phase in estuary waters (Tang et al., 2000a); however, determination of the thiol species present in freshwater has not yet been done, probably due to the low concentrations of thiols present. In the present study, SBD-F was used as a fluorescence reagent to measure the concentrations of the thiols in natural freshwater samples including both dissolved and particulate phases.

Due to the low concentration of thiols present in freshwaters, a preconcentration technique was pursued. Two preconcentration techniques, lyophillization and a combination of rotary evaporation-lyophillization, were selected to reduce the volume of the sample with minimum sample degradation. In an effort to account for the differences in trace mercury species concentrations in natural surface freshwater from two different locations in the Florida Everglades, we pursued some investigations about the identity and determination of the concentrations of the reduced organo-sulfur species that are present in freshwaters. To accomplish this purpose, a sensitive and reliable reversedphase HPLC method has been developed to analyze naturally occurring low-molecular weigh thiols using pre-column derivatization with SBD-F and fluorescence detection with isocratic elution.

\section{Experimental}

\subsection{Fluorimetric assay of thiols with SBD-F}

Thiols present in natural freshwater samples from the Florida Everglades were derivatized with SBD-F essentially following the fluorometric assay of thiols with fluorobenzoxadiazoles by Imai and Toyo'oka (1987). The modifications introduced to 
this procedure account mainly for the non-proteinic matrix analyzed in our study, as well as the smaller volumes used to economize the use of reagents. In addition, recent improvements reported in the literature (Rizzo et al., 1998; Oe et al., 1998; Miyairi et al., 1998) were taken into account as further explained below. This test applies to the determination of reduced and oxidized thiols in water samples by HPLC with fluorescence detection.

\subsubsection{Reaction conditions}

The reaction between SBD-F and thiols was shown previously [eq. 3]. The final SBD-F concentration in the analysis solution is equivalent to $370 \mathrm{pM}, 40$ times higher than the highest concentration of the standards used. This reaction is favored under basic conditions; therefore, the reaction was buffered at a $\mathrm{pH} 9.5$ by a $0.3 \mathrm{M}$ borate buffer with 2 mM EDTA. Borate buffer/EDTA was used as the reaction medium in the sample processing. The borate buffer concentration used by Araki and Sako (1987) was $2.5 \mathrm{M}$. It was reduced to $0.3 \mathrm{M}$ because the high concentrations of this salt, in fact, can cause occlusions along the narrow steel tubes of the HPLC equipment (Fermo et al., 1998).

By adding EDTA as complexing agent for metals, the thiol groups were made more accessible to SBD-F. By complexing metals EDTA releases thiols and prevents other metals from reacting with thiols in solution. At the $\mathrm{pH}(9.5)$ used, it is important to include $2 \mathrm{mM}$ EDTA to prevent metal catalyzed oxidation of the thiols present (Imai and Toyo'oka, 1987). At this $\mathrm{pH}$ the reaction is slow and needs to be conducted at high temperature, i.e. $60{ }^{\circ} \mathrm{C}$ for $1 \mathrm{~h}$.

Disulfides do not react with SBD-F and must be reduced to thiols (Imai and Toyo'oka, 1987). Tri-n-butylphosphine (TBP) has a very basic and nucleophillic nature, 
and is effective in reducing alkyl disulfides to thiols (Humphey and Potter, 1965). The reaction is presumed to proceed as shown,

$$
\mathrm{RSSR}+\left(\mathrm{C}_{4} \mathrm{H}_{9}\right)_{3} \mathrm{P}+\mathrm{H}_{2} \mathrm{O} \rightarrow 2 \mathrm{RSH}+\left(\mathrm{C}_{4} \mathrm{H}_{9}\right)_{3} \mathrm{PO}
$$

Quantitative reduction of the disulfides was found within five to sixty minutes after reaction of these compounds with TBP (Imai and Toyo'oka, 1987). TBP does not interfere with the fluorogenic reaction and may be added directly to the reaction medium. Approximately $100 \%$ excess of the theoretical amount of TBP is used in all cases. Additionally, TBP has a characteristic disagreeable odor, which can be recognized and is poorly soluble in water so that it must be dissolved in dimethylformamide for use (Gilfix et al., 1997).

\subsection{Analysis of thiols in natural waters}

\subsubsection{Chemicals}

Distilled deionized water (DDIW): DDIW was produced by filtering tap water through a Culligan system consisting of activated charcoal and two mixed bed ion exchange cartridges. The filtered water is then piped to a Barnstead distillation system and stored in 25 gallon polypropylene carboy.

Ammonium-7-fluorobenzo-2-oxa-1,3-diazole-4-sulphonate (SBD-F) 1000 ppm solution: approximately $1000 \mu \mathrm{g}$ of SBD-F (Fluka) are weighted in a $2 \mathrm{ml}$ microcentrifuge vial (Fisher Scientific) in an analytical balance and dissolved in an appropriate volume of DDIW $(1000 \mu \mathrm{L})$ to yield a final concentration of $1 \mu \mathrm{g} / \mu \mathrm{L}$ (1000 ppm). It is prepared on a daily basis. 
$10 \%(\mathrm{v} / \mathrm{v})$ tri-n-butylphosphine (TBP) in N,N-dimethylformamide (DMF): $5 \mathrm{ml}$ of TBP are transferred to a $50 \mathrm{ml}$ volumetric flask and the volume is completed with $45 \mathrm{ml}$ of DIW. It is prepared as needed.

$0.3 \mathrm{M}$ sodium borate ( $\mathrm{pH} 9.5$ ) with $2 \mathrm{mM}$ ethylenediaminetetraacetic acid (EDTA): $2.4543 \mathrm{~g}$ of $\mathrm{NaBO}_{3}$ and $0.0744 \mathrm{~g}$ of EDTA are weighted in an analytical balance and transferred to a $100 \mathrm{ml}$ volumetric flask where the volume is completed with DDIW. A few drops of $1 \mathrm{M} \mathrm{NaOH}$ are added to the solution, and the $\mathrm{pH}$ further adjusted to 9.5 using $0.1 \mathrm{M} \mathrm{NaOH}$ and $0.1 \mathrm{M} \mathrm{HCl}$. It is prepared as needed.

$4 \mathrm{~N}$ hydrochloric acid $(\mathrm{HCl}): 33.33 \mathrm{ml}$ of $12 \mathrm{~N}$ hydrochloric acid (Trace Metal grade, Fisher Scientific) are transferred to a $100 \mathrm{ml}$ volumetric flask containing DDIW and the volume completed with DDIW. It is prepared as needed.

Acetonitrile: HPLC optima grade (Fisher Scientific).

$0.1 \%$ trifluoroacetic acid (TFA): $1 \mathrm{ml}$ of TFA (Peptide Synthesis grade, Fluka) is transferred to a $1000 \mathrm{ml}$ volumetric flask containing DDIW and the volume completed with DDIW to the mark. It is prepared as needed.

Calibration glutathione and cysteine primary standards (1000 ppm): approximately $1000 \mu \mathrm{g}$ of glutathione and cysteine, respectively were weighted and dissolved in approximately $1000 \mu \mathrm{L}$ of DDIW (the exact volume must be determined based on the actual weight). It is prepared on a daily basis.

Glutathione and cysteine secondary standards $(10 \mathrm{ppm})$ : take $10 \mu \mathrm{L}$ of glutathione and cysteine $1000 \mathrm{ppm}$ primary standard and complete to a total volume of $1000 \mu \mathrm{L}$ with DDIW. 
Glutathione and cysteine calibration standards: five calibration standards are

prepared in $2 \mathrm{ml}$ microcentrifuge vials. $0,50,100,200$ and $500 \mu \mathrm{L}$ of the glutathione and cysteine (respectively) secondary standards are spiked into the vials and completed with DDIW to a total volume of $1000 \mu \mathrm{L}$.

\subsubsection{Procedure}

This procedure is applied to the preparation of the water samples as well as the matrix spiked sample, standards and reagent blanks. $1.5 \mathrm{ml}$ of preconcentrated sample were placed into a $2 \mathrm{ml}$ micro-centrifuge vial and centrifuged at $12,000 \mathrm{rpm}$ for $10 \mathrm{~min}$ at $20{ }^{\circ} \mathrm{C} .200 \mu \mathrm{l}$ of aliquot of this were placed in a $2 \mathrm{ml}$ micro-centrifuge vial and $40 \mu \mathrm{l}$ of derivatizing agent SBD-F were added. To measure total reduced and oxidized thiol concentration, $10 \mu \mathrm{l}$ of a $10 \%$ solution of TBP in dimethylformamide were added to accomplish reduction of the thiols and disulfides present that otherwise would not react with the fluorescent tag. Subsequently, $200 \mu \mathrm{l}$ of $0.3 \mathrm{M}$ sodium borate buffer $\mathrm{pH} 9.5$ containing $2 \mathrm{mM}$ EDTA were added, vigorously shaken in a Vortex, and the mixture was incubated for 1 hour at $60{ }^{\circ} \mathrm{C}$ to accomplish derivatization. $10 \mu \mathrm{HCl}(4 \mathrm{M})$ were added to terminate the reaction, because the reaction does not proceed in acidic medium. The fluorescence intensity of the SBD-thiolates is measured at ambient temperature with emission at $515 \mathrm{~nm}$ and excitation at $380 \mathrm{~nm}$.

\subsection{Determination of thiols in suspended particulate matter}

\subsubsection{Chemicals}

$1 \mathrm{M}$ methanesulfonic acid (MSA): $4.805 \mathrm{~g}$ of MSA are dissolved in a $50 \mathrm{ml}$ volumetric flask with DDIW. 
$20 \mathrm{mM}$ MSA: $1 \mathrm{ml}$ of $1 \mathrm{M}$ MSA is transferred to a $50 \mathrm{ml}$ volumetric flask and diluted with DDIW.

$0.1 \mathrm{M} \mathrm{NaOH}: 0.4 \mathrm{~g}$ of $\mathrm{NaOH}$ are dissolved in $100 \mathrm{ml}$ of DDIW.

1000 ppm SBD-F: see above

$0.1 \%$ TFA: see above

Acetonitrile: see above

\subsubsection{Procedure}

The filter containing the particulate from $250 \mathrm{ml}$ of water sample was extracted according to the procedure described by Tang et al (2000a) for particulate analysis from estuarine waters. $1.4 \mathrm{ml}$ of $20 \mathrm{mM}$ MSA solution was added to the micro-centrifuge vial containing the frozen filter and heated at $60{ }^{\circ} \mathrm{C}$ for $3 \mathrm{~min}$ in a water bath. The vial was then ultrasonicated for 10 minutes to lyse the phytoplankton cells, and centrifuged at $12,000 \mathrm{rpm}$ for $20 \mathrm{~min}$ at $4{ }^{\circ} \mathrm{C} .500 \mu \mathrm{l}$ of supernatant were used for SBD-F derivatization by adding $30 \mu \mathrm{l}$ of $10 \% \mathrm{TBP}$ in DMF to $2 \mathrm{ml}$ micro-centrifuge vial. A $10 \mathrm{~min}$ period was allowed for reduction by cleaving the disulfides bonds that permits SBD-F to react with thiols produced. Then $40 \mu \mathrm{l}$ of SBD-F solution $(1 \mathrm{mg} / 4 \mathrm{ml})$ were added. Then $20 \mu \mathrm{l}$ of $\mathrm{NaOH}(1 \mathrm{M})$ and $200 \mu \mathrm{l}$ of borate buffer $(0.1 \mathrm{M})$ containing $2.0 \mathrm{mM}$ EDTA $(\mathrm{pH} 9.5)$ were added; the $\mathrm{pH}$ was further adjusted to its optimum condition of 9.5 with $0.1 \mathrm{M} \mathrm{NaOH}$. The reaction was allowed to proceed at $60{ }^{\circ} \mathrm{C}$ for $60 \mathrm{~min}$ and then stopped by adding 100 $\mu \mathrm{l}$ of MSA (1M). Aliquots of this solution $(50 \mu \mathrm{l})$ were injected into the HPLC system using $0.1 \%$ TFA (pH 2) - acetonitrile (90:10) as the mobile phase. Filter blanks were subject to deionized water filtration, kept and analyzed in the same manner. 


\subsection{Chromatographic system}

A high-performance liquid chromatograph Shimadzu model LC-10AT (Shimadzu, MD), with a Shimadzu FCV-10AL gradient elution system coupled to a Shimadzu SIL-10A $A_{\mathrm{XL}}$ autosampler and a Shimadzu SCL-10A system controller were used. The system was fitted with a Zorbax SB-C18 (250 mm x $46 \mathrm{~mm}$ ID) analytical column. A reversed-phase guard column was used to protect the analytical column. A fluorometric detector Shimadzu RF-551 was set to $\lambda_{\text {excitation }}=385 \mathrm{~nm}$ and $\lambda_{\text {emission }}=515$ $\mathrm{nm}$. The HPLC mobile phase consists of two solutions: (A) $0.1 \%$ trifluoroacetic acid (TFA) and (B) $100 \%$ acetonitrile (ACN) at a flow rate of $1 \mathrm{ml} / \mathrm{min}$. The column was equilibrated with a $90: 10$ of $0.1 \%$ trifluoroacetic acid:acetonitrile.

$50 \mu \mathrm{l}$ aliquots of the derivatized samples were used for analysis. The operating conditions for water analysis are summarized in Table IV-1. For the first $25 \mathrm{~min}$ the flow was maintained constant at the initial conditions, the valve was then switched to higher gradient proportions of eluent B for $40 \mathrm{~min}$ in order to clean the column from any remaining adsorbed organic matter. Finally, the valve was switched to $10 \%$ eluent $\mathrm{B}$ for 25 min for column re-equilibration and for readiness for next sample injection. The operating conditions for particulate analysis are summarized in Table IV-2.

\subsection{Sampling}

For convenience, surface water from the Florida Everglades was collected using 10L acid-cleaned polyethylene carboys. The depth of the water at the sampling locations was about 0.5 to 1 meter. Care was taken not to disturb the sediments. Samples were transported to the laboratory within two hours of collection. The samples collected in the field were subjected to the experimental procedures described below. 
Table IV-1. Operating conditions for HPLC with fluorescence detection for thiol analysis in water samples.

\begin{tabular}{|c|c|c|c|}
\hline Liquid Chromatograph & Shimadzu LC-10AT & & \\
\hline System Controller & Shimadzu SCL-10A & & \\
\hline Degasser & Shimadzu GT-104 & & \\
\hline $\begin{array}{l}\text { Gradient Elution } \\
\text { System }\end{array}$ & Shimadzu FCV-10AL & & \\
\hline Autosampler & Shimadzu SIL-10AXL & & \\
\hline Spectrofluorimetric & Shimadzu RF-551 & Excitation & Emission \\
\hline detector & & (a) $385 \mathrm{~nm}$ & (a) $515 \mathrm{~nm}$ \\
\hline Software & Class V.P. 4.2 & & \\
\hline Guard Column & $\mathrm{C} 18$ & & \\
\hline Column & Zorbax SB-C18 $4.6 \times 25 \mathrm{~cm}$ & & \\
\hline \multirow[t]{2}{*}{ Mobile phase } & $0.1 \%$ TFA & Pump A & \\
\hline & $100 \%$ Acetonitrile & Pump B & \\
\hline \multirow[t]{7}{*}{ Gradient elution } & $0-25 \mathrm{~min}$ isocratic & $10 \% \mathrm{~B}$ & $\mathrm{~A} \%=100 \%-\mathrm{B} \%$ \\
\hline & $25-25.01$ & $10-35 \% \mathrm{~B}$ & \\
\hline & $25-35 \mathrm{~min}$ & $35-50 \% \mathrm{~B}$ & \\
\hline & $35-50 \mathrm{~min}$ & $50-90 \% \mathrm{~B}$ & \\
\hline & $50-65 \mathrm{~min}$ isocratic & $90 \% \mathrm{~B}$ & \\
\hline & $65-66 \mathrm{~min}$ & $90-10 \% \mathrm{~B}$ & \\
\hline & $66-90 \mathrm{~min}$ isocratic & $10 \% \mathrm{~B}$ & \\
\hline
\end{tabular}


Table IV-2. Operating Conditions used to measure thiolic compounds in particles

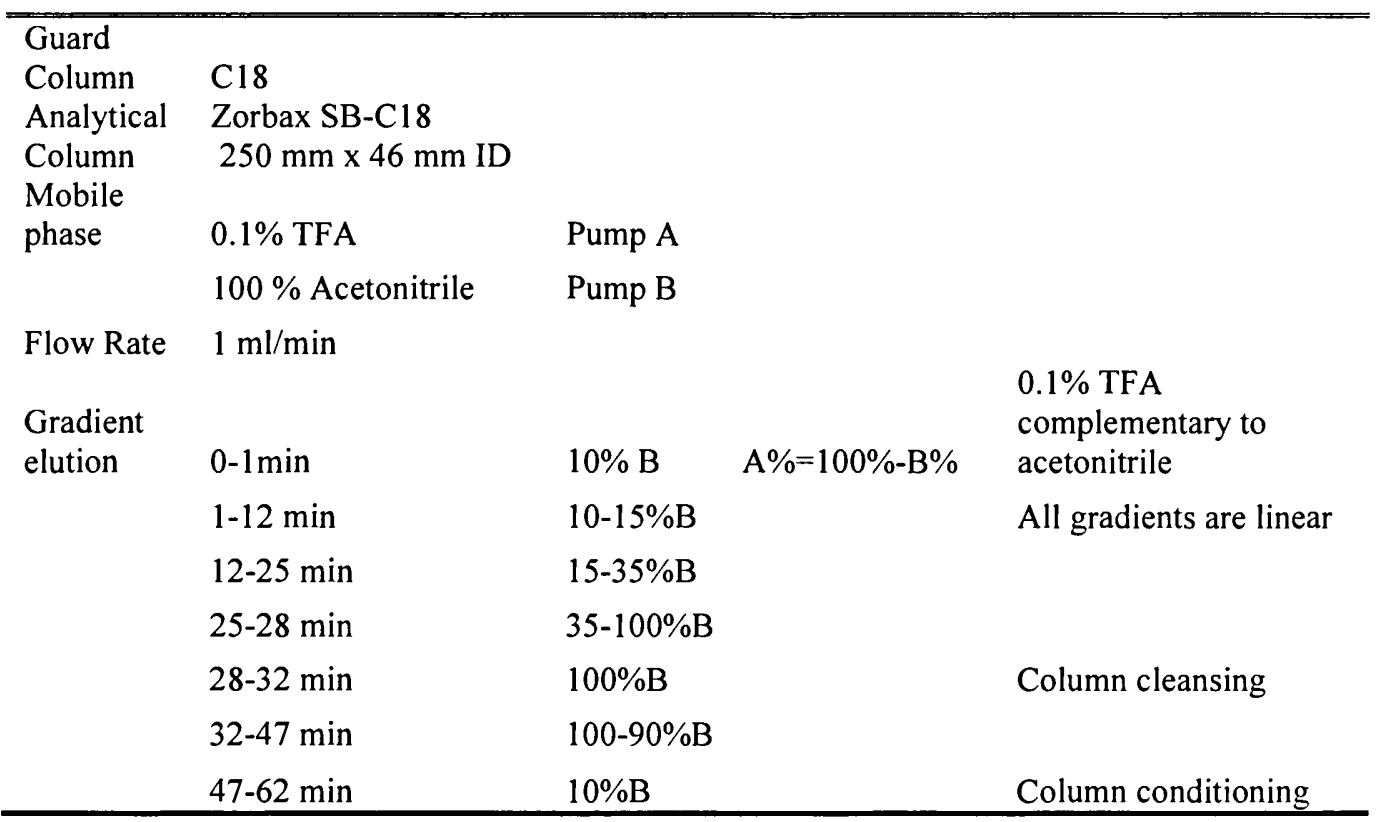

Surface waters were collected at the two sampling sites previously described in Chapter II (section 2.3.1.), and shown in Figure II-1, from canals located in Water Conservation Areas (WCA) 1A and 3A.

Water samples were collected and screened with a $105 \mu \mathrm{m}$ nylon filter to prevent the collection of large particles. No sample preservation was used. $250 \mathrm{ml}$ aliquots water samples were obtained after filtration through a $0.2 \mu \mathrm{m}$ nitrocellulose filter in order to pursue further analysis of thiols present in the dissolved phase.

For the collection of suspended particulate matter, $2 \mathrm{~L}$ of surface water were directly collected in a $2 \mathrm{~L}$ Teflon bottle. Within two hours of collection, the particulate from surface waters was collected by vacuum filtration of $250 \mathrm{ml}$ of water through a $47 \mathrm{~mm}$ Nucleopore nitrocellulose filter with a $0.2 \mu \mathrm{m}$ pore size. The filter was then placed 
in a $2 \mathrm{ml}$ centrifuge vial and kept frozen at $-4{ }^{0} \mathrm{C}$ until analysis. Filter blanks were subject to deionized water filtration, kept and analyzed in the same manner.

For the characterization of thiols in size-fractionated samples, larger volumes of water were needed for the analytical procedure; 2-20 L acid-cleaned polyethylene carboys were used for sampling. The $0.2 \mu \mathrm{m}$ filtered sample was then subjected to ultrafiltration.

\subsection{Preconcentration procedure}

Preconcentration steps were necessary to reach concentration levels above the detection limit of the chromatographic technique with fluorescence detection for thiol analysis in natural waters. After several trials, it was found that a preconcentration factor of forty or higher was necessary to achieve minimum concentration levels to improve the analytical properties. Several possible techniques could be used for reducing the original volume of the water sample containing the thiols. The most frequently used methods involve distillation, extraction and adsorption techniques. Some of these techniques were used in this study and their advantages and disadvantages for the analysis of thiols in water are briefly summarized in Table IV-3.

The thiol group is present in the aqueous dissolved organic matter matrix, probably as functionality in the branched structures (Filley et al., 2002). Low temperatures are required in order to avoid decomposition or oxidation of these natural compounds. Possible reactivity of thiol groups towards glass or metal containers must be considered as well, and time constraints are also to be taken into account. 


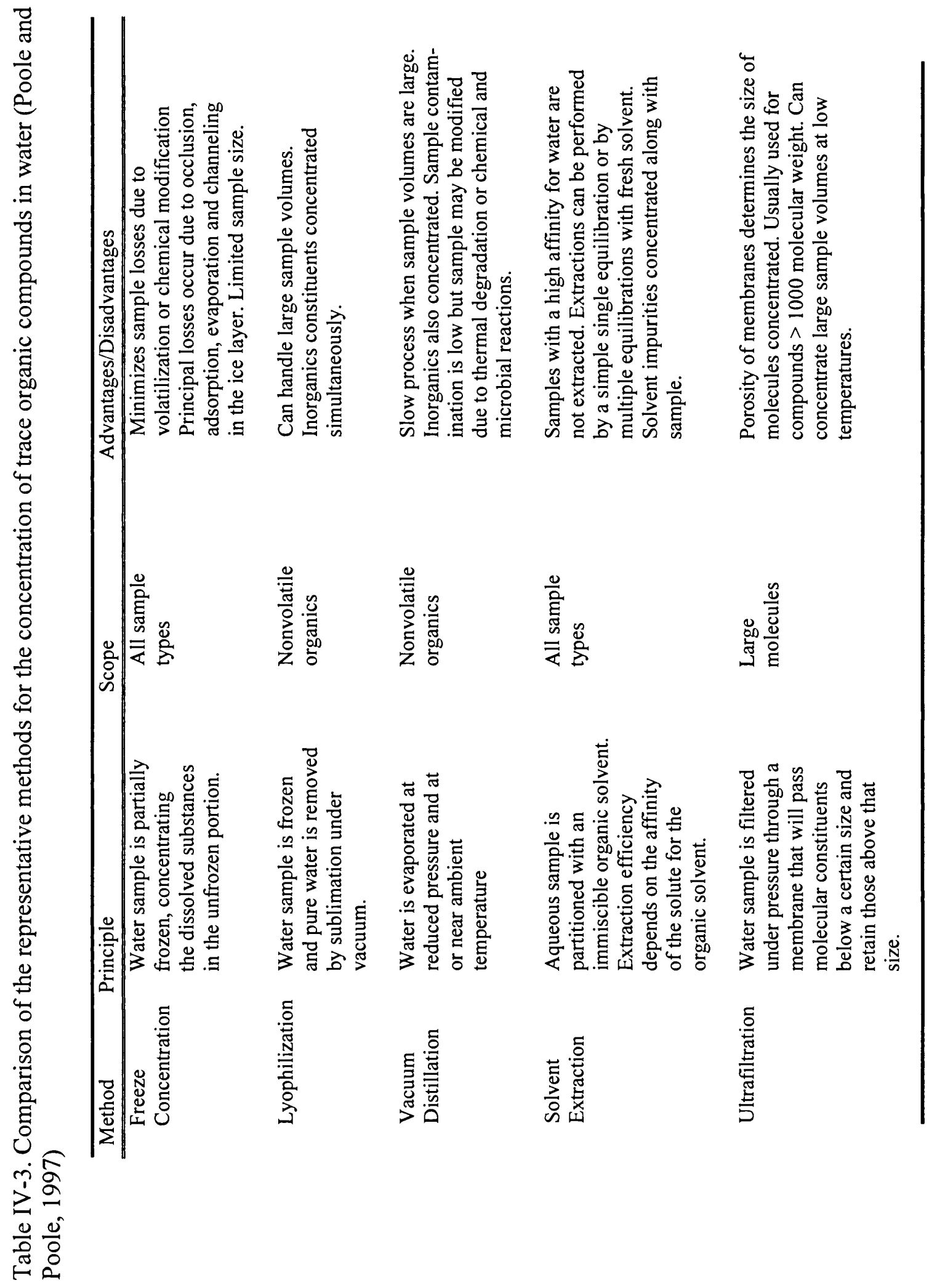




\subsubsection{Lyophilization (Freeze-drying)}

$250 \mathrm{ml}$ of water sample previously filtered with a $0.2 \mu \mathrm{m}$ nitrocellulose filter, were distributed into three $100 \mathrm{ml}$ wide-mouth polyethylene specimen container cup (125 $\mathrm{ml}$, Fisher Scientific), covered and frozen overnight; then they were placed into the freeze-dry container for four days until dryness. The solid dissolved organic matter (DOM) was placed into a $20 \mathrm{ml}$ polyethylene vial and reconstituted with $5 \mathrm{ml}$ of distilled deionized water to achieve a preconcentration factor of fifty.

\subsubsection{Rotary evaporation $\&$ lyophilization}

$250 \mathrm{ml}$ of water sample previously filtered with a $0.2 \mu \mathrm{m}$ nitrocellulose filter were placed into a round bottom flask and rotary evaporated at approximately $40{ }^{\circ} \mathrm{C}$ until reduced to approximately $20 \mathrm{ml}$. Then the sample was transferred into a $20 \mathrm{ml}$ polyethylene vial and frozen overnight, then placed in the freeze dry until dryness. The solid DOM obtained was reconstituted similarly to the previous case with $5 \mathrm{ml}$ of distilled deionized water, to achieve a preconcentration factor of 50. Due to the quick reduction of volume through evaporation, the freeze-drying process time was reduced significantly to 2 days.

The significance of the preconcentration techniques to the thiol analytical process lies in the fact that by reducing the volume we increase sensitivity by raising the concentration of the analyte. Due to the multi-step transfers involved in any of the preconcentration steps, these preliminary operations are considered the gross sources of accidental and systematic errors (Valcarcel, 2000). A systematic control of the instruments used was performed by testing the temperature readings, and quality control 
was achieved by performing several preconcentration processes to the same sample and by spiking the original matrix with known thiol concentrations.

\subsection{Ultrafiltration}

In order to obtain size-fractionated samples by ultrafiltration, two different molecular weight pore size membranes were used. The details concerning the processing of the samples by ultrafiltration were described previously in Chapter II (section 2.4). The concentration of thiols was determined in every fraction. Due to the low concentration of thiols present in freshwaters, the obtained size-fractionated samples were subject to rotary evaporation and lyophilization for preconcentration prior to analysis.

An Amicon ultrafiltration system (Amicon, MA) was used as previously illustrated in Figure II-3. The Diaflo nitrocellulose ultrafiltration membranes (Amicon, MA) YM3 and YM30 were used. The membranes provided the nominal molecular weight of $>3 \mathrm{KDa}$ and $>30 \mathrm{KDa}$, respectively. The treatment of the membranes before and after use was done following the steps outlined in Chapter II (section 2.4.1.).

\section{Results and Discussion}

\subsection{Conditions for the derivatization reaction}

\subsubsection{Termination of the reaction and derivative stability}

For quantitative analysis, acid was necessary to terminate the derivatization reaction and the products should be stable during the analysis. The samples derivatized with and without TBP, the reducing agent, were kept in the autosampler at $21{ }^{\circ} \mathrm{C}$ for 10 
days. The percent error (standard deviation divided by the mean) of the fluorescent peak height during that time should be low for all thiols, in any of the derivatization conditions (with or without TBP). A 3-days period adequately accounts for the analysis time for a large set of samples. In the present study, no significant changes in the fluorescence intensity of SBD-labeled thiol compounds were observed during storage of the reaction mixture for 1 week at $21^{\circ} \mathrm{C}$.

\subsubsection{Reduction of oxidized thiols by TBP}

Because thiol compounds are relatively unstable and easily converted to disulfides, and disulfides do not react with SBD-F, TBP is necessary for quantitative reduction of the disulfides previously to the assay of the thiols (both in macromolecules and in compounds of smaller molecular weight) with the fluorescent tag SBD-F. Oe et al (1998) demonstrated that TBP efficiently reduces oxidized thiols under similar conditions to these used in this study, and additionally it does not affect the recoveries of thiols. Compounds with sulfhydryl groups are known to be strong complexing ligands for some soft transition metals. It has been observed that some strong metal-thiolates are not reactive to the fluorescence tag when fluorometric techniques are applied (Tang, et al., 2000a), even in the presence of complexing agents such as EDTA or an effective reductant as TBP. It is known that EDTA has limited effects on the fluorescent signal when compared with TBP, this is so because EDTA is a weaker ligand than thiols for soft metals such as mercury and copper and TBP can reduce the formation of metal-thiolates cluster formation, particularly at high metal concentrations.

In the present experiment, the addition of TBP yielded higher fluorescence signals than in samples without the reducing agent. These results suggest that oxidized thiols do 
not react with SBD-F in the absence of TBP, and TBP efficiently reduces oxidized thiols under the present experimental conditions. Metal-thiol complexes in solution may be present as clusters or polymers (Bell and Kramer, 1999), TBP acts as a disulfide-cleaving agent as well as reducing the tendency for thiol cluster formation therefore making the metal-thiolates more accessible to the fluorescent tag, increasing the signal. Oxidized thiols may also occur as metabolites of the original thiols. SBD-F is useful for the determination of oxidized thiols by their reduction with TBP without interference.

\subsection{Thiol standards}

\subsubsection{Analysis of thiol standards}

HPLC with fluorescence detection was calibrated by the analysis of several thiol containing standards that can react with SBD-F to produce fluorescent SBD-thiolates, as previously described. Among the variety of available thiol standards that exists, several peptides dissolved in a DDI water matrix were initially used. Ten thiol standards (namely, ${ }_{\mathrm{L}}$-cysteine, ${ }_{\mathrm{L}}$-cystine, cystamine, ${ }_{\mathrm{L}}$-cysteinyl-glycine, cystathionine, ${ }_{\mathrm{L}}$ -

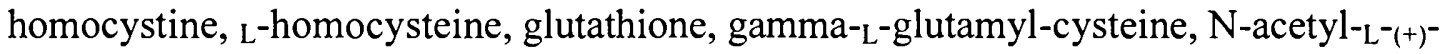
cysteine) were derivatized and analyzed. Most of these thiol standards are aminoacids, or n-peptides $(\mathrm{n}<3)$, that could be present in water. Proteins and aminoacids released are important sources of mineralizable nitrogen and sulfur. Most aminoacids are bound to organic polymers or organo-mineral complexes, because decomposers and autotrophs rapidly take up free aminoacids (Howarth et al., 1992).

Some of these primary analytical standards were not stable under normal environmental conditions, and they were kept in the refrigerated accordingly. Preparing a 
homogeneous and stable secondary standard solution was easy, since all standards are soluble in water. 5 ppm working standards solutions were derivatized with SBD-F and used for analysis immediately. As qualitative analysis, every standard was analyzed independently in order to obtain a clear identification of peaks.

Some standard thiols used, such as cystine, are disulfides that, without reduction, would not react with SBD-F. The effects of the presence and absence of the reducing agent TBP on the fluorescence signal of thiols in the derivatization of the different standards was examined. As an example, Figure IV-1 shows the chromatograms of SBDcystine derivatives with and without the addition of the reducing agent. Because SBD-F does not react with disulfides cystine was detected. If instead TBP is used as a reducing agent for disulfides, reduced thiol compounds are derivatized with SBD-F. The chromatogram shows clearly the formation of SBD-thiolates after the reduction of cystine. The most intense peak (Peak 1) can be identified as cysteine by comparison with the chromatogram of this standard. Two other unidentified peaks can be observed in this chromatogram, as products of the reduction-derivatization reaction of the original disulfide. The presence of multiple peaks for a single standard could be due to the presence of intermediates or side reaction products, as well as SBD-thiolate decomposition products. Any of these possibilities results in different retention characteristics in the chromatographic system.

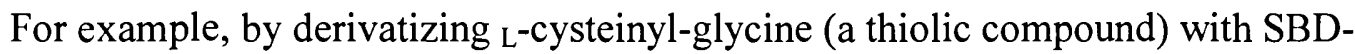
F, three peaks are observed (Figure IV-2) without the addition of the reducing agent. All three peaks result from thiols that appear to proceed from decomposition (e.g. cysteine) or rearrangement ( $\gamma$-glutamyl-cysteine) reactions, as deducted after comparison of these 


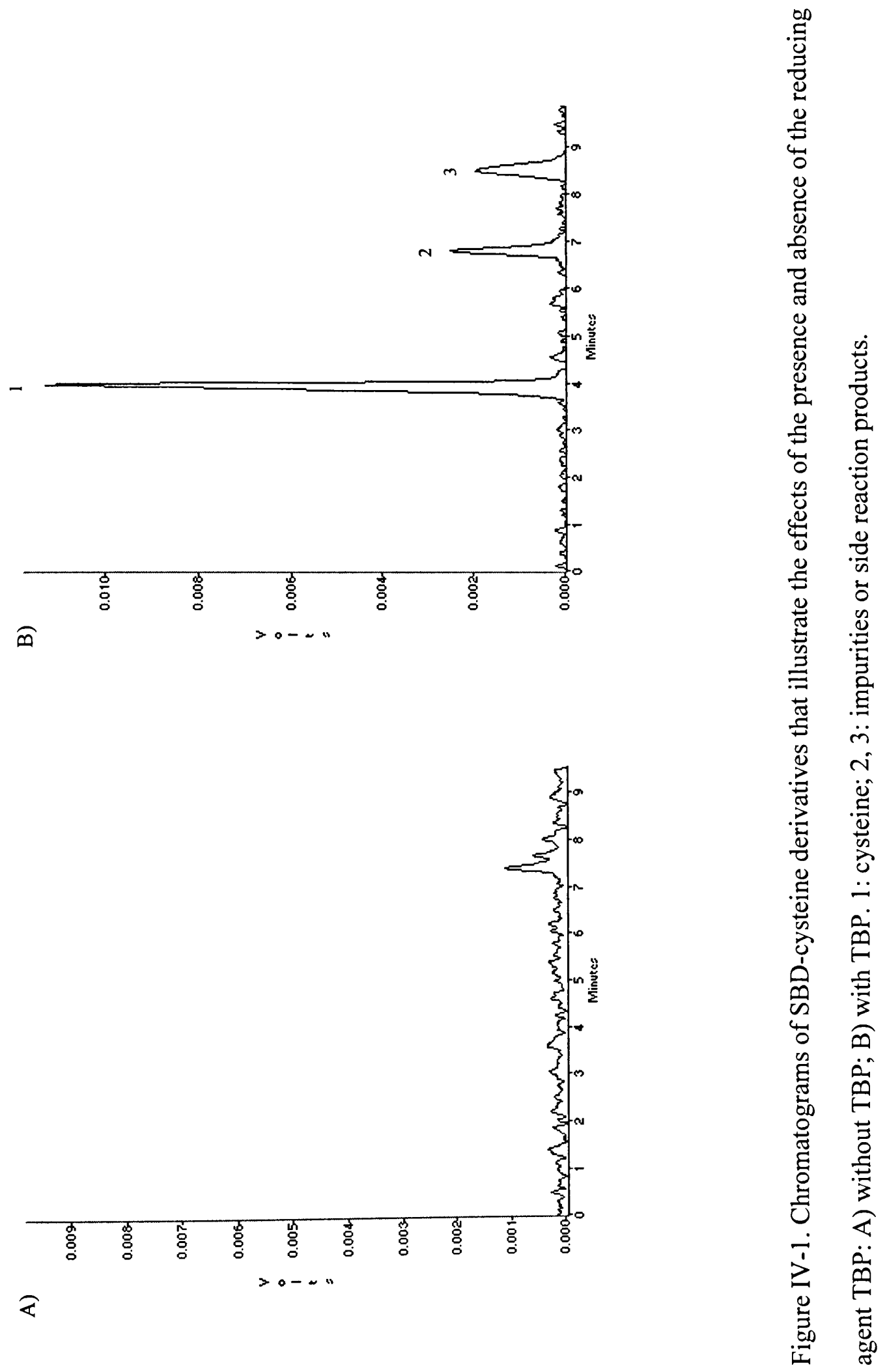




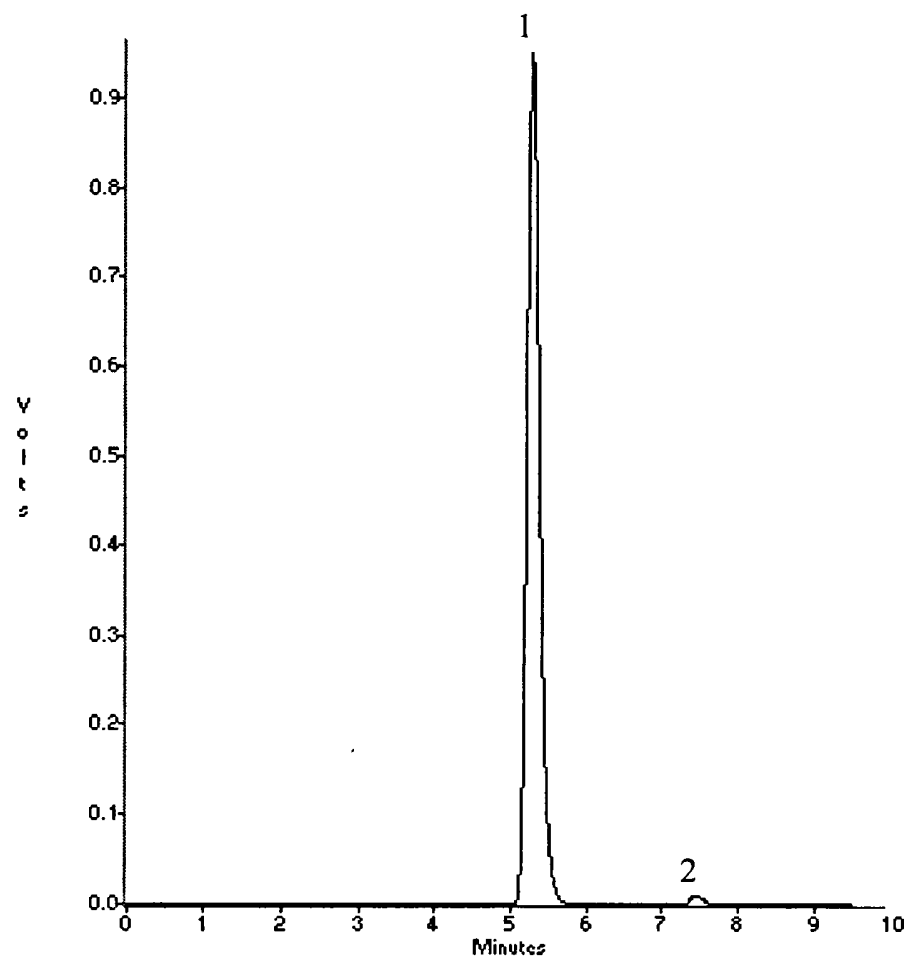

Figure IV-2. Chromatogram of $\mathrm{L}_{\mathrm{L}}$-cysteinyl-glycine shows 1 : SBD-L-cysteynil-glycine and 2: other product resulted from decomposition and/or rearrangement reactions, likely SBD- $\gamma$-L-glutamil-L-cysteine. 
additional peaks' retention times with those of the mentioned standards. No further changes were observed after the addition of the reducing agent to the ${ }_{\mathrm{L}}$-cysteinyl-glycine thiol standard. This confirms the lack of interference by TBP and SBD-F in the derivatization reaction, and points to minor decomposition of thiols as the origin of additional peaks in the chromatogram.

A chromatogram for multiple SBD-thiol standard derivatives is shown in Figure IV-3. The thiol standards used were chosen for comparison with previous studies of thiolic compounds in biological samples where SBD-F was used as derivatizing reagent (Imai and Toyo'oka, 1987). $50 \mu \mathrm{l}$ of the SBD-derivatized $1 \mathrm{ppm}$ solutions of cysteine, cystamine, homocysteine, glutathione and $\gamma$-glutamylcysteine were injected; this results in $124,90.5,122,70.7,86.9$ pmol of individual standard, respectively. Each thiol compound exhibited a sharp and symmetric peak and good separation from the other compounds. The sensitivity of the SBD-glutathione derivatives was higher than for cysteine. The fact that cysteine gives lower fluorescence than the other thiol compounds was also observed by Imai et al. (1983). This could be attributed to: (a) the lower yield of the reaction of cysteine with SBD-F; (b) the fluorescence quantum yield of the product is lower; (c) the lower stability of the product; and (d) cysteine itself decomposes faster than the other thiol compounds under the reaction condition.

\subsubsection{Calibration curve of thiol standards}

Figure IV-4 shows the calibration curve of three relevant low-molecular weight thiol standards in the presence of the reducing agent TBP. The calibration graphs for thiol compounds examined in the range $3.54 \mathrm{pmol}$ to $1 \mathrm{nmol}$ showed excellent linearity for all 


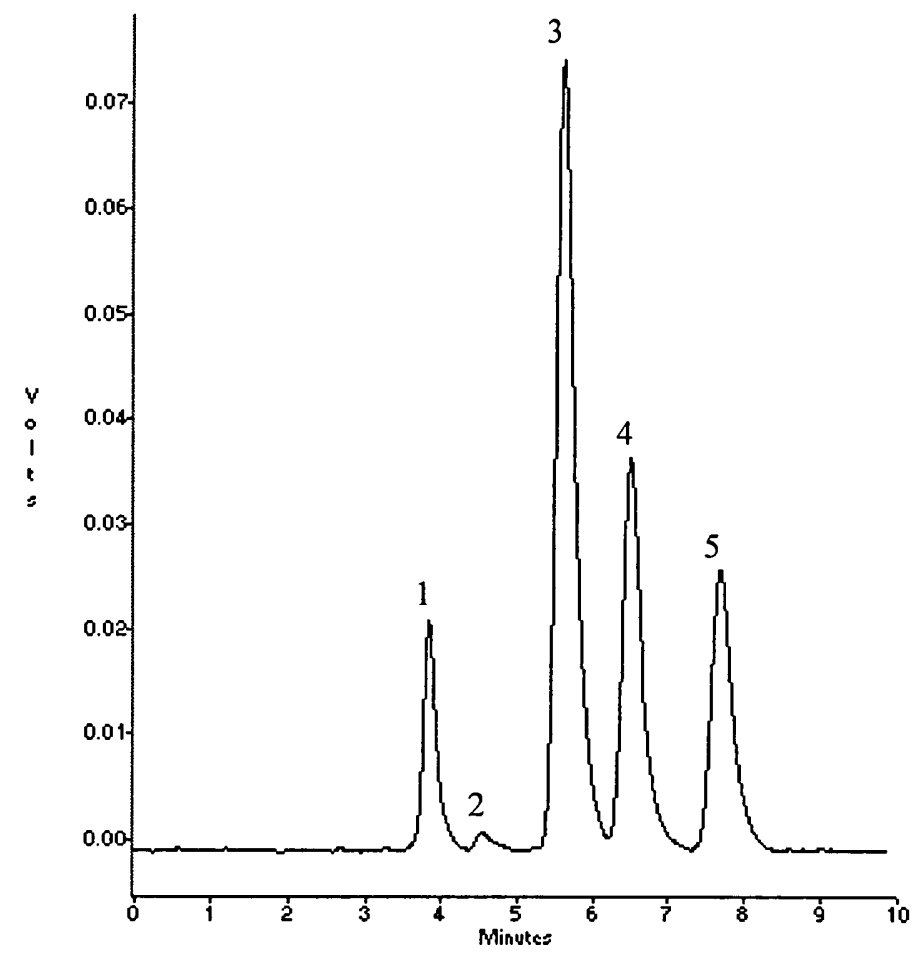

Figure IV-3. Chromatogram of multiple SBD-thiol standard derivatives.

$1:{ }_{\mathrm{L}}$-cysteine; 2 : cystamine; $3:{ }_{\mathrm{L}}$-homocysteine; $4:$ glutathione; $5: \gamma-\mathrm{L}$-glutamil- $\mathrm{L}_{\mathrm{L}}$ cysteine. 
three compounds. The coefficients of correlation between amounts of these thiol compounds and observed peak heights were in the range from $r^{2}=0.9953$ to 0.9999 .

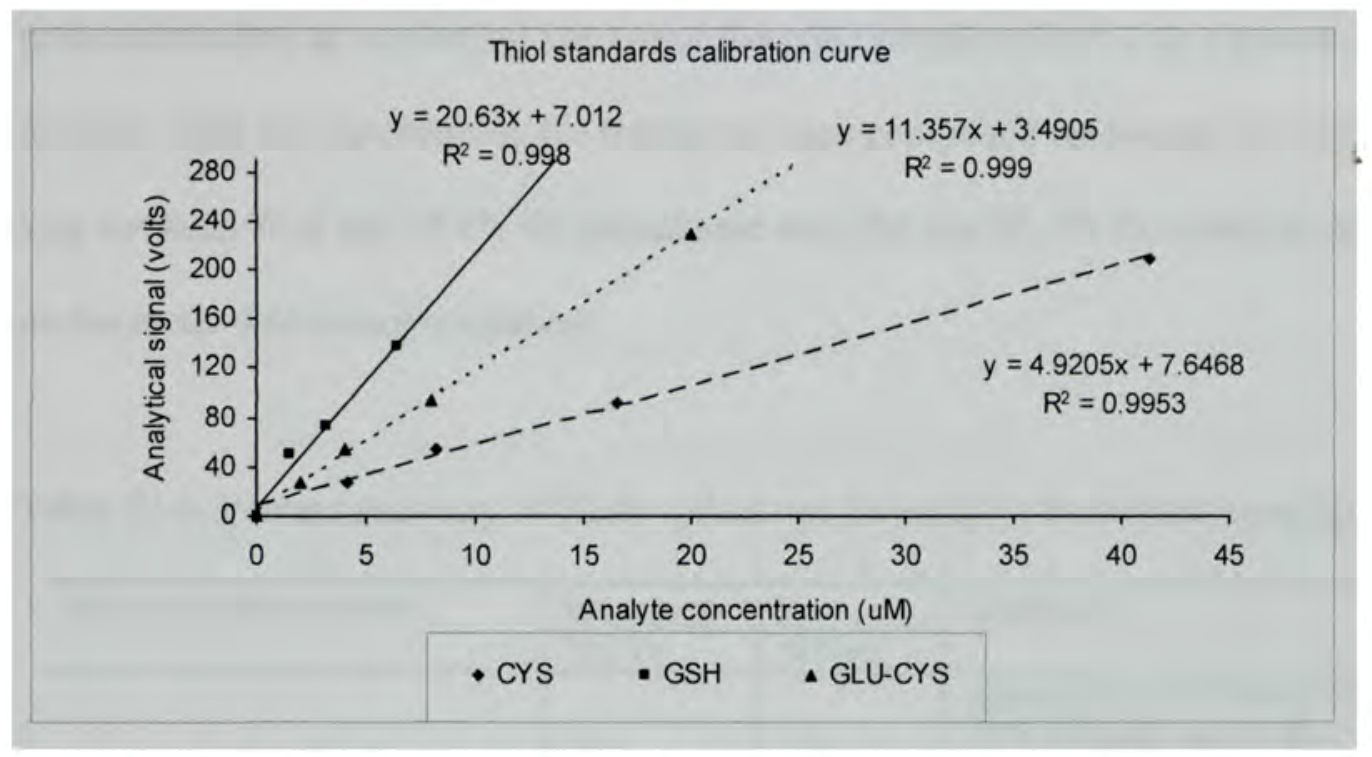

Figure IV-4. Calibration curves of three low-molecular weight thiols.

For the three standards shown as references the upper limit of the linear range is reached around $0.7 \mathrm{nmol}$ for glutathione and $\gamma$-glutamyl-cysteine and higher for cysteine ( $2 \mathrm{nmol})$, for a $50 \mu \mathrm{L}$ injection. At concentrations above the mentioned values, the curve is no longer linear. The calibration curves generated were linear at least between 4.35 pmol and $0.7 \mathrm{nmol}$ for GSH and $\gamma$-GLU-CYS and at least $2 \mathrm{nmol}$ for cysteine. The detection and quantitation of thiols can be achieved in a broad linear range by this method, which therefore can be used for a variety of samples.

\subsubsection{Recovery of thiol standards}

Table IV-4 shows the percentage recoveries for the thiols spiked into the Everglades water samples, preconcentrated by two different methods. The quality control 
for the preconcentration method was established by determination of percent recoveries for each method. The percent recovery was determined for each sample by preconcentrating an equivalent volume of the same sample spiked with a known amount of GSH, CYS and determining the fraction of each compound recovered. The recoveries vary between 76.8 and $37.1 \%$ for glutathione and 70.6 and $63.2 \%$ for cysteine, depending on the method of preconcentration.

Table IV-4. Percent recovery of thiols spiked into Everglades freshwater samples.

\begin{tabular}{c|l|l|l}
\hline Preconcentration method & \multicolumn{2}{|l|}{ Percent recovery } & Comments \\
\cline { 2 - 4 } & $\%$ CYS & $\%$ GSH & \\
\hline Freeze-drying & 63.2 & 37.1 & $\begin{array}{l}\text { Spiked 0.83 \& 0.32 nM CYS and } \\
\text { GSH standards to 250 ml, } \\
\text { concentrated to 33 ml and analyzed } \\
\text { directly }\end{array}$ \\
\hline Rotary Evaporation & 70.6 & 76.8 & $\begin{array}{l}\text { Spiked 0.83 \& 0.32 nM CYS and } \\
\text { GSH standards to 1000 ml, } \\
\text { concentrated to 30 ml, and analyzed } \\
\text { directly. }\end{array}$ \\
\hline
\end{tabular}

NA - not analyzed.

In addition, the method recovery was determined in a different way to evaluate the analytical method performance. A thiol standard spike was added to a preconcentrated sample and subjected to analysis to determine the percentage of recovery. By using this approach, the matrix effects can be evaluated, as well as the derivatization reaction. For simplicity, only two standards were spiked: cysteine and glutathione that were previously found to be relevant thiols in natural water samples (Tang et al., 2000a). The results are presented in Table IV-5. 
Table IV-5. Percent recovery of relevant thiols spiked into preconcentrated natural water samples and suspended particulate

\begin{tabular}{l|l|l}
\hline \multirow{2}{*}{ Matrix } & \multicolumn{2}{|c}{ \% Recovery } \\
\cline { 2 - 3 } & Cysteine & Glutathione \\
\hline Water & 89.3 & 83.2 \\
\hline SPM & 75.1 & 42.8 \\
\hline
\end{tabular}

Because of the low concentration of thiols found in natural water samples, large volumes of samples were handled, and the process was slow. Additionally, both preconcentration techniques concentrate the inorganic components simultaneously, and sample may be modified by thermal degradation. Other preconcentration techniques may overcome these disadvantages such as freeze concentration, where the sample is partially frozen and the dissolved substances are concentrated in the dissolved portion, which would minimize the losses due to volatilization or chemical modification. Cross-flow ultrafiltration, where constituents above a certain size are retained, can concentrate large sample volumes at low temperatures and desalting is easily achieved. New preconcentration techniques are necessary to improve the recoveries of thiols.

\subsection{Thiols in natural samples}

\subsubsection{Thiols in surface waters}

Figure IV-5 shows the results for thiol analysis in surface water from the Everglades after freeze-drying preconcentration. It can be seen that thiol-SBD fluorescent derivatives cannot be determined in the preconcentrated water sample without addition of the reducing agent TBP (Figure IV-5A). This analysis shows the presence of oxidized thiols that may occur by reduction of disulfide, because of the presence of new peaks 

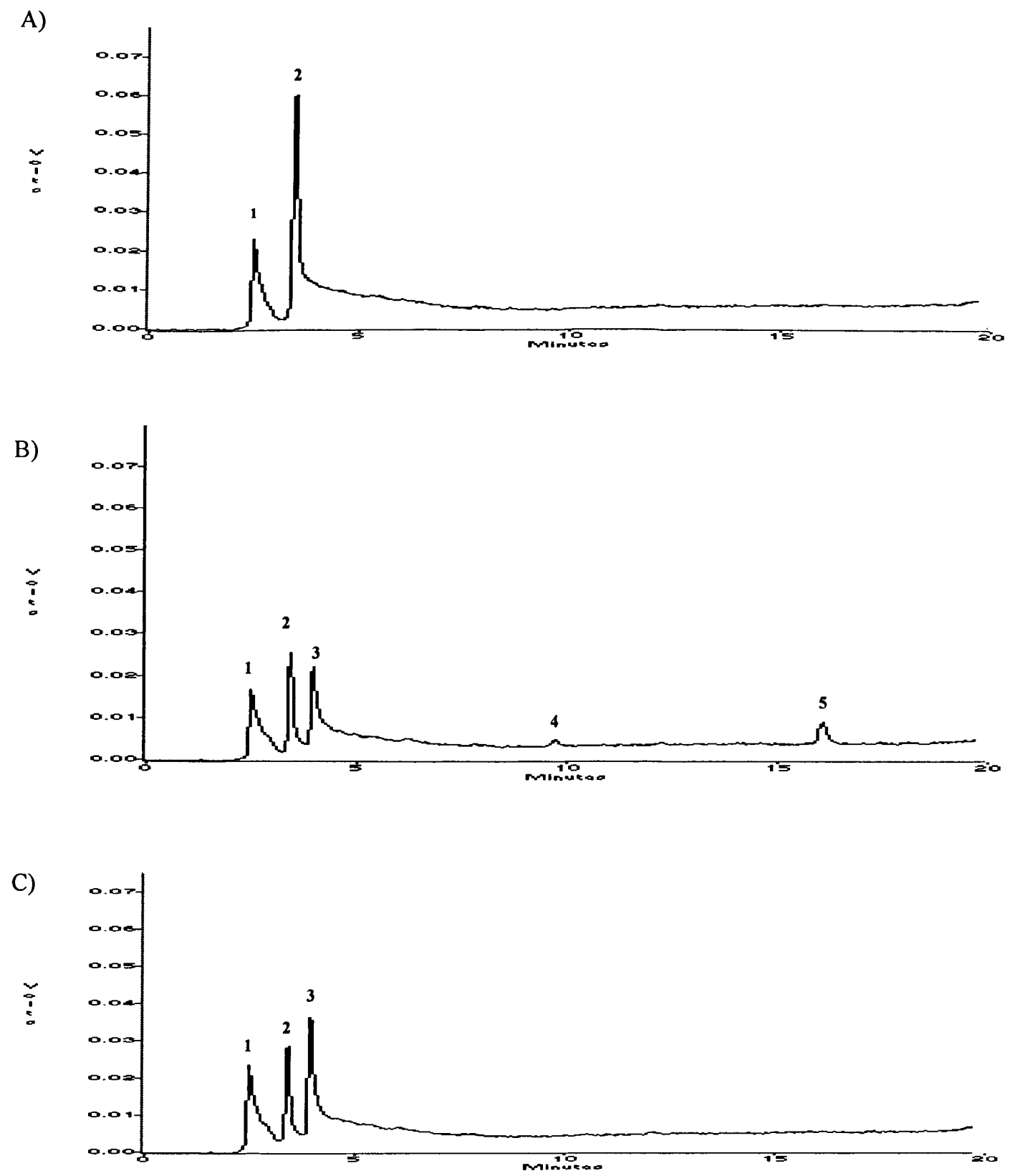

Figure IV-5. Determination of thiols and disulfides in a natural preconcentrated water sample collected in the Florida Everglades. A) Derivatized sample without reduction; B) Derivatized sample after reduction with TBP; C) Natural freshwater sample blank, treated in the same manner as the latter but without the fluorogenic tagging reagent (SBD-F). 
after reduction (Peaks 4 and 5, Figure IV-5B). The presence of oxidized thiols in this sample could be expected because these are surface waters in oxic conditions with only anoxic microenvironments that could hold thiolic reduced species. The sample blank chromatogram (Figure IV-5C) was included for comparison purposes. Some of the peaks (peaks 1 to 3, in Figure IV-5B) detected by fluorescence correspond to some natural occurring fluorophores present in the DOM that interfered with this reaction.

The derivatization procedure involved several steps, including $\mathrm{pH}$ adjustment, reduction and labeling. These steps may also induce interferences, which in turn could interfere the determination of thiols in the samples. In order to assure correct interpretation of the results, the multistep derivatization was investigated by isolating each step.

The original preconcentrated sample was subject to thiol analysis by HPLC as described previously. 4-200 $\mu \mathrm{l}$ aliquots were analyzed in order to determine several factors:

Trial 1 (sample blank): Original sample without any of the derivatization reagents but diluted accordingly with deionized water, i.e. wherever reagents used, DDIW was added instead. This sample was meant to evaluate the effect of the different reagents in the matrix, if any, and the natural sample fluorescence of the compounds dissolved in the natural water.

Trial 2 (matrix + reagent blank): Original sample, without adding the derivatizing reagent SBD-F, undergoing all the rest of steps, including reduction, $\mathrm{pH}$ adjustment, reaction at $60^{\circ} \mathrm{C}$ for 60 minutes and final acidification to stop the reaction. The purpose of analyzing this sample is to ensure adequate matrix sample-blank, and being able to 
evaluate the fluorescence background adequately. The fluorescence signals observed in this case, if any, may represent naturally occurring fluorescent compounds, and those induced by the multistep reaction, but not thiols and disulfides.

Trial 3 (original sample derivatized, but not reduced): The fluorophore tag was added, therefore thiols are to be detected but the lack of a reductant means that the thiols oxidized or clustered species cannot be determined due to their lack of ability to react with SBD-F.

Trial 4 (original sample derivatized with SBD-F, reduced with TBP, buffered at $\mathrm{pH}$ 9.5): This process will determine all the thiol and oxidized thiols (disulfides) species present in the water sample. The fluorescence signals include those from some natural occurring compounds and those from reagents, if any.

From the matrix blank (Trial 1) (chromatogram shown in Figure IV-6A) it can be seen that there are a number of peaks in the retention time range from two to four minutes. Because the sample was not treated with any reagents, these peaks are not thiolic compounds or thiols with fluorophores. They are interferences from the original sample. It is well known that DOM present in natural water samples produces fluorescence and fluorescence spectroscopy has been used to provide qualitative and quantitative information on the DOM (Lu and Jaffe, 2001).

The experimental conditions for fluorescence detection call for an excitation wavelength $385 \mathrm{~nm}$ and an emission wavelength of $515 \mathrm{~nm}$ for the detection of the SBD-thiolates after derivatization of the natural water samples. These conditions are in the range of maximum excitation and emission wavelengths of the natural fluorophores present in the DOM water sample matrix (Clark et al., 2002), therefore some fluorescence from the 

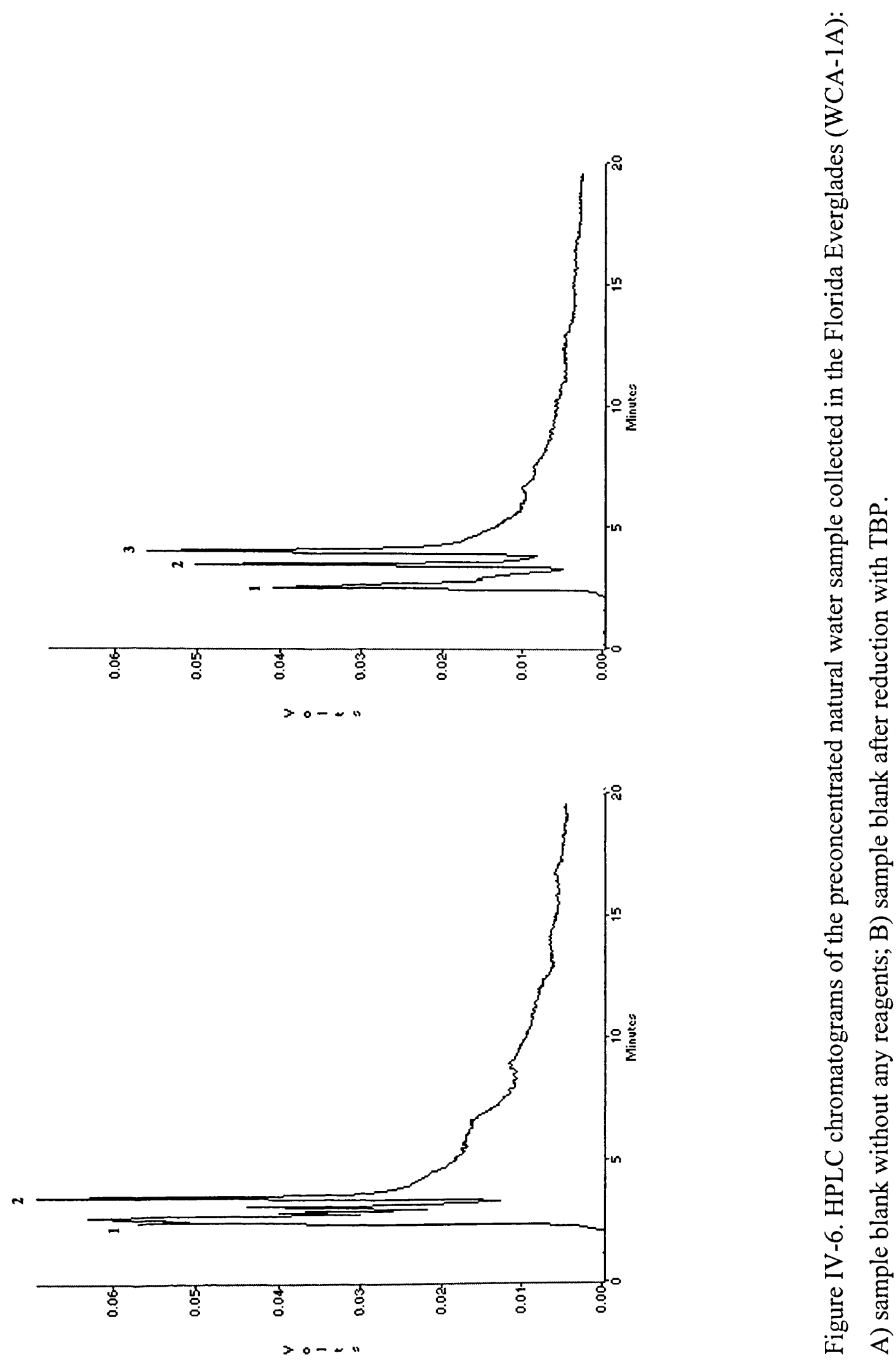
natural matrix could interfere with our thiol fluorescence detection. The chromatographic analysis of the sample that underwent all the reaction steps, including reduction with TBP, $\mathrm{pH}$ adjustment to 9.5 with a borate buffer, heating for $60 \mathrm{~min}$ at $60^{\circ} \mathrm{C}$ and final acidification to $\mathrm{pH} 2$ to $\mathrm{HCl}$, but without SBD-F derivatization (Trial 2) is shown in Figure IV-6B. Compared to the sample blank (Figure IV-6A) new fluorescent species appeared on the chromatogram. Since these peaks appeared in the matrix + reagent blank, they interfered the thiol compound determination. The fact that they appear after the addition of the reducing agent TBP means that this unknown interference was likely to be an oxidized species that reacted with TBP generating a new fluorescent compound. It is also possible that the $\mathrm{pH}$ treatments produce this new species. No further effort was made to investigate their exact source.

The HPLC chromatograms of the thiol SBD-F derivatives in preconcentrated (by rotary evaporation) water samples collected in the Florida Everglades) are shown in Figure IV-7. There are several peaks observed. Two peaks were observed in the derivatized sample without reduction (Figure IV-7A) (Trial 3). By comparison with the chromatogram from the sample blank (Figure IV-6A), these interferences appear at the same retention times with or without derivatization. The fluorescent compounds in the DOM seemed not to be affected by the presence of the thiol-specific reagent SBD-F, instead reduction or $\mathrm{pH}$ adjustment appear to be the main factors for the natural fluorophore groups fluorescence. This implies that these interferences possess a nonthiolic nature. They may be aromatic moieties present in DOM.

By comparison of the chromatogram from the samples with complete derivatization (Figure IV-7B, Trial 4) and the derivatization without reduction (Figure IV-7A), we 


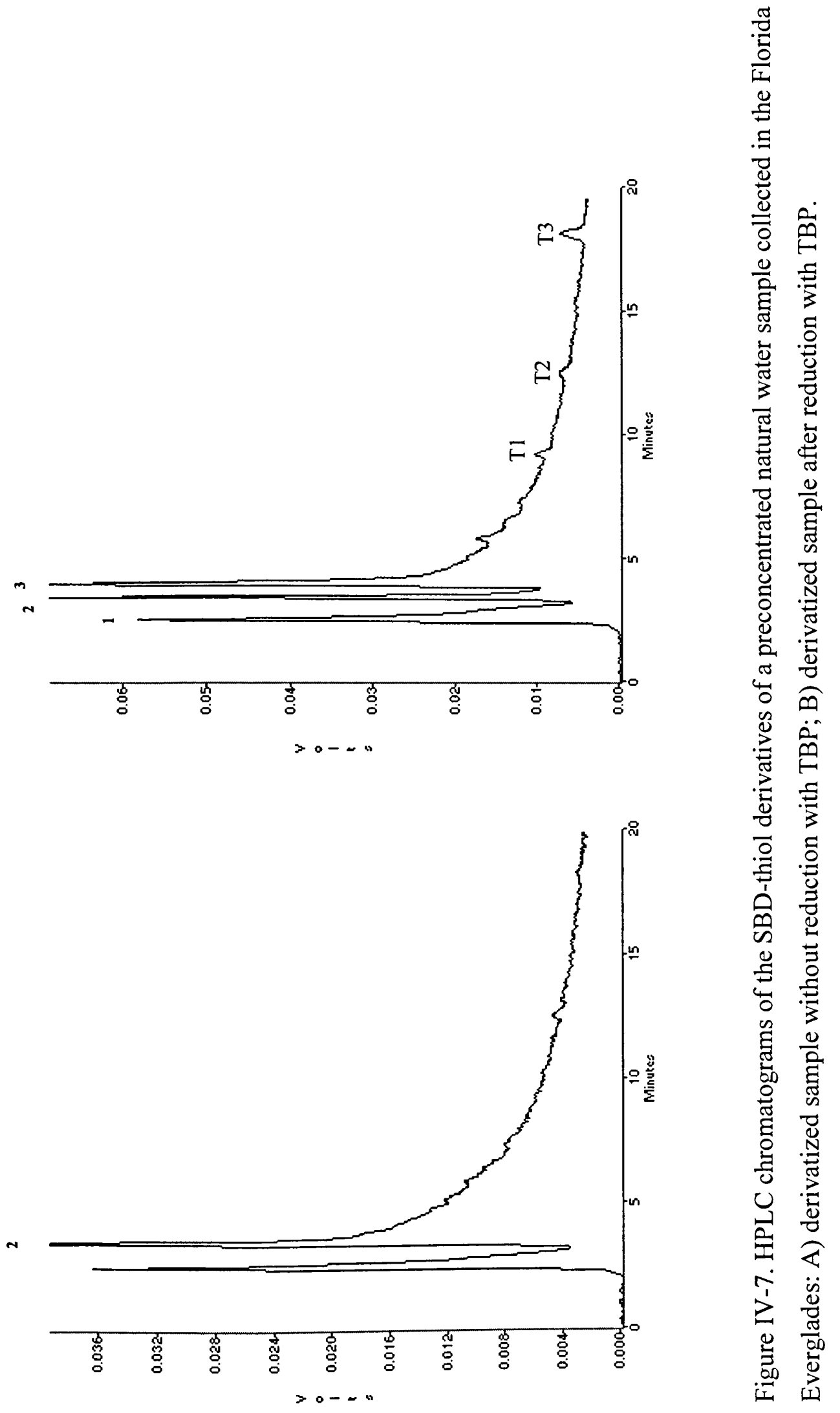


observed several peaks not observed previously in the sample blank chromatograms (Figure IV-6). The chromatogram for the derivatized sample after reduction (Figure IV7B) shows three peaks ( $\mathrm{T} 1, \mathrm{~T} 2 \& \mathrm{~T} 3)$ at later retention times that correspond to unknown thiolic compounds in oxidized forms, since they were obtained after reduction with TBP. These peaks did not appear without reduction or without the reaction with the derivatizing reagent SBD-F. This reagent is strong enough to replace weak metal-thiol complexes, but not strong enough to replace the soft metal complexed thiols (Tang et al., 2000a). TBP is needed to split the metal-thiol clusters into pieces in order for SBD-F to react with the sulfhydryl group of thiols. Therefore, these new peaks resulted from thiolic compounds present in the DOM. They were previously sterically hindered for reaction with SBD-F or alternatively, the thiols could be strongly bound to metals as metalthiolates-DOM complexes that will impede the reaction due to their greater stability.

It can be concluded that the last three peaks are likely SBD-thiolates originated from reactive or labile-thiols in oxidized forms present in surface waters of the Florida Everglades. It is impossible to assess the presence of other earlier outgoing thiols due to strong interference peaks from the matrix in the first minutes. By comparison of these sample chromatograms with those of different thiol standards no conclusion can be drawn about the identity of the three reactive oxidized thiols found in the water.

By applying the previously described calibration and using GSH as reference standard the following values were found for natural water total thiol levels in two locations in the Florida Everglades: $149 \pm 13 \mathrm{pM}$ (as GSH) for WCA-3A and $215 \pm 9 \mathrm{pM}$ (as GSH) for WCA-1A. Concentration of mercury in the Everglades is around $10 \mathrm{pM}$. Because of the strong binding capability of thiols to mercury, it appears that the 
interactions between mercury and thiols may play an important role in the biogeochemistry of mercury in this aquatic system. Since the thiol species present in water are oxidized, it is proposed that the following reactions are likely to occur with mercury species:

$$
\begin{aligned}
& \mathrm{RSSR}+\mathrm{Hg}^{2+} \rightarrow(\mathrm{RS})_{2} \mathrm{Hg} \\
& \mathrm{RSSR}+\mathrm{CH}_{3} \mathrm{Hg}^{+} \rightarrow 2 \mathrm{RSCH}_{3} \mathrm{Hg}
\end{aligned}
$$

\subsubsection{Thiol-characterization of size fractionated samples}

It was indicated in Chapter II that certain size fractions of DOC are more reactive with mercury. The determination of thiols in selected molecular size fractions could lead to further understanding of mercury-DOC interactions. Samples from two locations in the Florida Everglades were size-fractionated as previously described by using two ultrafiltration nitrocellulose membranes $(30 \mathrm{KDa}$ and $3 \mathrm{KDa})$. Molecular weight fractions were preconcentrated using rotary evaporation and freeze-drying and derivatization of the thiols present in these samples was achieved. Three unknown thiol compounds were present in the surface waters of both sites studied.

Figure IV-8 shows the results for the determination of thiols in the truly dissolved fraction $(<3 \mathrm{KDa})$ collected in WCA-1A. Contrary to what was observed previously, a very small amount of a SBD-thiolate could be detected without addition of the reduction agent TBP (Figure IV-8B). Peak T1 corresponds to a reduced thiol present in the natural freshwater. This analysis shows that most of this thiol was present in the water in disulfide form (oxidized thiol) because a much intense peak was observed at the same retention time (Figure IV-8C) as peak T1 after reduction. The proportion of the reduced thiol to oxidized thiols in the truly dissolved fraction is less than $20 \%$. This proves that 

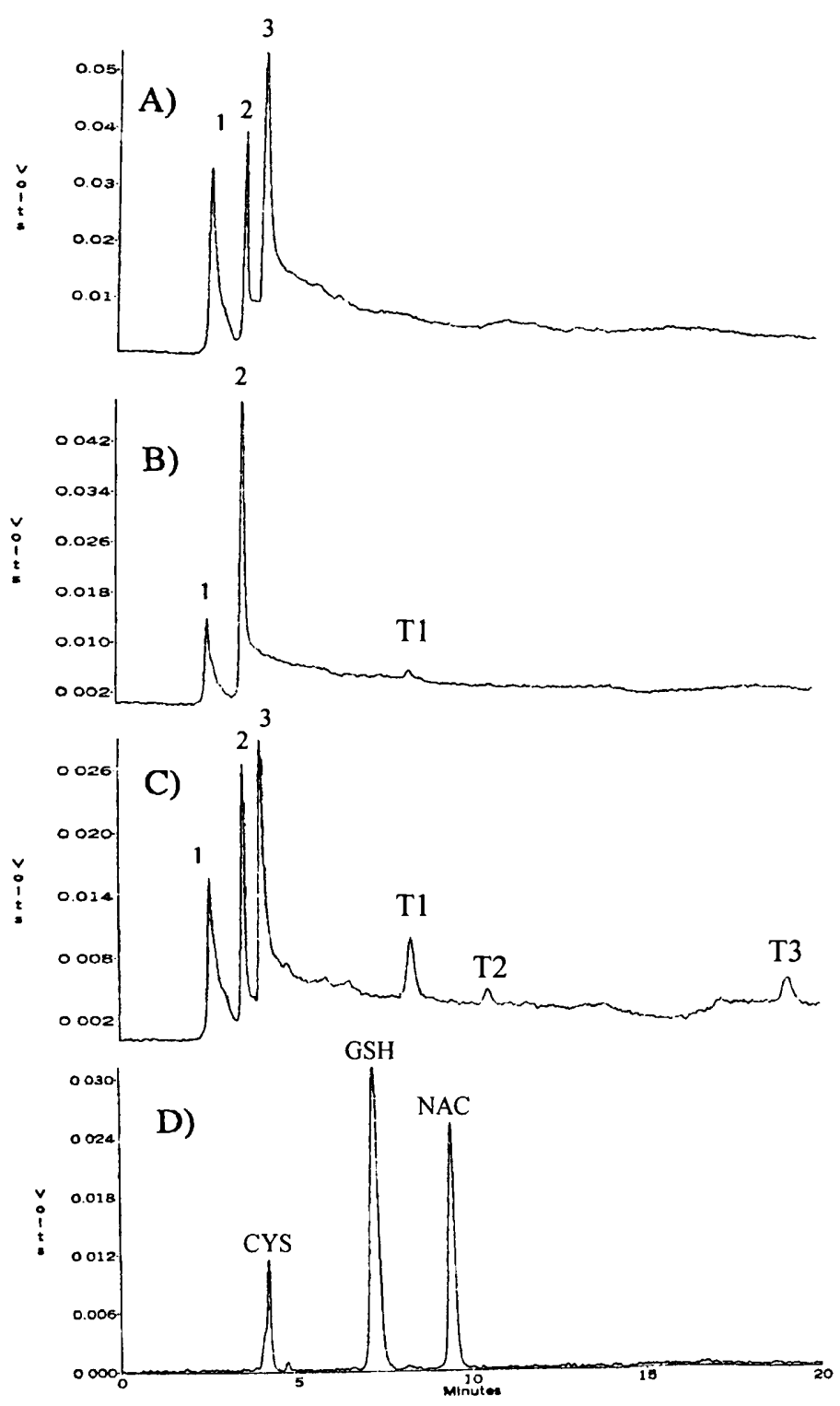

Figure IV-8. Determination of thiols and disulfides in the truly dissolved fraction $(<3 \mathrm{KDa})$ of preconcentrated natural water sample collected in the Florida Everglades (WCA-1A). A) Natural sample blank, reduced with TBP but without the fluorogenic tagging reagent (SBD-F); B) Reduced thiols in the derivatized sample obtained without adding TBP; C) Oxidized thiols, derivatized sample after treatment with TBP; D) Mixture of three standards: cysteine, glutathione and N-acetyl-cysteine. 
surface waters in oxic conditions may hold thiolic reduced species only in an anoxic microenvironment.

Table IV-6 summarizes the average concentrations of three unidentified thiols labeled as peaks $\mathrm{T} 1, \mathrm{~T} 2$ and $\mathrm{T} 3$, respectively) in the different molecular weight fractions of the DOC. The thiols in the dissolved fraction $(<0.2 \mu \mathrm{m})$ represented $58.9-72.0 \%$ of the total thiols in the sample; therefore most of these thiols in the Everglades freshwater were associated with the dissolved fraction. The distributions of the different thiols in different molecular weight cut off fractions are also shown in Table IV-6. The data shows that the truly dissolved fraction $(<3 \mathrm{KDa})$ contains the majority of the total dissolved thiols. The thiol content in the colloidal fraction $(0.2 \mu \mathrm{m}-3 \mathrm{KDa})$ constitutes only a small portion of the total dissolved thiols.

It should be pointed out that, besides the errors introduced by the preconcentration steps, the derivatization steps for the analysis of thiols and oxidized thiols in water samples have several potential concerns that would require further study. First, thiols with large molecular weight may be eliminated during the sample preparation steps (e.g. $\mathrm{pH}$ adjustment, centrifugation), even though they may play an important role in the interaction between DOM and mercury. Second, the SBD-F reactivity of thiols bound to soft metals in the presence of TBP is not clear.

\subsubsection{Alternative preconcentration technique for water sample}

Cross-flow ultrafiltration was tried as an alternative preconcentration technique for one sample. $100 \mathrm{~L}$ of water were filtered through a $3 \mathrm{KDa}$ nitrocellulose membrane cartridge and the non-pass filter portion (retentate) concentrated to $0.7 \mathrm{~L}$. This process 
included a rinsing step with DDIW for desalting. The sample obtained was free of particles and 


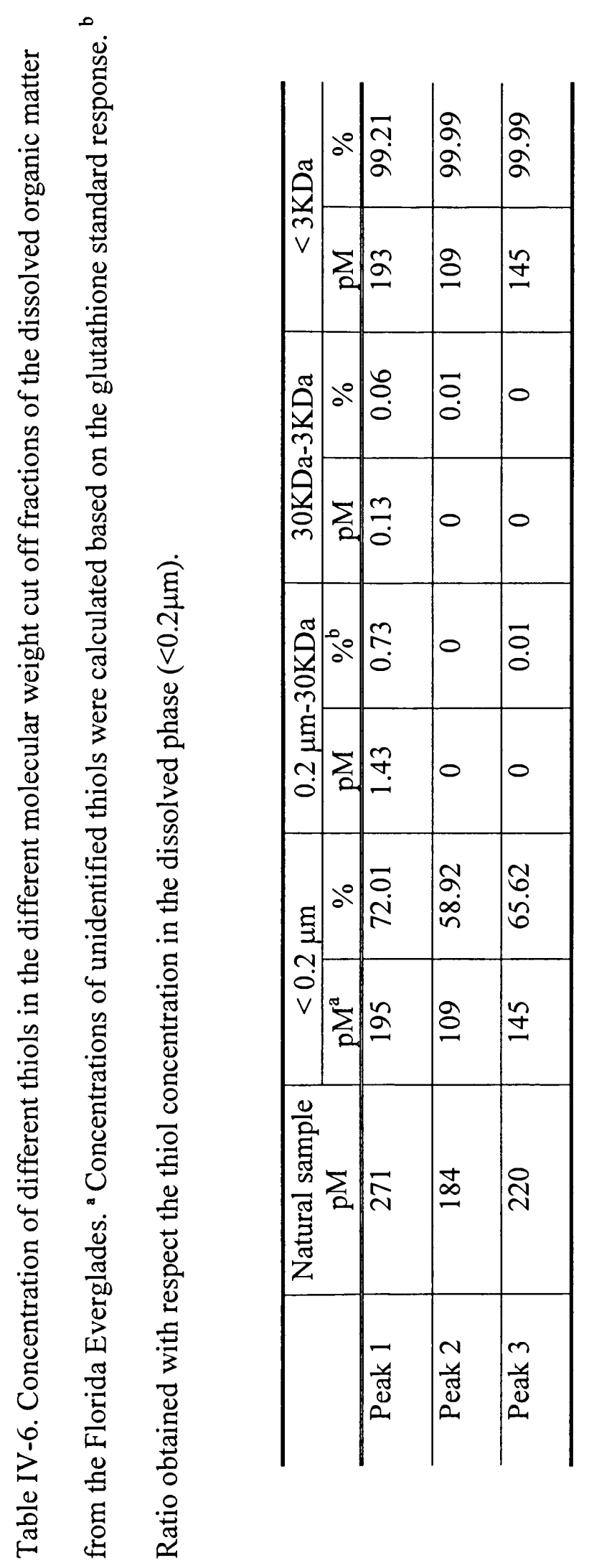


clear, with a preconcentration factor of 140 , more than 3 times higher than achieved by the methods described previously. This preconcentration process has the additional advantage of taking place at low temperature. The process is relatively fast ( 8 days) and requires monitoring of the retentate to avoid dryness. An aliquot of this preconcentrated sample was derivatized and analyzed, and the resulting chromatogram is presented in Figure IV-9. This is a very promising preconcentration technique for its simplicity and for the possibility of preconcentrating thiols of different molecular size ranges.

\subsubsection{Thiols in suspended particulate matter}

This analytical method was applied to the determination of thiol compounds in particulate $(\geq 0.2 \mu \mathrm{m})$ from surface waters from the Florida Everglades. The present method allows the measurement of low molecular mass thiols in the particulate. Chromatograms of particulate extracted from waters obtained from the WCA-1A are shown in Figure IV-10. A good separation without interfering peaks was achieved.

Cysteine and glutathione standards derivatized with MSA for the quantification of thiols in the particulate for natural water samples were used because they have been proved to be relevant thiols in the particulate of natural coastal waters (Tang et al, 2000a). The standards were initially prepared without MSA, since this acid is used to precipitate proteins present in solution. It was noted that these standards had a longer retention time than that derivatized with an additional $20 \mu \mathrm{l}$ of MSA (1M) to equal the MSA concentration in the supernatant of the derivatized filters. In Figure IV-10 we can identify two peaks corresponding to cysteine and glutathione present in the particulate. 

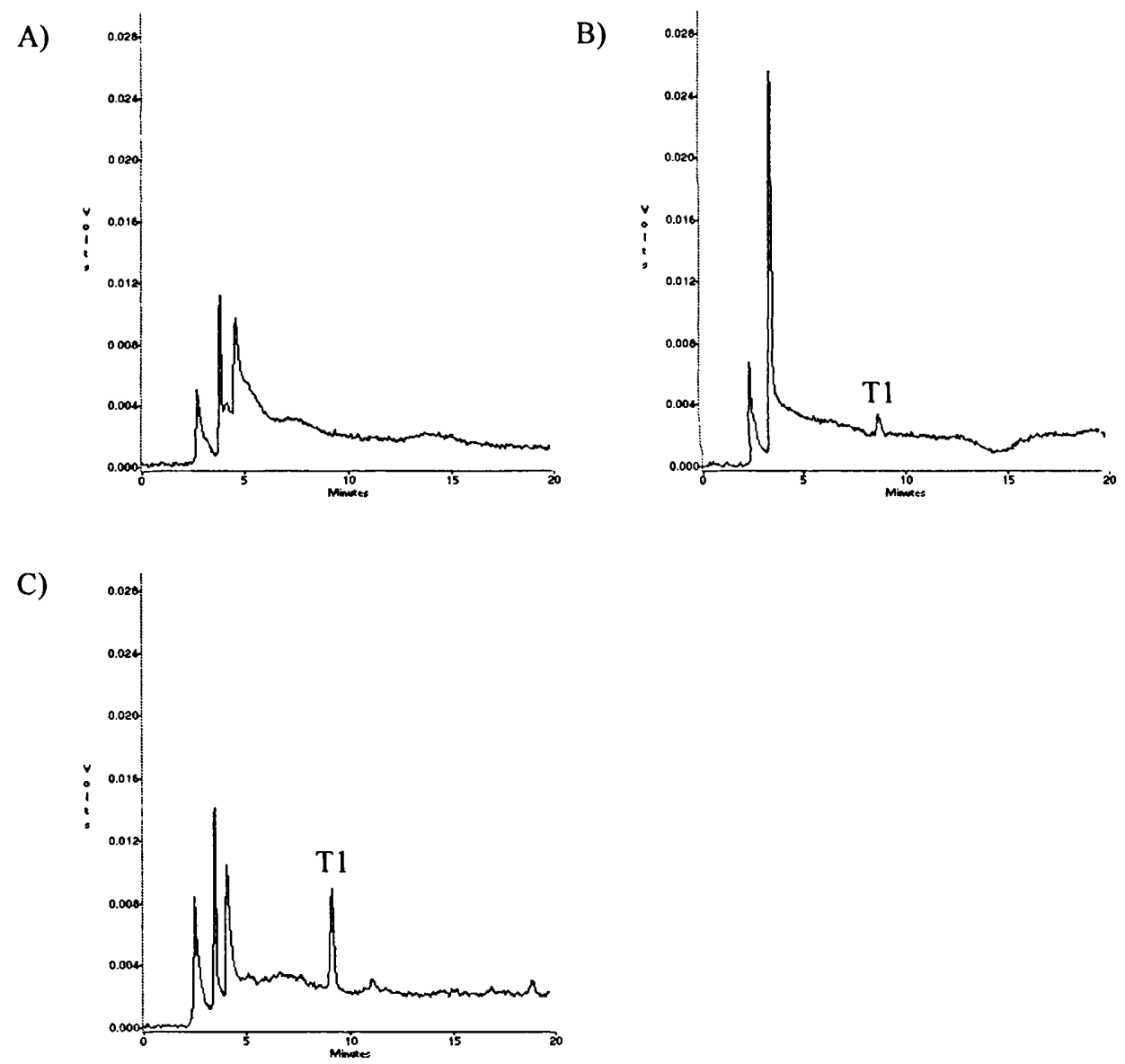

Figure IV-9. Determination of thiols and disulfides in a natural water sample collected in the Florida Everglades preconcentrated by cross-flow ultrafiltration and desalted. A) Natural sample blank, reduced with TBP but without the fluorogenic tagging reagent (SBD-F); B) Reduced thiols in the derivatized sample obtained without adding TBP; C) Oxidized thiols, derivatized sample after treatment with TBP 
A)

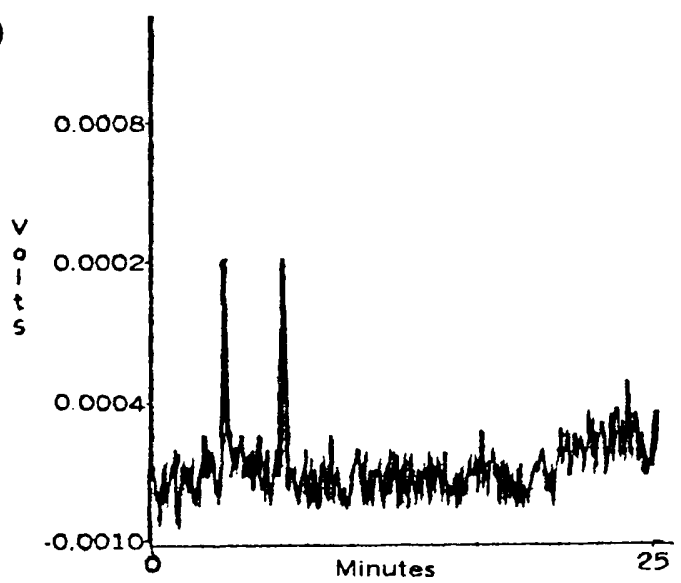

B)

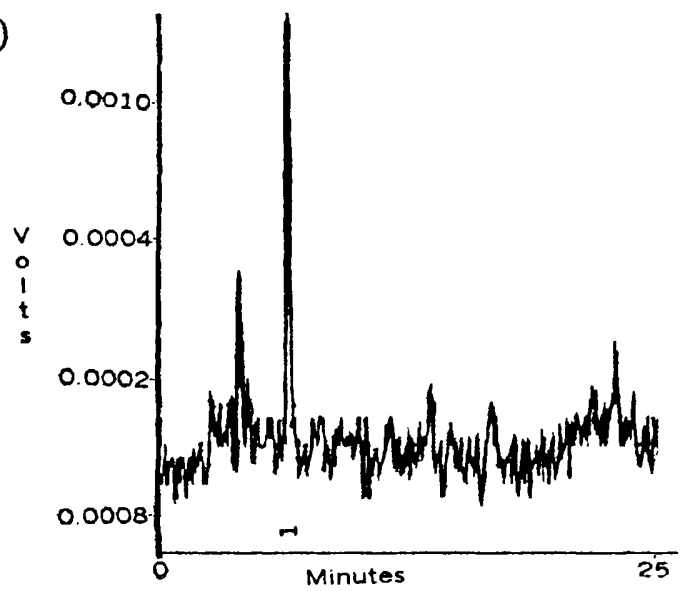

C)

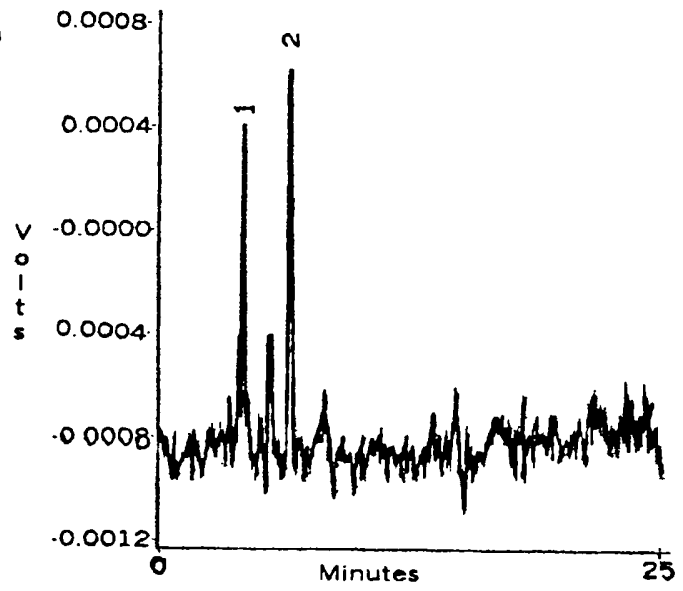

Figure IV-10. A) The presence of multiple peaks for a single standard in the absence of TBP is illustrated for L-cysteynil-glycine. B) Key to compunds: decomposition and/or rearrangement reactions give yield to these products. 
No other peaks were found, therefore only the concentrations of cysteine and glutathione were determined in the particulate. The possible source of these thiols present in the particulate could be from phytoplankton. Al-Farawati and Van Den Berg (2001) reported in their study of thiols in coastal waters, a co-variation between chlorophyll and thiols in near shore locations. Glutathione is thought to be the most abundant non-protein thiol in animals, plants and bacteria (Giovanelli, 1987); this could be its source in the particulate. Table IV-7 summarizes the analysis of thiols in the SPM extracted from different locations in the Florida Everglades.

Table IV-7. Analysis of thiols extracted from the SPM from water samples from different locations in the Florida Everglades. $(\mathrm{ND} \equiv$ not detected).

\begin{tabular}{ccc}
\hline \multirow{2}{*}{ Sample origin } & Cysteine & Glutathione \\
\hline WCA-1A & $248 \mathrm{pM}$ & $86 \mathrm{pM}$ \\
\hline WCA-3A & $206 \mathrm{pM}$ & ND \\
\hline Method recovery & $75.1 \% \pm 6.2$ & $42.8 \% \pm 7.8$
\end{tabular}

Recovery: $250 \mathrm{ml}$ of DDIW were spiked with $100 \mathrm{ppb}$ of cysteine and glutathione and filtered through a $0.2 \mu \mathrm{m}$ nitrocellulose filter and analyzed.

\section{Conclusions}

A sensitive and reliable reversed-phase HPLC method has been used to analyze naturally occurring low-molecular weight thiols using pre-column derivatization with ammonium 7-fluorobenzo-2-oxa-1,3-diazole-4-sulfonate (SBD-F) and fluorescence 
detection. The detection limit of the method has been limiting because of the low thiol levels in the samples; therefore, preconcentration steps were necessary. Several techniques were evaluated for preconcetration of the water samples. Using CYS and GSH as sample thiols, CYS spiking recoveries were found to be 63.2 and 70.6 for freeze-dry and rotary evaporation, respectively, and GSH spiking recoveries were 37.1 and 76.8 for freeze-dry and rotary evaporation, respectively.

The derivatization technique is relatively simple and fast and the derivatized products reflect the presence of various thiol species present in the sample. Thiol species present in natural freshwater samples were derivatized successfully. However, for water sample analysis strong interferences were observed at short retention times $(<5 \mathrm{~min})$ from the sample matrix. This inhibits the application of this technique for analysis of some thiols, which may appear in this range, such as CYS. For particulate phase analysis, such interferences were not observed. Three unidentified thiol compounds are present in the surface waters of the Florida Everglades. Characterization and identification of these three species were not carried out due to the lack of standards and their fairly low concentrations. Nevertheless, through the application of the HPLC fluorescence techniques we have shown that while the concentrations of any given compound in the aqueous phase is small, the cumulative effect of all complexing species may be appreciable. According to Luther and Church (1992), porewater thiols may compete for mercury complexation, which increases mercury mobility. Ravichandran et al. (1998) found that dissolved organic carbon (DOC) can promote the solubility of cinnabar ( $\mathrm{HgS}$, an insoluble sulfide present in the sediments) in natural water of the Florida Everglades; 
this could be attributed to the thiols present in DOM, which have a strong binding capacity for mercury.

A different pattern was found for thiols in particulate phase. Since no interferences were observed in the short retention time period, we were able to determine CYS and GSH. These two thiol species were found in the particulate phase at relatively high concentrations. Their occurrence is most likely caused by the present phytoplankton and other microbial organisms. The three unidentified thiols found in the dissolved phase $(<0.2 \mu \mathrm{m})$ were not observed in the particulate phase. 


\section{Future Research}

While this study is the first to report the presence of thiols in surface waters of the Florida Everglades there are many questions that remain to be answered. Some of the potential areas of research are listed below.

It has been shown (Chapter II) that the influence of DOC in the transport and fate of mercury plays a role in the transport and bioavailability of mercury species in surface waters of the Everglades. Although correlations between total sulfur, DOC and methylmercury concentrations in surface waters were studied, the influence of reducing sulfur species on the transport and fate of mercury requires further study. The technique used for sulfur analysis provided the total amount of sulfur present, including sulfate. A more specific approach is needed to include mostly reduced organosulfur compounds analysis.

The technique for thiol analysis was investigated in this study (Chapter IV). However, due to the low amounts of organosulfur compounds found in water, a preconcentration technique was necessary prior to analysis. Based the results obtained in this study, a more reliable preconcentration procedure is needed. Cross-flow ultrafiltration is worth of further investigation.

The effect of different types of DOC with different sulfur content on the complexation of mercury species in water could be of interest to explain the fate of these species in different locations of the Everglades. Further progress is necessary to identify and quantify potential mercury binding sites in DOM by using different spectroscopic techniques. 
The influence of DOC in the transport and fate of mercury species in the Florida Everglades could be related to an abiotic interrelation of three natural cycles carbon, sulfur and mercury, where the presence of some radical compounds obtained from the interaction of organosulfur compounds with light, combined with the abundance of organic matter could produce very reactive methyl radicals able to abiotically methylate inorganic mercury species present in the water. Possible compounds to capture such carbon and sulfur radicals should be looked for, in order to establish their presence and their ability for methylation. 


\section{References}

Ahner, B.A.; Lee, J.G.; Price, N.M.; Morel, F.M.M. (1998). Phytochelatin concentrations in the equatorial Pacific. Deep-Sea Research Part I, 45: 1779-1796.

Aiken, G. and Reddy, M. (1998) Interactions of mercury with dissolved organic carbon. Project for 1998. Program Fragile Environments, USGS.

Akagi, H.; Castillo, E.S.; Cortes-Maramba, N.; Francisco-Rivera, A.T. and Timbang, T.D. (2000) Health assessment for mercury exposure among school children residing near a gold processing and refining plant in Apokon, Tagum, Davao del Norte, Philippines. The Science of the Total Environment, 259: 31-43.

Allard, B. and Arsenie, I., 1991. Abiotic reduction of mercury by humic substances in aquatic system: an important process for the mercury cycle. Water, Air and Soil Pollution, 56: 457-464.

Alli, A.; Jaffe, R. and Jones, R.D. (1994). Analysis of organomercury compounds in sediments by capillary GC atomic fluorescence detection. Journal of High Resolution Chromatography, 17: 745-748.

Alli, A. (1994) Analysis of organomercurials in environmental and biological samples by capillary column gas chromatography with atomic fluorescence detection. Master's Thesis, Florida International University, Department of Chemistry.

Al-Farawati, R. and Van Den Berg, M.G. (2001) Thiols in coastal waters of the Western North Sea and English Channel. Environmental Science and Technology, 35: 1902-1911.

Andren, A.W. and Harriss, R.C. (1975) Observations on the association between mercury and organic matter dissolved in natural waters. Geochim. Cosmochim. Acta, 39: 1253-1257.

Amalfitano, C.R.A.; Quezada, M.A.; Hanna, J.V. (1995) Chemical composition of humic acids: A comparison with precursor "light fraction" litter from different vegetations using spectroscopic techniques. Soil Science, 159: 391-401.

Amicon (1999) Instructions for Diaflo ultrafilters. Publication I-101M, MA

Araki, A. and Sako, Y., (1987). Determination of free and total homocysteine in human plasma by high-performance liquid chromatography with fluorescence detection. Journal of Chromatography, 422: 43-52.

Arctic Monitoring and Assessment Program (1997) Arctic pollution issues: a state of the Arctic environment report. 
Babiarz, C.L., Hurley, J.P.; Hoffmann, S.R.; Shafer, M.M.; Andren, A.W. and Armstrong, D.E. (2001). Partitioning of mercury to the colloidal phase in fresh waters. US EPA, Workshop on the fate, transport, and transformation of mercury in aquatic and terrestrial environments. West Palm Beach, FL, May 8-10, 2001.

Babiarz, C.L.; Hoffmann, S.R.; Shafer, M., Hurley, J.P.; Andren, A.W.; Armstrong, D.E. (2000). Critical evaluation of tangential-flow ultrafiltration for trace metal studies in freshwater systems. 2. Total mercury and methylmercury. Environmental Science and Technology, 34: 3428-3434.

Babiarz, C.L.; Hurley, J.P.; Benoit, J.M.; Shafer, M.M.; Andren, A.W. and Webb, D.A. (1998) Seasonal influences on partitioning and transport of total and methylmercury in rivers from contrasting watersheds. Biogeochemistry 41: 237-257.

Bates, A.L.; Orem, W.H.; Harvey, J.W. and Spiker, E.C. (2000) Geochemistry of sulfur in the Florida Everglades 1994 through 1999. U.S. Geological Survey. U.S. Department of Interior. Open file report 01-7.

Bates, A.L., Spiker, E.C. and Holmes, C.W. (1998) Speciation and isotopic composition of sedimentary sulfur in the Everglades, Florida, USA. Chemical Geology, 146: 155-170.

Battin, T.J. (1998) Dissolved organic matter and its optical properties in a blackwater tributary of the upper Orinoco river. Organic Geochemistry, 28: 561-569.

Bell, R.A. and Kramer, J.R., (1999). Structural chemistry and geochemistry of silversulfur compounds: Critical review. Environmental Toxicology and Chemistry, 18: 9-22.

Benoit, J.M.; R. P. Mason, C. C. Gilmour and G. R. Aiken (2001). Constants for mercury binding by dissolved organic matter isolates from the Florida Everglades, Geochimica et Cosmochimica Acta, 65: 4445-4451.

Benoit, G. and Rozan, T.F. (1999) The influence of size distribution on the particle concentration effect and trace metal partitioning in rivers. Geochimica et Cosmochimica Acta, 63: 113-127.

Benoit, J.M.; Gilmour, C.C.; Mason, R.P.; and Heyes (1999). Sulfide controls on mercury speciation and bioavailability to methylating bacteria in sediments pore waters. Environmental Science and Technology, 33: 951-957.

Benoit, G. (1995) Evidence of the particle concentration effect for lead and other metals in freshwaters based on clean techniques analyses. Geochimica et Cosmochimica Acta, 59: 2677-2687. 
Beyer, L.; Sorge, C.; Blume, H. -P. and Schulten, H.R. (1995) Soil organic matter Composition and Transformation in Gelic Histosols of Coastal Continental Antarctica. Soil Biology and Biochemistry, 27: 1279-1288.

Bloom, N.S. and Fitzgerald, W.F. (1988) Determination of volatile mercury species at the picogram level by low-temperature gas chromatography with cold-vapor atomic fluorescence detection. Analytica Chimica Acta, 208: 151-161.

Bloom, P.R. and Leenheer, J.A. (1989). Vibrational, electronic and high-energy spectroscopic methods for characterizing humic substances. In: Humic substances II, eds. M.H.B. Hayes, P. MacCarthy, R.L. Malcom and R.S. Swift, pp.409-446. John Wiley \& Sons, New York.

Branfireum, B.A.; Roulet, N.T.; Kelly, C.A. and Rudd, W.M. (1999) In situ sulphate stimulation of mercury methylation in a boreal peatland: toward a link between acid rain and methylmercury contamination in remote environments. Global Biogeochemical Cycles, 13: 743-750.

Buesseler, R.O.; Bauer, J.; Chen, R.; Eglinton, T.; Gustafson, O.; Landing, W.; Mopper, K.; Moran, S.B.; Sanstchi, P.; VernonClark, R.; Wells, M. (1996) Sampling marine colloids using cross-flow ultrafiltration: an overview and results from an intercomparison study. In Buffle, J., van Leuwen, H.P. (Eds.) Environmental Particles, Vol. 1, Lewis, Boca Raton, 171-230.

Buffle, J.; Deladoey, P.; Haerdi, W. (1978) The use of ultrafiltration for the separation and fractionation of organic ligands in fresh water. Analytica Chimica Acta, 55: 1781-1797.

Buffle, J.; Deladoey, P.; Zumstein, J. and Haerdi, W. (1982) Analysis and characterization of natural organic matters in freshwaters. I. Study of analytical techniques. Schweiz. Hydrol., 44: 325-362.

Buffle, J. (1988) Complexation reactions in aquatic systems: an analytical approach. Ellis Horwood Limited, pp. 345-354.

Buffle, J. and Leppard, G.G. (1995a) Characterization of aquatic colloids and macromolecules. 1. Structure and behavior of colloidal material. Environmental Science and technology, 29: 2169-2175.

Buffle, J. and Leppard, G.G. (1995b) Characterization of aquatic colloids and macromolecules. 2. Key role of physical structures on analytical results. Environmental Science and Technology, 29:2176-2184. 
Burba, P.; Shkinev, V.; Spivakov, B.Y.; (1995) On-line fractionation and characterization of aquatic humic substances by means of sequential stage ultrafiltration. J. Anal. Chem., 351: 74-82.

Burba, P.; Aster, B.; Nifant'eva, T.; Shkinev, V. and Spivakov, B.Ya. (1998) Membrane filtration studies of aquatic humic substances and their metal species: a concise overview. Part 1. Analytical fractionation by means of sequential stage ultrafiltration. Talanta, 45: 977-988.

Cabaniss, S.E. and Shuman, M.S. (1988) Copper binding by dissolved organic matter: I. Suwannee river fulvic acid equilibria. Geochimica et Cosmochimica Acta, 52: 185-193.

Cabaniss, S.E.; Zhou, Q.; Maurice, P.A. Chin, Y.P., Aiken, G.R. (2000) A log-normal distribution model for the molecular weight of aquatic fulvic acids. Environmental Science and Technology, 34:1103-1109.

Cai, Y.; Jaffe, R.; Alli, A. Jones, R. (1996) Determination of organomercury compounds in natural waters by solid-phase extraction with sulfhydryl cotton fibers and capillary chromatography-atomic fluorescence spectrometry detection. Analytica Chimica Acta, 34: 251-259.

Cai, Y.; Tang, G.; Jaffe, R. and Jones, R.D. (1997). Evaluation of some isolation methods for organomercury determination in soil and fish samples by capillary gas chromatography atomic fluorescence spectrometry. International Journal of Environmental Analytical Chemistry, 68: 331-345.

Cai, Y., Jaffe, R. and Jones, R. (1997). Ethylmercury in soils and sediments of the Florida Everglades. Environmental Science and Technology, 31: 302-305.

Cai, Y. (1999) Size distribution measurements of dissolved organic carbon in natural waters using ultrafiltration technique. Water Research, 33: 3056-3060.

Cai, Y.; Jaffe, R.; Jones, R.D. (1999) Interactions between dissolved organic carbon and mercury species in surface waters of the Florida Everglades. Applied Geochemistry, 14: 395-407.

Cai, Y.; Monsalud, S.; Jaffe, R. and Jones, R. (2000). Gas chromatographic determination of organomercury following aqueous derivatization with sodium tetraethylborate and sodium tetraphenylborate; Comparative study of gas chromatography coupled with atomic fluorescence spectrometry, atomic emission spectrometry and mass spectrometry, Journal of Chromatography A, 876: 147-155 .

Carroll, G. and Truman, C.R. (1995) J. Air Waste Managem. Assoc. 45 (1995), p. 730. 
Cestari, R.A. and Airoldi C. (1997). Chemisorption on thiol-silicas: divalent cations as functions of $\mathrm{pH}$ and primary amines on thiol-mercury adsorbed. Journal of Colloids and Interface Science. 195: 338- 347.

Chalmers, A. and Krabbenhoft, D. (2001). Mercury distribution along an urban gradient in New England streams. US EPA, Workshop on the fate, transport, and transformation of mercury in aquatic and terrestrial environments. West Palm Beach, FL, May 8-10, 2001.

Chen, Y.; Senesi, N. and Schnnitzer, M. (1977). Information provided on humic substances by $\mathrm{E}_{4} / \mathrm{E}_{6}$ ratios. Soil Sci. Soc. Am. J., 41, 352-358.

Chen, Z. and Pawluk, S. (1995). Structural variations of humic acids in two soils of Alberta Mollisols. Geoderma, 65: 173-193.

Chin, Y-P; Aiken, G.; Danielsen, K.M.. (1997) Binding of pyrene to aquatic and commercial humic substances: the role of molecular weight and humic structure. Environmental Science and Technology, 31: 1630-1635.

Choe, K.Y.; Gill, G.A. (2001). Isolation of colloidal monomethyl mercury in natural waters using cross-flow ultrafiltration techniques. Marine Chemistry, 76: 305318.

Clark, C.D.; Jimenez-Morais, J., Jones, G., Zanardi-Lamardo, E., Moore, C.A. and Zika, R.G. (2002) A time-resolved fluorescence study of dissolved organic matter in a riverine to marine transition zone. Marine Chemistry, 78: 121-135

Clarkson, T.W. (1972). CRC Review in Toxicology. Chem Rubber Co., Cleveland, 203234

Clarkson, T.W. (1992). Mercury: Major issues in environmental health. Environmental Health Perspectives, 100: 31-38.

Clarkson, T.W. (1995). The toxicity of mercury and its compounds, in: (Ed. Watras, C.J., Huckabee, J.W.). Mercury as Pollution-Integration and Synthesis, CRC Press pp.631-680.

Cleckner, L.B.; Gilmour, C.C.; Hurley, J.P. and Krabbenhoft, D.P. (1999) Mercury methylation in periphyton of the Florida Everglades. Limnology and Oceanography, 44: 1815-1825.

Conte, P.; Piccolo, A.; van Lagen, B.; Buurman, P. and de Jager, P.A. (1997). Quantitative differences in evaluating soil humic substances by liquid- and solidstate ${ }^{13}$ C-NMR spectroscopy. Geoderma, 80: 339-352. 
Conte, P. and Piccolo, A. Environ. (1999). Conformational arrangement of dissolved humic substances. Influence of solution composition on association of humic. Science and Technology, 33: 1682-1690.

Craig, J.P. (1986). Organometallic compounds in the environment, Wiley, New York.

Craig, P.G. and Moreton, P.A. (1984). The role of sulphide in the formation of dimethyl mercury in river and estuary sediments. Marine Pollution Bulletin, 15: 406-408.

Dai, F.; Burkert, V.P.; Singh, H.N.; Hinze, W.L. (1997) Update and evaluation of different thiols and micellar media in Roth's fluorimetric method for the determination of primary amino compounds. Microchemical Journal, 57: 166198.

Didillon, B.; Savary, L.; Ryndin, Y.A.; Candy, J.P. and Basset, J.M. (2000). IFP demercurisation and de-arsenification process: the application of catalysis to the decontamination of natural feedstocks, Comptes Rendus de l'Académie des Sciences - Series IIC - Chemistry,3: 413-416.

Driscoll, C.T., Yan, C., and Schofield C.L. (1994). Mercury cycle and fish in the Adirondack lakes. Environmental Science and Technology, 28: 136A-143A.

Driscoll, T.; Blette, V.; Yan, C.; Schofield, C.L.; Munson, R. and Holsapple, H. (1995). The role of dissolved organic carbon in the chemistry and bioavailability of mercury in remote Adirondack Lakes. Water Air Soil Pollut. 80: 499-508.

Driscoll, Nelson J. ; Evans, R. Douglas (2000). Analysis of methyl mercury binding to freshwater humic and fulvic acids by gel permeation chromatography/hydride generation ICP-MS, Environmental Science \& Technology, 34: 4039-4043

Duarte, R.; Santos, E. and Duarte A.C. (2001) Comparison between diafiltration and concentration operation modes for the determination of permeation coefficients of humic substances through ultrafiltration membranes. Analytica Chimica Acta, 442: 155-164.

Dupre, B.; Viers, J; Dandurand, J.L.; Polve, M.; Benezeth, P.; Vervier, P.; Braun, J.J. (1999) Major and trace elements associated with colloids in organic-rich waters: ultrafiltration of natural and spiked solutions. Chemical Geology, 160: 63-80.

Dyrssen, D. and Wedborg, M. (1991) The sulfur-mercury (II) system in natural waters. Water, Air and Soil Pollution, 56: 507-519.

EARL SOP-99-I 001-0 (1999) Quantitative determination of trace metals by ICP-MS. Advanced Mass Spectrometry Facility. Florida International University, Miami, Florida. 
Environmental Reporter, 2000. Mercury from electric power plants to be regulated under Air Act, 31: 2654-2656.

Eyrolle, F.; Benedetti, M.F.; Benaim, J.-Y. and Fevrier, D. (1996) The distributions of colloidal and dissolved organic carbon, major and trace elements in small tropical catchments. Geochimica et Cosmochimica Acta, 60: 3643-3656.

Fahey, R.C. and Newton, G.L., (1987). Determination of low-molecular weight thiols using monobromobimane fluorescent labeling and high-performance liquid chromatography. Methods in Enzymology 143: 85-96.

Fermo, I.; Arcelloni, C.; Vecchi, E.D.; Vigano, S. and Porini, R. (1992) High performance liquid chromatographic method with fluorescence detection for the determination of total homocyst(e)ine in plasma. Journal of Chromatography, 593: 171-176.

Fermo, I.; Arcelloni, C.; Mazzola, G.; D’Angelo, A. and Paroni, R. (1998) Highperformance liquid chromatographic method for measuring total plasma homocysteine levels. Journal of Chromatography, 719: 31-36.

Filley, T.R.; Freeman, K.H.; Wilkin, R.T.; Hatchet, P.O. (2002) Biogeochemical controls on reaction of sedimentary organic matter and aqueous sulfides in holocene sediments of Mud Lake, Florida. Geochimica et Cosmochimica Acta, 66: 937-954.

Fitzgerald, W.F., Engstrom, D.R., Mason, R.P., Nater, E.A. (1998). The case for atmospheric mercury contamination in remote areas. Environmental Science and Technology 32: 1-7.

Florida Department of Environmental Protection, (1994). Health advisories for mercury in Florida freshwater fish. Tallahassee, Florida.

Francioso, O.; Sanchez-Cortes, S., Tugnoli, V. Ciavatta, C.; Sitti, L. and Gessa, C. (1996) Infrared, Raman, and Nuclear Magnetic Resonance $\left({ }^{1} \mathrm{H},{ }^{13} \mathrm{C}\right.$, and $\left.{ }^{31} \mathrm{P}\right)$ Spectroscopy in the Study of Fractions of Peat Humic Acids. Applied Spectroscopy, 50: 1165-1174.

Frederick, P.C. and Spalding, M.G. (1994). Factors affecting reproductive success of wading birds in the Everglades ecosystem and its restoration. S.M. Davis and J.C. Ogden (Eds.) St. Lucie Press.

Gilfix, B.M.; Blank, D.W.; and Rosenblatt, D.S. (1997). Novel reductant for determination of total plasma homocysteine. Clynical Chemistry, 43: 687-688. 
Gilmour, C.C.; Riedel, G.S.; Ederington, M.C.; Bell, J.T.; Benoit, J.M.; Gill, G.A. and Stordal, M.C. (1998). Methylmercury concentrations and production rates across a trophic gradient in the northern Everglades. Biogeochemistry, 40: 327-345.

Giovanelli, J. (1987) Sulfur aminoacids of plants: an overview. Methods in Enzymology, 143: 419-426.

Guentzel, J.L., Powell, R.T., Landing, W.M. and Mason, R.P. (1996). Mercury associated with colloidal material in an estuarine and an open ocean environment. Marine Chemistry, 55: 177-188.

Halbach, S. (1995). Toxicity of detrimental metal ions. In: Handbook of Metal-Ligand Interactions in Biological Fluids. Bioinorganic Medicine, Vol.2 (Ed. G. Berthon), pp. 640-643.

Hall, B. (1995). The phase oxidation of elemental mercury by ozone. Water, Air and Soil Pollution 80: 301-315.

Hanisch, C. (1998). Where is mercury contamination coming from? Environmental Science and Technology, 32: 176A-179A.

Hautala, K., Peuravuori, J. and Pihlaja, K. (2000) Measurement of aquatic humus content by spectroscopic analyses. Water Research, 34: 246-258.

Hedges, J.; Stern, J. (1984). Carbon and nitrogen determinations of carbon containing soils. Limnology and Oceanography, 29: 657-663.

Helander, B., Olsson, M. and Reutergardh, L. (1982). Residue levels of organochlorine and mercury compounds in unhatched eggs and the relationships to breeding success in white-tailed sea eagles Haliaeetus Albicilla in Sweden. Holarctic Ecol., 5: 349-366.

Hintelmann, H., Welbourn, P.M. and Evans, R.D. (1995). Binding of methylmercury compounds by humic and fulvic acids. Water Air and Soil Pollution, 80: 1031-1034.

Hintelmann, H. and Wilken, R.D. (1995) Levels of total mercury and methylmercury compounds in sediments of the polluted Elbe River: influence of seasonally and spatially varying environmental factors. The Science of the Total Environment, 166: 1-10.

Hintelmann, H., Welbourn, P.M. and Evans, R.D. (1997). Measurement of complexation of methylmercury(II) compounds by freshwater humic substances using equilibrium dialysis. Environmental Science and Technology 31: 489-495. 
Hoffmann, S.R.; Shafer, M.M.; Babiarz, C.L.; Armstrong, D.E. (2000) Critical evaluation of tangential-flow ultrafiltration for trace metal studies in freshwater systems. 1. Organic carbon. Environmental Science and Technology, 34: 3420-3427.

Honeyman , B.D. and Santschi, P.H. (1988) Metals in aquatic systems. Environmental Science and technology, 22: 862-871.

Horowitz, A.J.; Lum, K.R.; Garbarino, J.R.; Ha, G.E.M.; Lemieux, C.; Demas, C.R. (1996). The effect of membrane filtration on dissolved trace elements concentrations. Water, Soil and Air Pollution, 90: 281-294.

Hosokawa, Y. (1993). Remediation work for mercury contaminated bay-experiences of Minimata Bay project, Japan. Water Science and Technology, 28: 339-348.

Howarth, R.W., Stewart, J.W.B., Ivanov, M.V. Editors (1992). Sulfur Cycling on the continents, Wetlands, terrestrial Ecosystems and Associated Water Bodies. John Wiley and Sons, New York.

Humphey, R.E. and Potter, J.L. (1965). Reduction of Disulfides with tributylphosphine. Analytical Chemistry, 37: 164-165.

Hurley, J.P.; Watras, C.J.; Bloom, N.S. (1994a) Distribution and flux of particulate mercury in four stratified seepage lakes, In: Watras, C.J.; Huckabee, J.W. (Eds.) Mercury pollution, integration and synthesis. Lewis: Boca Raton, pp. 69-82.

Hurley, J.P.; Krabbenhoft, D.P.; Babiarz, C.L.; Andren, A.W. (1994b). Cycling of mercury across the sediment-water interface in seepage lakes. In: Baker, L.A> (Eds.) Environmental chemistry of lakes and reservoirs, ACS Advances in Chemistry Series No. 237, ACS, pp. 425-429.

Hurley, J.P.; Benoit, J.M.; Babiarz, C.L.; Shafer, M.M.; Andren, A.W.; Sullivan, J.R. Hammond, R. and Webb, D.A. (1995) Influences of waterbed characteristics on mercury levels in Wisconsin rivers. Environmental Science and technology, 29: 1867-1875.

Hurley,J.P.; Cowell, S.E.; Shafer, M.M. and Hughes, P.E. (1998a) Partitioning and Transport of Total and Methylmercury in the Lower Fox River, Wisconsin Environmental Science and Technology, 32: 1424-1432.

Hurley, J.P.; Krabbenhoft, D.P.; Cleckner, L.B.; Olson, M.L., Aiken, G.R. and Rawlik, J.R. (1998b) System controls on the aqueous distribution of mercury in the northern Florida Everglades. Biogeochemistry, 40: 293-311. 
Hurley, J.P.; Back, R.C.; Rolfhus, K.R.; Harris, R.C.; Armstrong, D.E.; Harris, R.; Babiarz, C.L.; Shafer, M.M. (2001) Watershed influences on transport, fate and bioavailability of mercury in Lake Superior. US EPA, Workshop on the fate, transport, and transformation of mercury in aquatic and terrestrial environments. West Palm Beach, FL, May 8-10, 2001.

Imai, K.; Toyo'oka, T.; Watanabe, Y. (1983) a novel fluorogenic reagent for thiols: ammonium7-fluorobenzo-2-oxa-1,3-diazole-4-sulfonate.Analytical Biochemistry, 128: $471-473$.

Imai, K.; Toyo'oka, T. (1987) Fluorimetric assay of thiols with fluorobenzodiazoles. Methods in Enzymology, 143: 67- 75

Jackson, T.A.; Kipphut, G.; Hesslein, R.H. and Schindler, D.W. (1980). Experimental study of trace metal chemistry in soft-water lakes at different $\mathrm{pH}$ levels. Canadian Journal of Fish and Aquatic Science, 37: 387-402.

Jackson, A.T. (1993). Effects of environmental factors and primary production on the distribution and methylation of mercury in a chain of highly eutrophic riverine lakes. Water Pollution Research Journal Canada, 28: 177-216.

Jacobs, W.A.; Leburg, M.W. and Maday, E.J. (1986). Evidence for the presence of functional beta-adrenoreceptor along the proximal tubule of the rat kidney. Analytical Biochemistry, 156: 334- 339.

Jacobsen, D.W., Gatautis, V.J. and Green, R. (1989) Determination of plasma homocysteine by high -performance liquid chromatography with fluorescence detection. Analytical Biochemistry, 178: 208-214.

Jacobsen, D.W.; Gatautis, V.J.; Green, R.; Robinson, K.; Savon, S.R.; Secic, M.; Ji, J.; Otto, J.M.; Taylor, L.(1994). Rapid HPLC determination of total homocysteine and other thiols in serum and plasma: sex differences and correlation with cobalamin and folate concentrations in healthy subjects. Clinical Chemistry, 40/6: 873-881.

Jensen, S. and Jernelov, A. (1969). Biological methylation of mercury in aquatic organisms. Nature, 223: 753-754.

Jonasson, I.R. and Boyle, R.W., 1972. Geochemistry of mercury and origins of natural contamination of the environment. Canadian Institute of Mining and Metallurgical Bulletin 65, pp. 32-39. 
Jones, R.D.; Jacobson, M.E. and Jaffe, R. (1995). Method development and sample processing of water, soil and tissue for the analysis of total and organic mercury by cold vapor atomic fluorescence spectrometry. Water, Air and Soil Pollution, 80: $1285-1294$.

Jones, M.N. and Bryan, N.D. (1998). Colloidal properties of humic substances. Advances in Colloid and Interface Science, 78:1-48.

Kalbitz, K.; Geyer, S.; Geyer, W. (2000) A comparative characterization of dissolved organic matter by means of original aqueous samples and isolated humic substances. Chemosphere, 40: 1305-1312.

Kambey, J.L.; Farrell, A.P. and Bendell-Young, L.I. (1989). Determination of methlmercury in natural waters at the sub-nanograms per litre level by capillary gas chromatography after ladsorbent preconcentration. Analytica Chimica Acta, 221: 259-268.

Kannan, K.; Smith, R.G.; Lee, R.F., Windom, H.L., Heitmuller, P.T.; Macauley, J.M. and Summers, J.K. (1998) Distribution of total mercury and methylmercury in water, sediment, and fish from South Florida Estuaries. Archives of Environmental Contamination and Toxicology, 34: 109-118.

Kendall, C.; Bemis, B.; Wankel, S.; Silva, S.; Chang, C.; Krabbenhoft, D.; Stober, J. (2001) Spatial and temporal changes in food web structure and biogeochemical reactions in the Everglades. US EPA, Workshop on the fate, transport, and transformation of mercury in aquatic and terrestrial environments. West Palm Beach, FL, May 8-10, 2001.

Kolattukudy, P.E. (1984) Biochemistry and function of cutin and suberin. Canadian Journal of Botany, 62: 2818-2933.

Korshin, G.V., Li C-W, and Benjamin, M.M. (1997). Monitoring the properties of natural organic matter through UV spectroscopy: A consistent theory. Water Research, 31: 1787-1795.

Krabbenhoft, D.P., Hurley, J.P.; Olson, M.L.; Cleckner, L.B. (1998) Diel variability of mercury phase and species distributions in the Florida Everglades. Biogeochemistry, 40: 311-325.

Krabbenhoft, D.P. and Babiarz, C.L. (1992). The role of groundwater transport in aquatic mercury cycling. Water Resour. Res. 28, pp. 3119-3128.

Krishnamurthy, R.V.; Syrup, K.A.; Baskaran, M. and Long, A. (1995). Late glacial climate record of Midwestern United States from the hydrogen isotope ratio of lake organic matter. Science, 269: 1565-1567. 
Lamborg, C.H.; Hoyer, M.E.; Keeler, G.J.; Olmez, I.; Huang, X. (1994). Particulate phase mercury in the atmosphere: collection/analysis method development and applications. In: Watras, C.J., Huckabee, J.W. Mercury as a Global PollutantIntegration and Synthesis, Lewis Publisher, pp. 215-259.

Lambou, V.W.; Barkay, T.; Braman, R.S., Delfino, J.J.; Jansen, J.J.; Nimmo, D.; Parks, J.W.; Porcella, D.B.; Rudd, J., Schultz, D.; Stober, J.; Watras, C.; Wiener, J.G.; Gill, G.; Huckabee, J.; Rodd, B. (1991). Mercury Technical Committee Interim Report. Florida State University, Tallahassee, Florida.

Lee, Y.-H. and Hultberg, H. (1990). Methylmercury in some Swedish surface waters. Environ Toxicol Chem., 9: 833-841

Lindberg, S.E.; Stratton, W.J. (1998). Atmospheric mercury Speciation: concentration and behavior of reactive gaseous mercury in ambient air. Environmental Science and Technology 32: 49-57.

Logan, B.E. and Jiang, Q. (1990) Molecular size distribution of dissolved organic matter. Journal of Environmental Engineering, 116: 1046-1062.

Lombardi, A.T. and Jardim, W.J. (1999) Fluorescence spectroscopy of high performance liquid chromatography fractionated marine and terrestrial organic materials. Water Research, 23, 327-332.

Loux, N.T. (1998). An assessment of mercury-species-dependent binding with natural organic carbon, Chemical Speciation and Bioavailability, 10: 127-136.

Lovgren, L. and Sjoberg, S. (1989) Equilibrium approaches to natural water systems. Complexation reactions of copper (II), cadmium (II) and mercury (II) with dissolved organic matter in a concentrated bog water. Water Research, 23: 327332.

Lu, X. and Jaffe, R. (2001) Interaction between Hg (II) and natural dissolved organic matter: a fluorescence spectroscopy based study. Water Research, 35: 1793-1805.

Luther, G.W., Church, T.M. (1992). An overview of the environmental chemistry of sulfur in wetland systems. In: Sulfur cycling on the continents, Wetlands, terrestrial Ecosystems and Associated Water Bodies. John Wiley and Sons, New York. pp. 123-144.

MacCarthy, P. and Rice, J.A. (1985) Spectroscopic methods (other than NMR) for determining functionality in humic substances. In Humic Substances in soil, sediment and water, eds. G.R. Aiken, D.M. McKnight, R.L. Wershaw and P. MacCarthy, pp. 527-559. John Wiley \& Sons, New York. 
Maie, N.; Watanabe, A.; Hayamizu, K. and Kimura, M. (2002) Comparison of chemical characterization of Type A humic acids extracted from subsoils of paddy fields and surface ando soils. Geoderma, 106: 1-19.

Malcolm, R.L. (1990). The uniqueness of humic substances in each of soil, stream and marine environments. Analytica Chimica Acta, 232: 19-10.

Mantoura R.F.C., and Riley, J.P. (1975). The use of gel filtration in the study of metal binding by humic acids and related compounds. Anal. Chim. Acta 78: 193-200.

Mantoura, R.F.C.; Dickson, A. and Riley, J.P. (1978). The complexation of metals with humic materials in natural waters. Estuarine and Coastal Marine Science, 6: 387408.

Martin, J.M.; Dai, M.H. and Cauwet, G. (1995). Significance of colloids in the biogeochemical cycling of organic carbon and trace metals in the Venice Lagoon (Italy) Limnology and Oceanography, 40: 119-131.

Maser R.; Obenland, H.; Jaeschke, W.; Beltz, N. and Herrmann, J. (1991). A new method for continuous measurements of $\mathrm{SO}_{2}$ in the pptv-range. In: Proceedings EUROTRAC Symposium 1990 Garmisch-Partenkirchem, Germany, pp. 557-558.

Mason, R.P., Fitzgerald, W.F., Morel, F.M.M. (1994). The biogeochemical cycling of elemental mercury: anthropogenic influences. Geochimica Cosmochimica Acta 58: 3191-3198.

Mason, R.P.; Morel, F.M.M. and Hemond, H.F. (1995). The role of microorganisms in elemental mercury formation in natural waters. Water, Air and Soil Pollution, 80: 665-677.

Mason, N.M.; Mason, R. and Laporte, J-M (2001) The fate and transport of mercury, methylmercury, and other trace metals in Chesapeake bay tributaries. Water Research, 35: 501-515.

McGarry, S.F. and Baker, A. (2000) Organic acid fluorescence: applications to speleothem palaeoenvironmental reconstruction. Quaternary Science review, 19: 1087-1101.

Meili, M. (1997). Mercury in lakes and rivers. In: Sigel, H. and Sigel, A., Editors. Mercury and its effect on environment and biology. Metal ions in biological systems, vol. 34, Marcel Dekker Inc, New York, pp. 21-51.

Meixner, F.X. and Jaeschke, W.A. (1981) The detection of low atmospheric $\mathrm{SO}_{2}$ concentrations with a chemiluminiscence technique. International Journal of Environmental Analytical Chemistry, 10: 51-67. 
Meyers, P.A., Dunham, K.W. and Dunham, P.L. (1986). Organic geochemistry of Cretaceous organic-carbon-rich shales and limestones from the western North Atlantic Ocean. In: North Atlantic Paleoceanography, eds. C.P. Summerhayes and N. Shacketon. Geological Society Special Publication, 21: 333-345.

Meyers, P.A. (1994) preservation of elemental and isotopic source identification of sedimentary organic matter. Chemical Geology, 144: 289-302.

Meyers, P.A. (1997) Organic geochemical proxies of paleoceanographic, paleolimnologic, and paleoclimatic processes. Organic geochemistry, 27: 213250 .

Miano, T.M.; Sposito, G.; Martin, J.P. (1988) Fluorescence spectroscopy of humic substances. Soil Science Society of America Journal, 52: 1016-1019.

Miano, T.M. and Senesi, N. (1992) Synchronous excitation fluorescence spectroscopy applied to soil humic substances chemistry. The Science of the Total Environment, 117/118: 41-51.

Mierle, G. and Ingram , R.(1991), The role of humic substances in the mobilization of mercury from watersheds. Water Air Soil Pollut., 56: 349-357.

Miyairi, S., Shibata, S., Naganuma, A., (1998). Determination of metallothioneins by high-performance liquid chromatography with fluorescence detection using an isocratic solvent system. Analytical Biochemistry, 258: 168-175

Monsalud, S. (1999). Determination of organomercury compounds in environmental and biological samples by using derivatization and chromatographic detection. M.S. Thesis, Florida International University, Miami, Florida.

Mopper, K. and Delmas, D., (1984). Trace determination of biological thiols by liquid chromatography and precolumn fluorometric labeling with o-phthaladehyde. Analytical Chemistry, 56: 2557-60.

Morra, M.J.; Fendorf, S.E. and Brown, P. (1997). Speciation of sulfur in humic and fulvic acids using X-Ray absorption near-edge structure (XANES) spectroscopy. Geochimica et Cosmochimica Acta, 61: 683-688.

Nagase H.; Ose, Y.; Sato, K.; Ishikawa, T. (1982). Methylation of mercury by humic substances in an aquatic environment. The Science of the Total Environment, 25: 133-142.

NRC (National Research Council) (2000) Toxicological effects of methylmercury. Washington, DC, National Academy Press. 
Newman, R.H. and Tate, K.R. (1991). ${ }^{13}$ C NMR characterization of humic acids from soils of a development sequence. Journal of Soil Science, 35: 47-54.

Nifant'eva, T.I., Shkinev, V.M.; Spivakov, B.Ya.; Burba, P. (1999) Membrane filtration studies of aquatic humic substances and their metal species: a concise overview. Part 2. Evaluation of conditional stability constants by using ultrafiltration. Talanta, 48: 257-267.

Nriagu, J.O. (1994). Mercury pollution from past mining of gold and silver in the Americas. Science of Total Environment 149: 167-181.

O'Connor, D.J. and Connolly, J.P. (1980) The effect of concentration and adsorbing solids on the partition coefficient. Water research, 14: 1517-1523.

Oe, T.; Ohyagi, T.; Naganuma, A. (1998). Determination of $\boldsymbol{\gamma}$-glutamylglutathione and other low-molecular-mass biological thiol compounds by isocratic highperformance liquid chromatography with fluorimetric detection. Journal of Chromatography B, 708: 285-289.

Paquette, K.A. and Helz, G.R., (1997). Inorganic speciation of mercury in sulfidic waters: the importance of zero-valent sulfur. Environ. Sci. Technol. 31, pp. 2148-2153.

Pehkonen, S.O. and Li Che-Jen (1998) Oxidation of elemental mercury by aquatic chlorine $(\mathrm{HOCl} / \mathrm{OCl})$ : implications for tropospheric mercury chemistry. Journal of Geophysiscal Research, 103:28093-28102.

Pella, E. and Colombo, B. (1973) Study of carbon, Hydrogen and Nitrogen determination by Combustion-Gas chromatography. Mikrochimica Acta (Wien) 6: 697-719.

Peuravuori, J. and Pihlaja, K. (1998). Multi-method characterization of lake aquatic humic matter isolated with two different sorbing solids. Analytica Chimica Acta 363: $235-247$.

Peuravuori, J. (2000). Precision of isolation of aquatic humic matter by XAD-resin technology from NMR spectroscopy's point of view. International Journal of Environmental Analytical Chemistry, 76: 179-198.

Pilgrim, W.; Poissant, L. and Trip, L. (2001) The Northeast states and eastern canadian provinces mercury study: a framework for action. Summary of the Canadian chapter. Science of the Total Environment, 261: 177-184.

Pirrone, N. (2001). Mercury research in Europe: towards the preparation of the EU air quality directive. Atmospheric Environment, 35: 2979-2986. 
Poole, C.F. and Poole, S.K. (1997) Chromatography today ( $5^{\text {th }}$ Ed.). Elsevier Science, Amsterdam.

Porcella, D.B. (1994). Mercury in the environment. In: (Ed. Watras, C.J., Huckabee, J.W.) Mercury as Pollution-Integration and Synthesis, CRC Press pp. 3-19.

Porcella, D.B. Ramel, C., Jernelov, A., 1997. Global mercury pollution and the role of gold mining: an overview. Water, Air and Soil Pollution 97, 205-207.

Preston, C.M. (1996) Applications of NMR to soil organic matter analysis: history and prospects. Soil Science 161: 144-166.

Rall, H.T.; Thompson, C.J.; Coleman, T.J. and Hopkins, R.L. (1972). Sulfur compounds in crude oil. U.S. Bur. Mines Bull. 659: 187.

Rasmussen, P.E. (1994). Current methods of estimating atmospheric mercury fluxes in remote areas. Environmental Science and Technology, 28: 2233-2241.

Rasmussen, P.E., Edwards, G.C., Kemp, J.R., Fitzgerald-Hubble, C.R., Schroeder, W.H., (1998). Towards an improved natural sources inventory for mercury. In: Skeaff, J. (Ed.), Proceedings of the Metals in the Environment: An International Symposium, pp. 74-82.

Ravichandran, M.; Aiken, G.R.; Reddy, M.M. and Ryan, J.N. (1998) Enhanced dissolution of cinnabar (mercuric sulfide) by dissolved organic matter isolated from the Florida Everglades. Environmental Science and Technology, 32: 33053311 .

Ravichandran, M. (1999). Ph.D. Dissertation. Interactions between mercury and dissolved organic matter in the Florida Everglades. University of Colorado, Department of Civil, Environmental and Architectural Engineering.

Renneberg, A.J. and Dudas, M.J. (2001). Transformations of elemental mercury to inorganic and organic forms in mercury and hydrocarbon co-contaminated soils, Chemosphere, 45:1103-1109.

Rizzo, V.; Montalbetti, L.; Valli, M.; Bosoni, T.; Scoglio, E.; Moratti, J., (1998). Study of factors affecting the determination of total plasma 7-fluorobenzo-2-oxa-1,3diazole-4-sulfonate (SBD)-thiol derivatives by liquid chromatography. Journal of Chromatography B, 706: 209-215.

Roelke, M.E.; Schultz, D.P.; Facemire, C.F.; Sundlof, S.F.; Royals, H.E. (1991). Mercury contamination in Florida panthers. Prepared by the Technical Subcommittee of the Florida Panther Interagency Committee. 
Rolfhus, K.R.; Hurley, J.P.; Hall, B.; Krabbenhoft, D.P. and Bodaly, D. (2001) "Reservoir effect": synthesis and biological uptake of methylmercury in seasonally inundated systems. US EPA, Workshop on the fate, transport, and transformation of mercury in aquatic and terrestrial environments. West Palm Beach, FL, May 8-10, 2001.

Ronngren, L., Sjoberg, S., Sun, Z., Forsling, W. and Schindler, P.W. (1991). Surface reactions in aqueous metal sulfide systems. 2 . Ion exchange and acid/base reactions at the $\mathrm{ZnS}-\mathrm{H}_{2} 0$ Interface. J. Colloid Interface Sci. 145, pp. 396-404.

Ross, H.B.; Vermette, S.J. (1995). Precipitation. In: Salbu, B.; Steinnes, E. (Eds.) Trace Elements in Natural Waters. CRC Press, Ann Harbor, MI, pp. 99-116.

Roth, M. (1971) Fluorescence reaction for aminoacids. Analytical Chemistry, 43: 880882.

Sanchez-Uria, J.E. and Sanz-Medel, A. (1998) Inorganic and methylmercury speciation in environmental samples. Talanta, 47: 509-524.

Santschi, P.H. (1988) Factors controlling the biogeochemical cycles of trace elements in fresh and coastal marine waters as revealed by artificial radioisotopes. Limnology and Oceanography, 33: 848-866.

Schroeder, W.H.; Munthe, J.; Lindquist, O. (1989) Cycling of mercury between water, air and soil compartments of the environment. Water, Air and Soil Pollution, 48: 337-347.

Schubert, C.J. and Nielsen, B. (2000) Effects of decarbonation treatments on $\delta^{13} \mathrm{C}$ values in marine sediments. Marine Chemistry 72: 55-59.

Schuster, E. (1991). The behavior of mercury in the soil with special emphasis on complexation and adsorption processes - a review of the literature. Water Air and Soil Pollution, 56: 667-680.

Schuster, P.F.; Shanley, J.B.; Reddy, M.M. (2001) The influence of organic carbon on the mobility of mercury in contrasting ecosystems. US EPA, Workshop on the fate, transport, and transformation of mercury in aquatic and terrestrial environments. West Palm Beach, FL, May 8-10, 2001.

Senesi, N. (1990). Molecular and quantitative aspects of the chemistry of fulvic acid and its interactions with metal ions and organic chemicals. Part. 2. The fluorescence spectroscopy approach. Analytica Chimica Acta, 232: 77-106. 
Senesi, N., Miano, T.M., Provenzano, M.R.; Brunetti, G. (1991). Characterization, differentiation and classification of humic substances by fluorescence spectroscopy. Soil Science, 152: 259-271.

SFMSP (South Florida Mercury Science Program) (1996). Research Plan (Working Draft) by Interagency Mercury Science Program: Management Committee and Technical Assessment Committee.

SFWMD (South Florida Water Management District) (1995) Everglades 1995 Annual Report.

Sjöblom, A.; Meili M. and Sundbom, M. (2000). The influence of humic substances on the speciation and bioavailability of dissolved mercury and methylmercury, measured as uptake by Chaoborus larvae and loss by volatilization. The Science of the total Environment, 261: 115-124.

Slemr, F., Langer, E. (1992). Increase in global atmospheric concentrations of mercury inferred from measurements over the Atlantic Ocean. Nature, 355: 434-437.

Smith, W., Smith, A. (1975). Minimata. Holt, Rinehart and Winston. New York.

Sorensen, J.A., Glass, G.E., Schmidt, K.W. (1994). Regional patterns of wet mercury deposition. Environmental Science and Technology, 28: 2025-2032.

Stevenson, F.J. (1992). Humus Chemistry-Genesis, Composition, Reactions. $2^{\text {nd }}$ Ed., Wiley,New York.

Stober, Q.J.; Jones, R.D. and Scheidt, D.J. (1995). Ultratrace level mercury in the Everglades ecosystem, a multi-media canal pilot study. Water, Air and Soil Pollution, 80: 991-1001.

Stordal, M.C.; Gill, G.A.; Wen, L.-S. and Santschi, P.H. (1996a) Mercry phase seciation in the surface waters of three Texas estuaries: importance of colloidal forms. Limnol. Oceanogr., 41: 52-61.

Stordal, M.C.; Santschi, P.H. and Gill, G.A. (1996b). Colloidal pumping: evidence for coagulation process using natural colloids tagged with ${ }^{203} \mathrm{Hg}$. Environmental Science and Technology, 30: 3335-3340.

Strohal, P. and Huljev, D. (1971) Investigation of mercury-pollutant interaction with Humic acids by means of radiotracers. Nucl. Tech. Environ. Pollut., Proc Ser IAEA, Vienna, pp. 439-446.

Stumm, W. (1992). Chemistry of the Solid-Water Interface. , John Wiley \& Sons, New York. 
Svedas, V.J.K.; Galaev, I.J.; Borisov, I.L. and Berezin, I.V. (1980). The interaction of aminoacids with ophthaldialdehyde: a kinetic study and spectroscopic assay of the reaction product. Analytical Biochemistry, 101: 188.

Swain, E.B., Engstrom, D.R., Brigham, M.E., Henning, T.A., Brezonik, P.L. (1992). Increasing rates of atmospheric mercury deposition in midcontinental North America. Science, 257: 784-787.

Sznopoek, J.L. and Goonan, T.G. (2000) The material flow of mercury in the economics of the US and the Wworld. US Department of Interior. US Geological Survey. Open file report 00-281. Denver, CO, USGS.

Tadanier, C.J.; Berry, D.F. and Knocke, W.R. (2000) Dissolved organic matter apparent molecular weight (AMW) distribution and numerical average AMW by batch ultrafiltration. Environmental Science and technology, 34: 2348-2353.

Tang, G. (1997) Organomercurials in the aquatic environment: geochemical and analytical aspects. Master's thesis. Florida International University, Department of Chemistry.

Tang, D.; Wen, L.S.; Sanstchi, P., (2000a) Analysis of biogenic thiols in natural water samples by high-performance liquid chromatographic separation and fluorescence detection with ammonium 7-fluorobenzo-2-oxa-1, 3-diazole-4-sulfonate (SBD-F). Analytica Chimica Acta 408: 299-307.

Tang, D.; Hung, C.C.; Warnken, K.W.; Sanstchi, P. (2000b). The distribution of biogenic thiols in surface waters of Galveston Bay. Limnology and Oceanography, 45: 1289-1297.

Thayer, J.S. (1984). Organometallic Compounds and Living Organisms. Academic Press, Orlando, Florida.

Topping, G.; Davies, I.M. (1981). Methylmercury production in the marine water column. Nature 290: 243.

Toyo'oka, T.; Uchiyama, S.; Saito, Y. and Imai, K. (1988). Simultaneous determination of thiols and disulfides by high performance liquid chromatography with fluorescence detection. Analytica Chimica Acta, 205: 29-41.

Toyo'oka, T.; Imai, K. (1984a). Analyst, 109: 1003.

Toyo'oka, T. and Imai, K. (1984b) Analytical Chemistry, 56: 2461. 
Toyo'oka, T., and Imai, K., (1983). High-performance liquid chromatography and fluorimetric detection of biologically important thiols derivatized with ammonium 7-fluorobenzo-2-oxa-1,3-diazole-4-sulfonate (SBD-F). Journal of Chromatography, 282: 495-500.

Toyo'oka, T.; Ishibashi, M.; Takeda, Y.; Nakashima, K.; Akiyama, S.; Uzu, S. and Imai, K. (1991) Precolumn fluorescence tagging reagent for carboxylic acids in highperformance liquid chromatography: 4-substituted-7-aminoalkylamino-2,1,3benzoxadiazoles. Journal of Chromatography A, 588: 61-71.

Turekian, K.K. (1977). The fate of metals in the oceans. Geochimica et Cosmochimica Acta, $41: 1139-1144$.

Ubbink, J.B.; Vermaak, W.J.H.; and Bissbort, S. (1991) Rapid high-performance chromatography for total homocysteine levels in human serum. Journal of Chromatography, 565: 441-446.

United States Army Corps of Engineers and South Florida Water Management District (1999). Rescuing and endangered ecosystem: the plan to restore America's Everglades. The Central and Southern Florida project comprehensive review study. $\leq \mathrm{http}: / /$ www.evergladesplan.org/ $>$

United States Department of Interior, Bureau of Mines (1994) Mineral Industry Surveys, July 1994.

United States Environmental Protection Agency (1997). Mercury Study Report to Congress, volumes I-VIII. Office of Air Quality Planning and Standards and Office of Research and Development. EPA-452/R-97-003, Washington, DC, EPA. <http://www.epa.gov/oar/mercury.html/>.

United States Environmental Protection Agency (1998). South Florida Ecosystem Asessment. Vol. I. Final Technical report Phase I. EPA-904-R-98-002, Office of Research and Development, US Government Printing Office, Washington DC.

United States Environmental Protection Agency (1999a) Fact Sheet - Mercury Update. Impact on fish advisories. Office of Water. EPA-823-F-99-016. Washington, DC, EPA. $\leq$ http://www.epa.gov/ost/fish/mercury.html $>$

United States Environmental Protection Agency (1999b) Fact Sheet - Update. National listing of fish and wildlife advisories. Office of Water. EPA-823-F-99-005. Washington, DC, EPA) $\leq$ http://www.fish.rti.org/> 
United States Environmental Protection Agency (2000a) Workshop on source emission and ambient air monitoring of mercury. Office of Research and Development. EPA/625/R-00/002.

United States Environmental Protection Agency (2000b) Mercury research strategy. Office of research and Development. EPA/600/R-00/073. Washington, DC, EPA.

United States Geological Survey, (1998). Mercury contamination of aquatic ecosystems $\leq \mathrm{http}: / / \mathrm{h} 20$. usgs.gov/public/wid/Fs216-95.html/>

Vairavamurthy, M.A., Manowitz, B., Malietic, D. and Wolfe, H., (1997). Interactions of thiols with sedimentary particulate phase: studies of 3-mercaptopropionate in salt marsh sediments from Shelter Island, New York. Organic Geochemistry, 26: 577585 .

Vairavamurthy, A. and Mopper, K. (1987). Geochemical formation of organosulphur compounds (thiols) by addition of $\mathrm{H}_{2} \mathrm{~S}$ to sedimentary organic matter. Nature, 329: 623-625.

Valcarcel, M. (2000) Principles of Analytical Chemistry: a textbook. Springer, New York.

Ware, F.J.; Royals, H.; Lange, T. (1990). Proceedings of the Annual Conference of the Southeastern Association of Fish and Wildlife Agencies, 44: 5-12.

Watanabe, C. and Satoh H. (1996). Evolution of our understanding of methylmercury as a health threat. Environmental Health Perspectives, 104: 367-379.

Watras, C.J.; Morrison, K.A., and Bloom, N.S. (1995a). Chemical correlates of mercury and methylmercury in northern Wisconsin lakes' waters. Water, Air and Soil Pollution 84: 253-267.

Watras, C.J.; Morrison, K.A. and Host, J.S. (1995b). Concentration of mercury species in relationship to other site-specific factors in the surface waters of northern Wisconsin Lakes. Limnol. Oceanogr. 40: 556-565.

Watras, C.J.; Back, R.C.; Halvorsen, S.; Hudson, R.J.M.; Morrison, K.A. and Wente, S.P. (1998). Bioaccumulation of mercury in pelagic freshwater food webs. Sci. Total Environ. 219: 183-208.

Weber, J.H. (1993). Review of possible paths for abiotic methylation of mercury (II) in the aquatic environment. Chemosphere, 26: 2063-2077. 
Weiner, J.G. and Spry, D.J. (1994) Toxicological significance of mercury in freshwater fish. In G. Heinz and N. Beyer (Eds.), Interpreting concentrations of environmental contaminants in wildlife tissues. Lewis Publishers, Chelsea, MI.

Wells, M.L.; Smith, G.J.; Bruland, K.W. (2000) The distribution of colloidal and particulate bioactive metals in Narrangansett Bay, RI. Marine Chemistry, 7: 143163.

Willet, K.L., Turner, R.R. and Beauchamp, J.J. (1992). Effect of chemical form of mercury on the performance of dosed soils in standard leaching protocols: EP and TCLP. Hazard. Waste Hazard. Mater. 9: 275-288.

Wood J.M.; Kennedy, F.S. and Rosen, C.E. (1969). Synthesis of methylmercury compounds by extracts of methanogenic bacteria. Nature, 220:173-174.

Xia, K.; Weesner, F.; Bleam, W.F.; Bloom, P.R., Skylberg, W.L. and Helmke, P.A. (1998).XANES study of oxidation states of sulfur in aquatic and soil humic substances. Soil Sci. Am. J., 62: 1240-1246.

Xia, K.; Skylberg, U.L.; Bleam, B.F.; Bloom, P.R.; Nater, E.A.; Helmke, P.A. (1999) XRay absorption spectroscopic evidence for the complexation of $\mathrm{Hg}$ (II) by reduced sulfur in soil humic substances. Environmental Science and Technology, 62: 257261. 